Universidade de São Paulo
Instituto de Física

\title{
Avaliação de dosímetros termoluminescentes para uso em radioterapia com fótons de alta energia
}

\author{
Bernardo José Braga Batista
}

Banca Examinadora:

Prof. Doutora Elisabeth Mateus Yoshimura.(IF-USP)

Prof. Doutora Nora Lia Maidana (IF-USP)

Prof. Doutor Oswaldo Baffa Filho. (FFCLRP-USP)

Orientadora: Prof $^{a}$. Dr ${ }^{a}$. Elisabeth Mateus Yoshimura

Dissertação de mestrado apresentada ao Instituto de Física para a obtenção do título de Mestre em Ciências

São Paulo

2011 


\section{FICHA CATALOGRÁFICA}

Preparada pelo Serviço de Biblioteca e Informação do Instituto de Física da Universidade de São Paulo

Batista, Bernardo José Braga

Avaliação de dosímetros termoluminescentes para uso em radioterapia com fótons de alta energia - . São Paulo, 2011

(Dissertação de Mestrado) - Universidade de São Paulo. Instituto de Física - Depto. de Física nuclear

Orientador: Profa. Dra. Elisabeth Mateus Yoshimura

Área de Concentração: Métodos Experimentais e Instrumentação para Partículas Elementares e Física Nuclear

Unitermos: 1. Física médica 2. Física de partículas 3. Dosimetria termoluminescente 
"O primeiro princípio é não enganar a si mesmo - e você é a pessoa mais fácil de enganar".

Richard P. Feynman 


\section{AGRADECIMENTOS}

À Beth, exemplo pessoal e profissional, pela ótima orientação, apoio, dedicação e compreensão.

Aos meus pais e irmãos, que mesmo sem saber o que eu fazia me apoiavam.

À Lu, pelo companheirismo, incentivo e diversas ajudas ao longo desse trabalho.

Ao Fábio Júnior, que várias vezes trabalhou no meu lugar para que eu pudesse fazer essa dissertação, pelos incentivos, discussões e ajudas que sempre ofereceu.

Ao Leandro e André, físicos médicos que não se importam de gastar o tempo "produzindo ciência", pela ajuda nas irradiações com o Cobalto e pelas sugestões.

Ao físico Anselmo, pela disponibilidade em ajudar nas medidas.

Ao Marcos, que transformou em realidade as ponteiras que a gente imaginou.

À Nancy e Chico, por tomarem conta do laboratório e por ajudar a resolver os problemas que eu encontrava.

Às professoras Emico e Ana Regina, pelos sorrisos, conversas e incentivos.

À professora Nora, pela disposição em ajudar sempre que necessário.

Ao Marcelo e a Cris por dividirem o lar comigo na fase inicial desse trabalho e ao Daniel e Paula pela hospedagem durante a fase final.

Aos amigos Marcelo, Helvécio, Renan e Flávio por servirem de exemplo e por dividirem as suas experiências acadêmicas comigo.

Aos serviços de radioterapia que permitiram a realização das medidas.

Ao $C N P q$, pelo apoio financeiro. 


\section{SUMÁRIO}

RESUMO

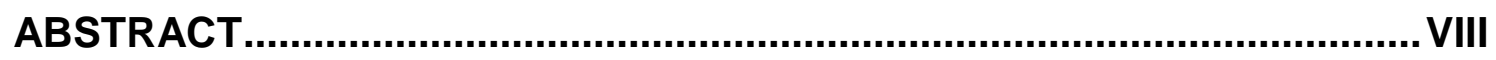

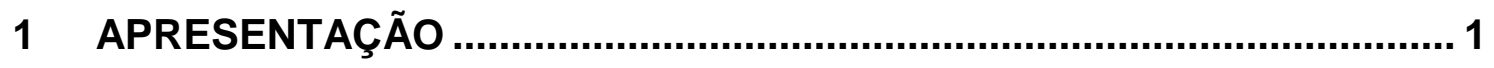

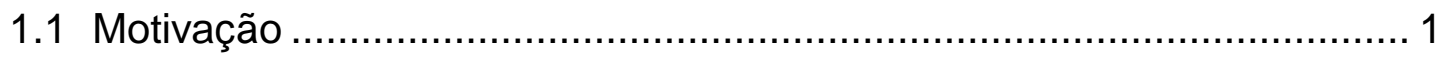

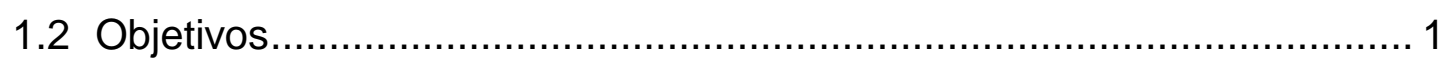

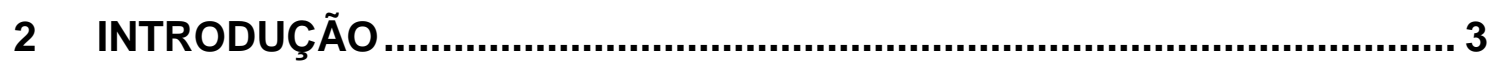

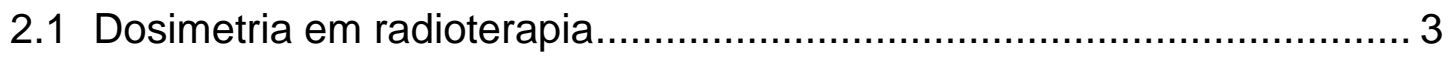

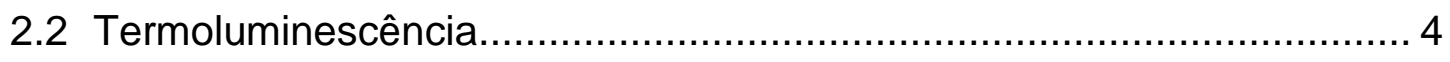

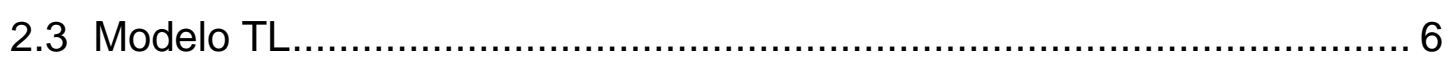

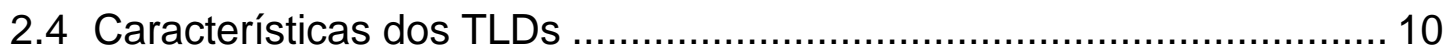

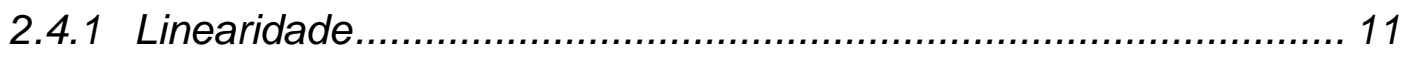

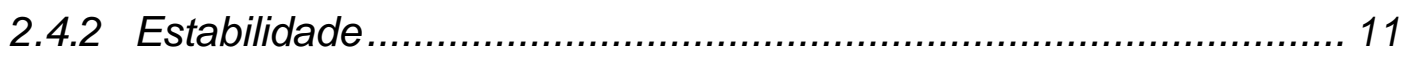

2.4.3 Dependência Energética ....................................................... 11

2.4.4 Tratamento Térmico .................................................................. 12

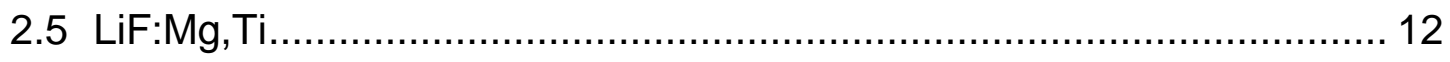

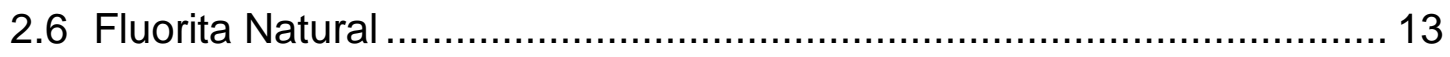

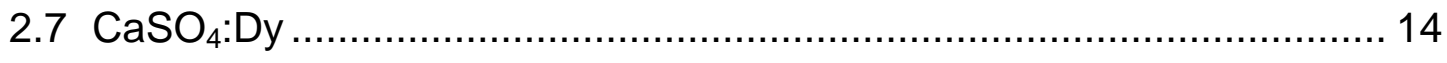

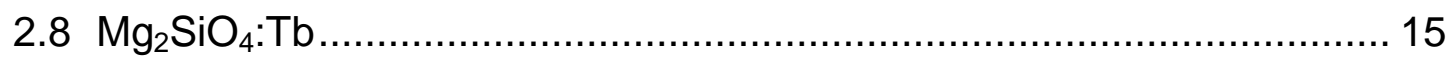

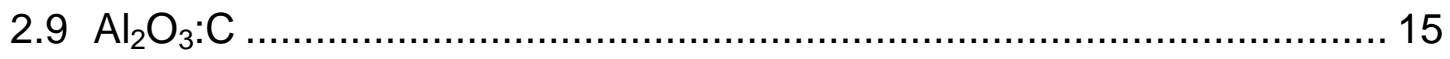

2.10 Especificação dos feixes de fótons de alta energia........................... 16

2.11 Geradores de feixes clínicos de fótons de Alta Energia ..................... 17

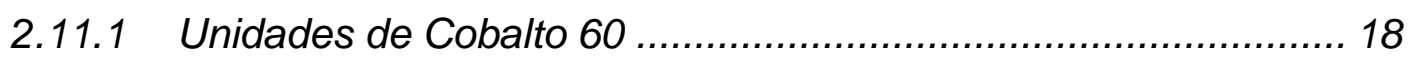

2.11.2 Aceleradores Lineares Clínicos ............................................ 18

2.12 Contaminação de nêutrons no feixe de fótons ................................. 20

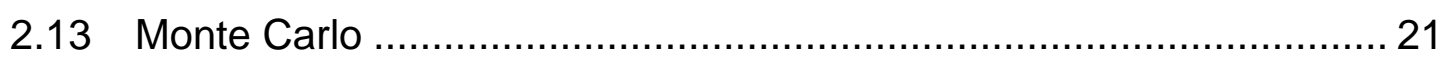

3 MATERIAIS E MÉTODOS ................................................................. 22

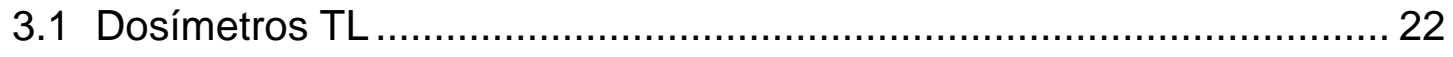




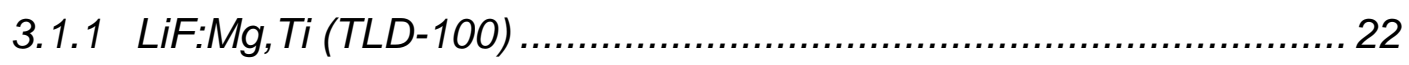

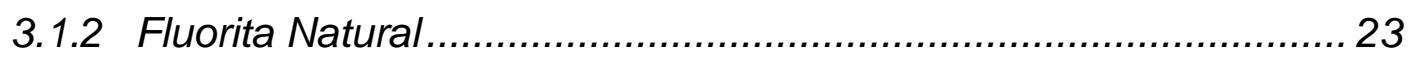

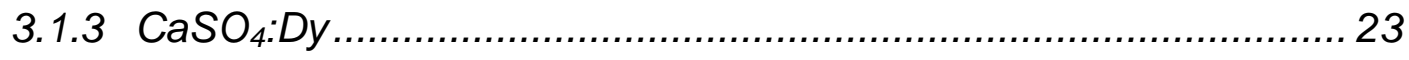

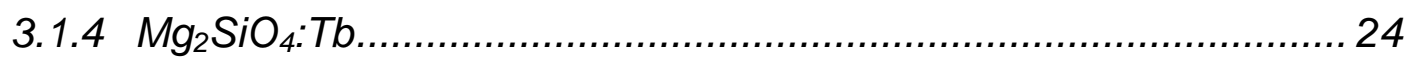

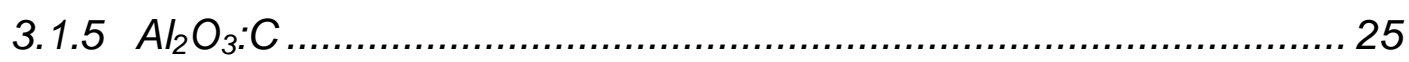

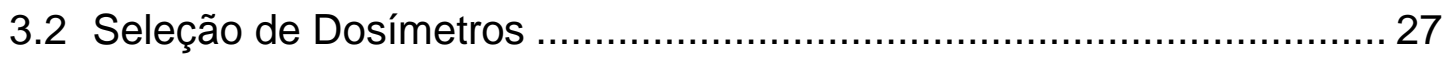

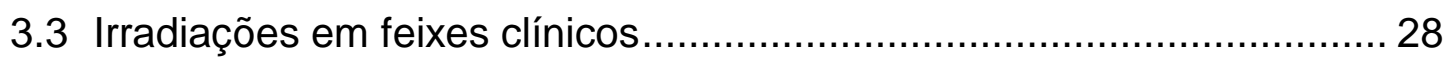

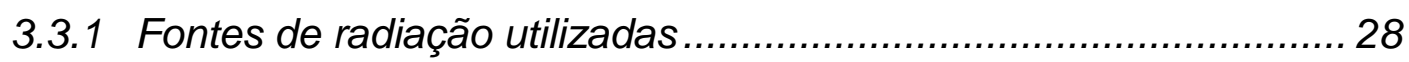

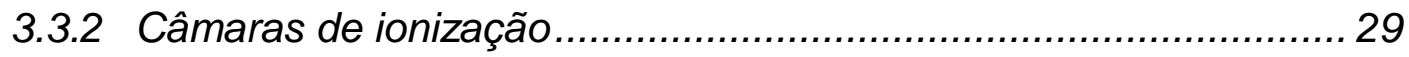

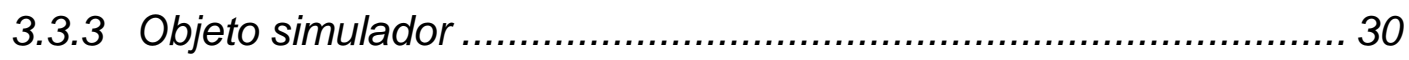

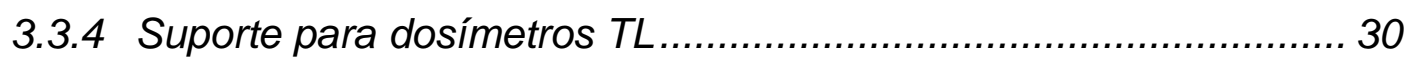

3.3.5 Geometria das Irradiações Clínicas........................................... 31

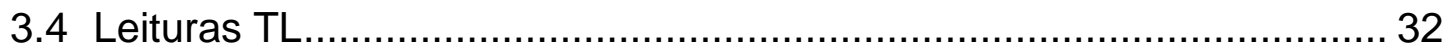

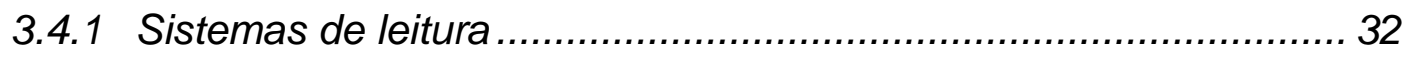

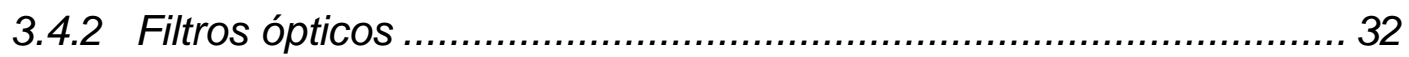

3.4.3 Correção para alterações no sistema de leitura .............................. 33

3.5 Irradiações com Nêutrons.................................................................... 33

3.6 Simulações com Monte Carlo ........................................................... 35

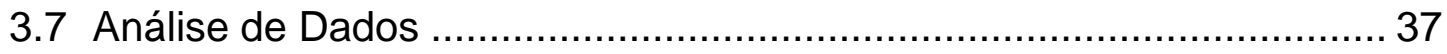

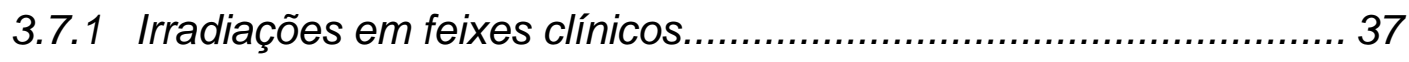

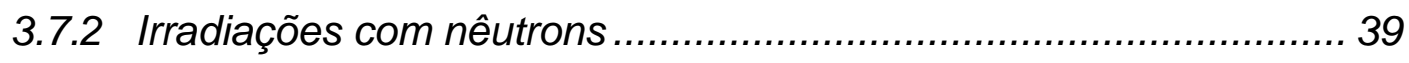

3.7.3 Simulações Monte Carlo ........................................................... 40

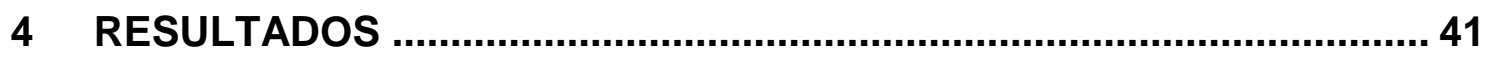

4.1 Seleção dos dosímetros estudados ................................................... 41

4.2 Resposta TL do fluoreto de lítio (TLD-100) em função da energia do feixe

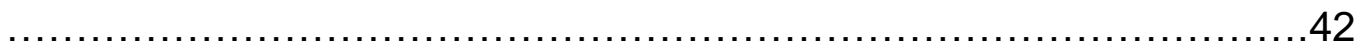

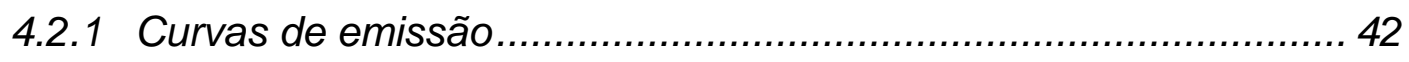

4.2.2 Resposta TL em função da energia do feixe ............................... 42

4.3 Resposta TL da fluorita natural brasileira em função da energia do feixe .45

4.3.1 Curvas de emissão. 45 
4.3.2 Resposta TL em função da energia do feixe ................................ 46

4.4 Resposta TL do sulfato de cálcio em função da energia do feixe.......... 48

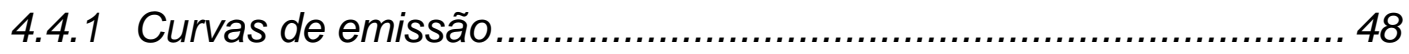

4.4.2 Resposta TL em função da energia do feixe ................................ 49

4.5 Resposta TL do silicato de magnésio em função da energia do feixe... 52

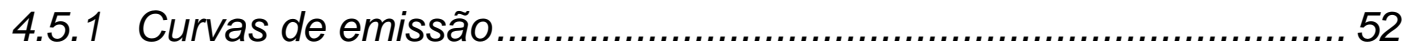

4.5.2 Resposta TL em função da energia do feixe ............................... 52

4.6 Resposta TL do óxido de alumínio em função da energia do feixe ....... 55

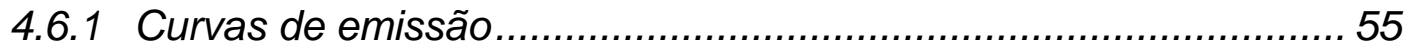

4.6.2 Resposta TL versus energia do feixe ........................................ 55

4.7 Teste de sensibilidade a nêutrons ……................................................ 59

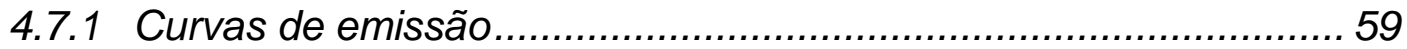

4.7.2 Resposta devido a radiação gama presente no feixe da fonte de

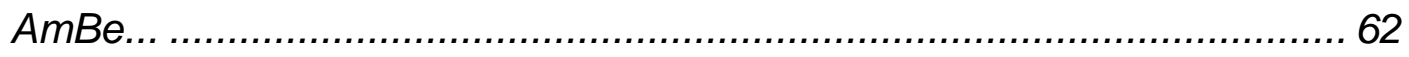

4.8 Simulações Monte Carlo...................................................................... 62

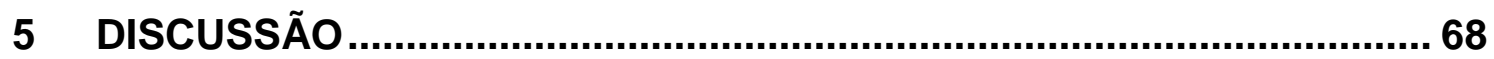

5.1 Resposta TL dos diferentes dosímetros em função da energia do feixe de

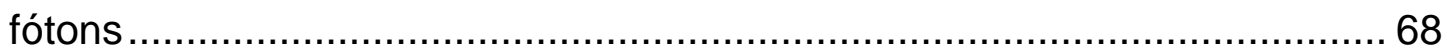

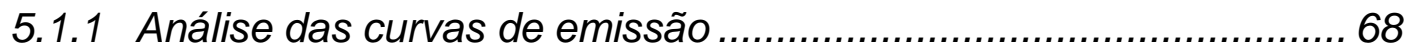

5.1.2 Linearidade de resposta TL em função da dose.............................68

5.1.3 Fatores de dependência energética .............................................69 69

5.1.4 Dispersão em função da dose medida ........................................ 70

5.2 Influência da contaminação por nêutrons na resposta TL ..................... 71

5.3 Simulações com o método Monte Carlo ............................................. 72

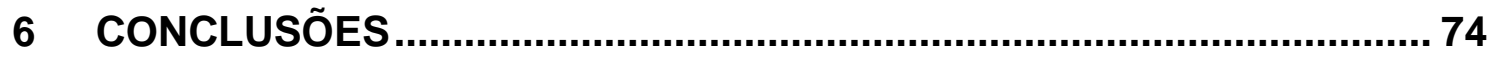

ANEXO - Curvas de resposta TL em função da dose absorvida em água para

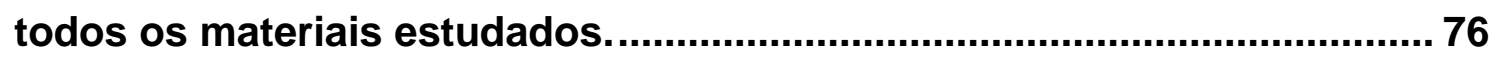

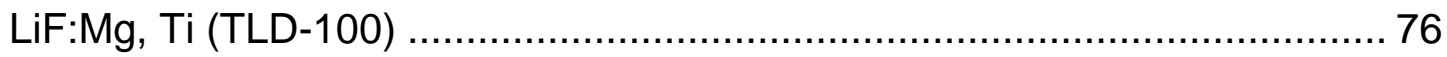

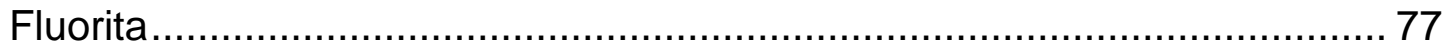

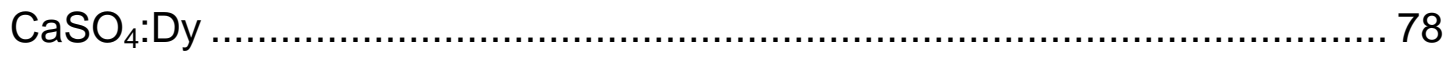




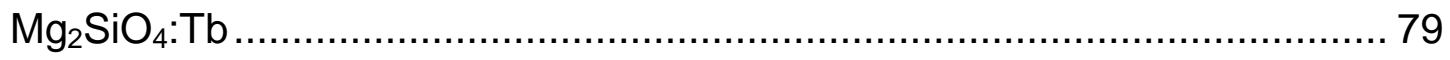

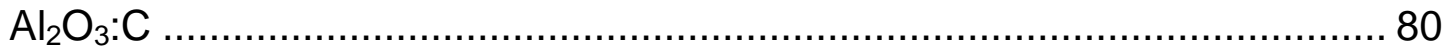

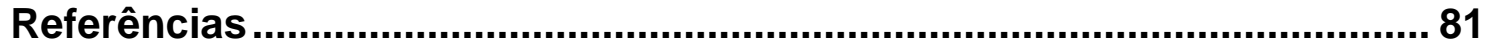

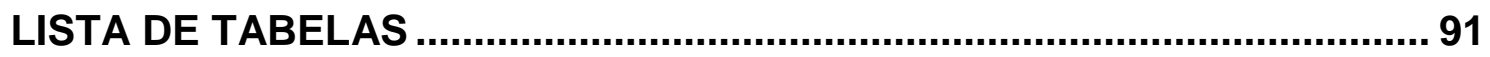

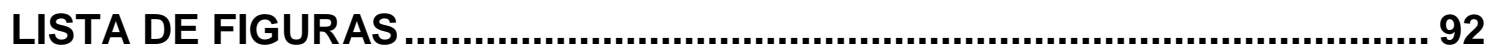




\section{RESUMO}

Atualmente a maior parte dos tratamentos radioterápicos é feita através de irradiações com feixes de fótons de alta energia. Esses feixes se originam em fontes radioativas (de nuclídeos como o cobalto 60) ou são gerados em aceleradores lineares de elétrons. Para as medidas dosimétricas nesses feixes, uma das técnicas mais utilizada é a termoluminescência (TL) e, para a correta utilização dos dosímetros termoluminescentes (TLDs), é necessário conhecer suas características dosimétricas como, por exemplo, a variação da sua resposta com a energia do feixe de radiação.

O objetivo desse trabalho foi estudar essa dependência energética da resposta TL de diversos materiais quando irradiados em feixes de fótons de alta energia. Para isso, foram obtidas curvas de resposta TL em função da dose absorvida em água para os TLDs de LiF:Mg, Ti (TLD-100), fluorita natural brasileira, CaSO ${ }_{4}: D y, M_{2} \mathrm{SiO}_{4}: \mathrm{Tb}$ e $\mathrm{Al}_{2} \mathrm{O}_{3}: \mathrm{C}$ irradiados em feixes gama de ${ }^{60} \mathrm{Co} e$ de raios $\mathrm{X}$ de aceleradores lineares com potenciais de aceleração nominais de 6, 10, 15 e $18 \mathrm{MV}$. O estudo foi feito em uma faixa de doses equivalente à utilizada em fracionamentos padrão de tratamentos de radioterapia e os resultados demonstram que, nessas condições, não há variação maior que $3 \%$ na resposta TL em função da energia dos fótons. A relação entre a deposição de doses nos TLDs e a deposição de doses na água em função da variação da energia foi estudada por simulação de Monte Carlo (MC), através do código PENELOPE, e os resultados foram coerentes com os resultados experimentais. Os TLDs também foram irradiados com nêutrons térmicos e epitérmicos e apresentaram sensibilidade a esse tipo de radiação. No entanto, a coerência dos resultados experimentais e de MC (que não levaram em conta a presença de nêutrons), o estudo da variação da sensibilidade relativa com a energia e a análise das curvas de emissão dos TLDs levam à conclusão de que a influência na resposta TL devida a nêutrons que contaminam os feixes de fótons estudados, é desprezível para todos os materiais.

Os resultados desse trabalho indicam que, para a faixa de doses e energias utilizadas rotineiramente na radioterapia, os TLDs de LiF:Mg, Ti (TLD-100), fluorita natural brasileira, $\mathrm{CaSO}_{4}: \mathrm{Dy}, \mathrm{Mg}_{2} \mathrm{SiO}_{4}: \mathrm{Tb}$ e $\mathrm{Al}_{2} \mathrm{O}_{3}: \mathrm{C}$ podem ser utilizados sem a aplicação de fatores de correção para a energia do feixe. 


\section{ABSTRACT}

Currently the majority of radiotherapy treatments are done by irradiation with high energy photon beams. These beams are emitted by radioactive sources (of nuclides such as cobalt 60 ) or generated in electron linear accelerators. For dosimetric measurements on these beams, one of the most used techniques is the thermoluminescence (TL). For the correct use of the thermoluminescent dosimeters (TLDs), it is necessary to know their dosimetric properties like, for example, the variation of their response with the energy of the radiation beam.

The purpose of this study was to assess the energy response of various TL materials when irradiated with high energy photon beams. So, curves relating the TL response and absorbed dose to water were obtained for LiF:Mg, Ti (TLD-100), Brazilian natural fluorite, $\mathrm{CaSO}_{4}: \mathrm{Dy}, \mathrm{Mg}_{2} \mathrm{SiO}_{4}: \mathrm{Tb}$ and $\mathrm{Al}_{2} \mathrm{O}_{3}: \mathrm{C}$ TLDs irradiated with gamma rays from a ${ }^{60} \mathrm{Co}$ source and linear accelerator $X$ ray beams with nominal accelerating potential of $6,10,15$ and 18 MV. The study was done in a dose range similar to that used in standard fractionated radiotherapy treatments and the results show that under these conditions, there is no variation larger than $3 \%$ in the TL response as a function of photon energy. The relationship between the dose deposition in the TLD and the dose deposition in water in function of the photon energy was studied by Monte Carlo method (MC), using the PENELOPE code system, and the results were consistent with the experimental outcomes. The TLDs were also irradiated with thermal and epithermal neutrons and proved to be sensitive to them. However, the consistency of the experimental and MC results (which did not take into account the presence of neutrons), the study of the variation in TL relative sensitivity with the beam energy, and the TLD glow curve shape analysis lead to the conclusion that the influence on TL response due to neutron contamination in the therapeutic photon beams is negligible for all materials.

The results indicate that for the range of doses and energies used routinely in radiotherapy, the LiF:Mg, Ti (TLD-100), Brazilian natural fluorite, $\mathrm{CaSO}_{4}: \mathrm{Dy}, \mathrm{Mg}_{2} \mathrm{SiO}_{4}: \mathrm{Tb}$ and $\mathrm{Al}_{2} \mathrm{O}_{3}: \mathrm{C}$ TLDs can be used without applying any correction factors for the beam energy. 


\section{APRESENTAÇÃO}

\subsection{Motivação}

A dosimetria termoluminescente ( $T L$ ) é cada vez mais empregada na radioterapia seja para verificação da dose na pele do paciente (na entrada ou saída do feixe ou em outros pontos de referência), para medidas de dose periférica (em estruturas críticas fora do feixe de radiação), ou para auditorias dos serviços de radioterapia. Para obter resultados de dose absorvida com confiança por meio dessa técnica é necessário conhecer a resposta em energia dos dosímetros empregados.

$\mathrm{Na}$ década de 70 e início dos 80 , quando os feixes de fótons para radioterapia estavam restritos a raios $\mathrm{X}$ gerados com até $350 \mathrm{kV}$ e feixes gama provenientes de fontes de ${ }^{137} \mathrm{Cs}$ e ${ }^{60} \mathrm{Co}$, muitos trabalhos foram feitos com $\mathrm{o}$ propósito de obter as respostas TL relativas à energia do cobalto 60 . $O$ emprego atual mais freqüente de aceleradores dedicados à teleterapia com fótons requer uma extensão desses trabalhos à região de mais alta energia.

A motivação desse trabalho foi estudar o comportamento de diversos dosímetros termoluminescentes (TLDs) pela análise do comportamento das suas curvas de emissão e da relação dose-resposta TL com a energia dos feixes de radiação (dependência energética), visando uma aplicação fundamentada desses materiais na dosimetria em radioterapia.

\subsection{Objetivos}

O objetivo principal desse trabalho foi verificar a resposta energética de diversos TLDs para feixes de fótons de alta energia. Para cumprir esse objetivo foi necessário:

- Obter as curvas de resposta TL em função da dose absorvida em água, em feixe de fótons de ${ }^{60} \mathrm{Co}$ e de aceleradores lineares clínicos.

- Analisar globalmente as curvas de emissão TL e verificar se elas são modificadas com a energia dos fótons. 
- Obter por meio de simulação com o método de Monte Carlo a razão entre a dose absorvida no TLD e a dose absorvida na água nas mesmas situações das medidas experimentais.

- Verificar se os dosímetros têm resposta apreciável a nêutrons que contaminem o feixe terapêutico. 


\section{INTRODUÇÃO}

\subsection{Dosimetria em radioterapia}

O papel mais importante de um físico nas clínicas de radioterapia é garantir uma entrega exata da distribuição de doses prescrita aos pacientes. Para isso, medir as doses envolvidas é um ponto fundamental e, portanto, a dosimetria em radioterapia é uma das principais preocupações desses físicos [lbbott, 2008].

Na literatura há um consenso de que é necessária, em um tratamento radioterápico, uma incerteza máxima de 5\% na deposição de dose no tumor [ICRU, 1976]. Para obter essa exatidão, é necessário controlar diversas fontes de incerteza como a calibração das máquinas usadas para gerar os feixes de radiação, o sistema de planejamento que calcula as distribuições de dose e o próprio posicionamento dos pacientes nos diversos dias do tratamento. Os controles de qualidade dessas diversas etapas são, geralmente, feitos com medidas de dose, ou outra grandeza física relevante (kerma ou fluência por exemplo), em um ponto de interesse em um meio (água, superfície do paciente, etc).

Para as várias medidas realizadas, diferentes tipos de dosímetros podem ser empregados. Os mais comuns são as câmaras de ionização, filmes, dosímetros termoluminescentes (TLD's) e diodos. A Tabela 2-1 apresenta algumas vantagens e desvantagens de cada um dos quatro tipos de dosímetros [Podgorsak, 2006]. 
Tabela 2-1: Principais vantagens e desvantagens dos dosímetros mais usados em radioterapia.

\begin{tabular}{|c|c|c|}
\hline Dosímetro & Vantagens & Desvantagens \\
\hline Câmara de ionização & $\begin{array}{ll}\text { - } & \text { Alta Precisão } \\
\text { - } & \text { Recomendado para } \\
& \text { calibração de feixes } \\
\text { - } & \text { Leitura instantânea }\end{array}$ & $\begin{array}{ll}\text { - } & \text { Necessita de cabos } \\
\text { - } & \text { Necessita de fonte de } \\
& \text { alta tensão } \\
\text { - } & \text { Necessita de correções } \\
& \text { para dosimetria em } \\
& \text { feixes de alta energia }\end{array}$ \\
\hline Filme & $\begin{array}{l}\text { - } \quad \text { Alta resolução espacial } \\
\text { - } \quad \text { Muito fino (não perturba } \\
\text { o feixe) }\end{array}$ & $\begin{array}{ll}\text { - } & \text { Necessita de } \\
\text { processamento em sala } & \text { escura } \\
\text { - } & \text { Apresenta forte } \\
\text { dependência energética } \\
\text { - } \quad \text { Necessita de calibração } \\
\text { com câmara de } \\
\text { ionização }\end{array}$ \\
\hline TLD & $\begin{array}{ll}\text { - } & \text { Tamanho pequeno } \\
& \text { (possível fazer medidas } \\
\text { pontuais) } \\
\text { - } & \text { Não necessita de cabos } \\
- & \text { Disponível em vários } \\
& \text { formatos } \\
- & \text { Barato }\end{array}$ & $\begin{array}{ll}\text { - } & \text { Perda do sinal após a } \\
\text { leitura } \\
\text { - } & \text { Necessita calibração } \\
\text { - } & \text { Calibração e leituras } \\
& \text { demoradas }\end{array}$ \\
\hline Diodo & $\begin{array}{ll}\text { - } & \text { Tamanho pequeno } \\
\text { - } & \text { Muito sensível } \\
\text { - } & \text { Leitura instantânea }\end{array}$ & $\begin{array}{l}\text { - } \quad \text { Necessita de cabos } \\
\text { - } \quad \text { A calibração varia com } \\
\text { a temperatura } \\
\text { - } \\
\text { A sensibilidade muda } \\
\text { com a dose acumulada }\end{array}$ \\
\hline
\end{tabular}

Vale ressaltar o importante papel que a dosimetria termoluminescente vem tendo na radioterapia: seja na verificação dos tratamentos e controle de doses na entrada de campos de radiação [Almond et al, 1999; Andersen et al, 2003; Cadman et al, 2002; Morlotti e Yoshimura, 2007; Nisbet et al, 2004] ou na auditoria de serviços de radioterapia [Gomola et al, 2001; Izewska et al, 2000; Swinnen et al, 2004], como etapa de programas de garantia da qualidade [Ministério da Saúde, 2001].

\subsection{Termoluminescência}

O fenômeno de emissão de luz por um material previamente excitado é chamado de luminescência. Dependendo da maneira como o meio foi excitado, 
diferentes denominações são utilizadas. Fotoluminescência (excitação por absorção de luz), eletroluminescência (excitação por campos elétricos), triboluminescência (excitação por forças mecânicas) e radioluminescência (excitação causada por radiação ionizante) são alguns exemplos.

Os fenômenos de luminescência podem ser divididos em dois tipos: fluorescência e fosforescência. A fluorescência ocorre espontaneamente, com a emissão de luz ocorrendo em um tempo menor que $10^{-8} \mathrm{~s}$ após a excitação (Figura 2-1 (a)). Na fosforescência, ao decair do estado excitado, o sistema permanece em um estado metaestável por um tempo muito maior que $10^{-8} \mathrm{~s}$. Para retornar ao estado fundamental, o sistema necessita receber energia suficiente para voltar ao estado excitado e só então sofrer a desexcitação por um processo semelhante ao da fluorescência (Figura 2-1 (b)). Assim como na excitação inicial, o estímulo necessário para retirar o sistema do estado metaestável pode ocorrer de diferentes maneiras, destacando-se a absorção de luz (fosforescência oticamente estimulada) e a absorção de calor (fosforescência termicamente estimulada).

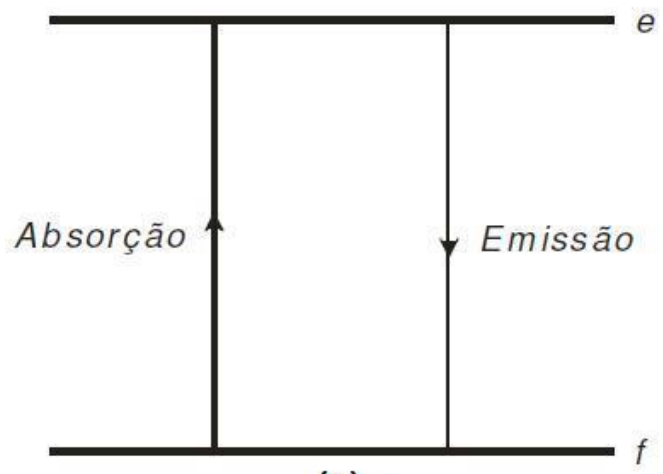

(a)

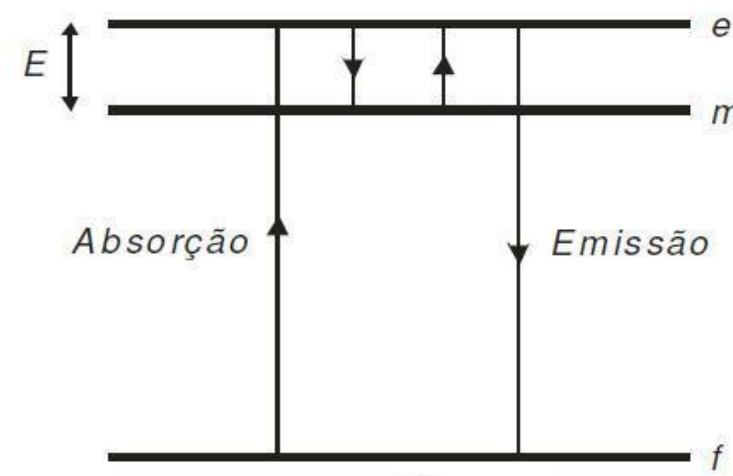

(b)

Figura 2-1: Esquema de níveis de energia mostrando os processos de fluorescência (a) e fosforescência (b) [Curie e Garlick, 1963]

A termoluminescência (TL) nada mais é que uma fosforescência termicamente estimulada. Ela é a emissão de luz por um isolante ou semicondutor quando este é aquecido. Como ela ocorre em materiais que foram excitados por radiação ionizante, sua denominação correta seria radioluminescência termicamente estimulada. Mas na literatura o termo termoluminescência vem sendo empregado desde o final do século XIX [McKeever, 1985]. 
A TL não deve ser confundida com a incandescência. A emissão de luz por TL só ocorre após uma absorção prévia de energia e, uma vez que o material tenha sido aquecido e a luz emitida, um novo aquecimento não ocasiona nova emissão de luz. Para que o fenômeno possa ser repetido, o material deve ser excitado novamente.

Dentre as diversas aplicações da termoluminescência estão o estudo de defeitos em sólidos, datação geológica e, principalmente, a dosimetria de radiação. A dosimetria é possível porque uma vez que a quantidade de luz emitida por um material termoluminescente é proporcional à dose de radiação absorvida por ele, medir a quantidade de luz é uma maneira indireta de medir a dose absorvida. O primeiro uso da TL, em dosimetria, que se tem notícia foi em 1953 quando a radiação de um teste de bomba atômica foi medida com fluoreto de lítio [Cameron et al, 1968]. Seu uso em aplicações médicas também vem sendo estudado desde essa época [Daniels et al, 1953]. O LiF, com diversos dopantes é hoje um dos materiais mais utilizados e estudados, pois apresenta algumas características muito importantes em dosimetria: é estável, linear em resposta em uma ampla faixa de dose e fácil de manusear [Piters et al, 1993].

\subsection{Modelo TL}

Em um isolante em condições ideais temos todos os elétrons na banda de valência. A outra banda possível de ocupação é a banda de condução e essas duas são separadas por uma região proibida de largura $\boldsymbol{E}_{\boldsymbol{g}}$. No caso de haver impurezas ou imperfeições na rede cristalina, alguns centros que os elétrons podem ocupar são criados na região proibida do cristal perfeito.

Em um modelo simplificado (Figura 2-2), podemos supor dois novos centros $\boldsymbol{T}$ e $\boldsymbol{R}$. O centro $\boldsymbol{T}$ localizado logo abaixo da banda de condução permanece vazio na situação de equilíbrio, pois tem energia maior que a energia de Fermi $\boldsymbol{E}_{\boldsymbol{f}}$. Esse tipo de centro apresenta potencial para aprisionar elétrons e por isso é chamado de armadilha de elétrons. O centro $\boldsymbol{R}$ fica logo acima da banda de valência e funciona como uma armadilha de buracos ou de lacunas (ausência de elétrons). 


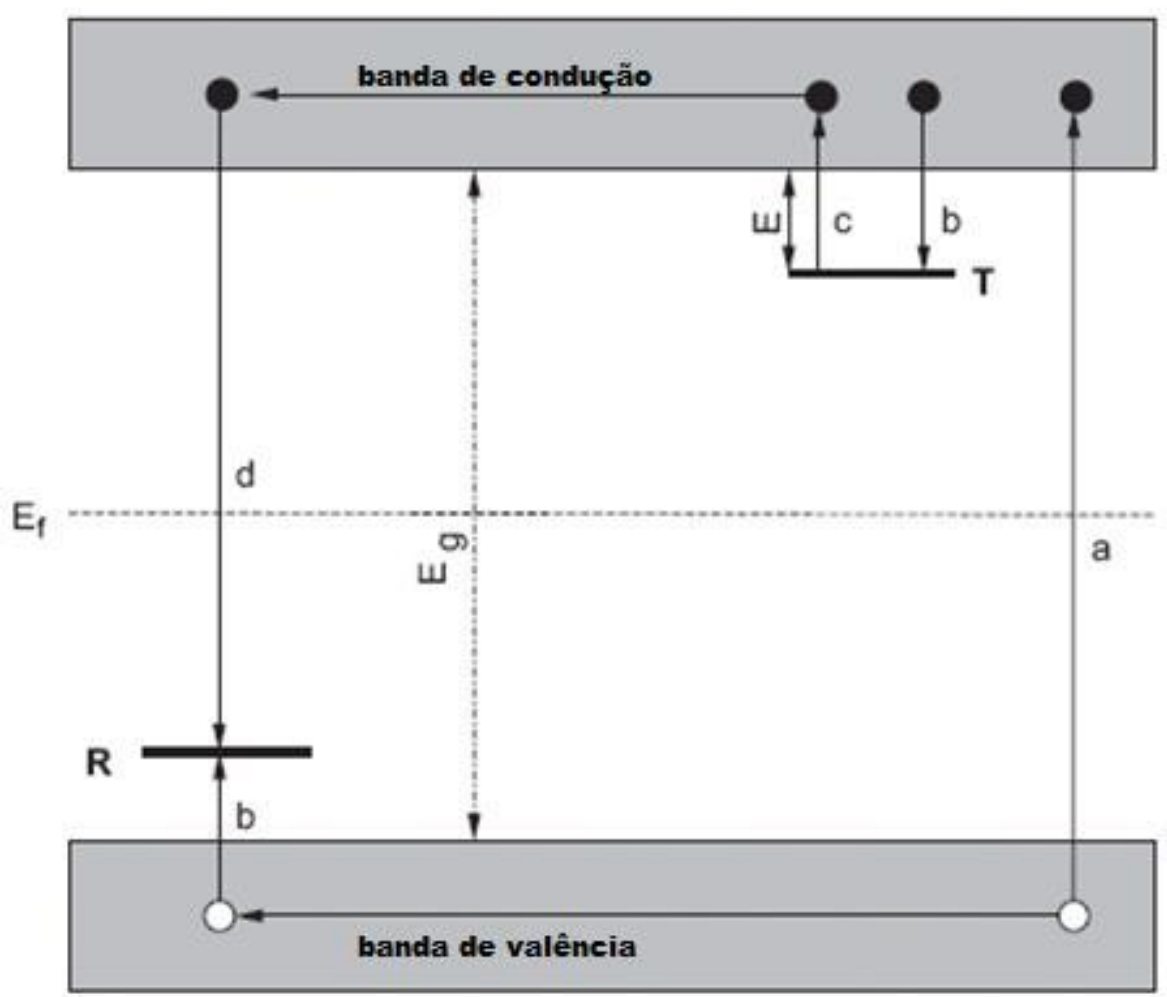

Figura 2-2: Modelo de bandas de energia mostrando as transições eletrônicas em um material TL: (a) geração de pares elétron-buraco; (b) aprisionamento dos portadores de carga; (c) elétron sendo liberado pelo aquecimento; (d) recombinação.

Quando o cristal absorve energia da radiação com $\boldsymbol{h} \boldsymbol{v}>\boldsymbol{E}_{\boldsymbol{g}}$, ocorrem ionizações na camada de valência, criando pares elétron-buraco. Os elétrons livres vão para a banda de condução deixando um buraco livre na banda de valência (transição a na Figura 2-2). A partir desse momento, essas cargas livres podem se recombinar diretamente (fluorescência) ou podem ficar aprisionadas nos centros $\boldsymbol{T}$ e $\boldsymbol{R}$ (transição b). Após ficar aprisionado, a probabilidade de o elétron ser liberado pode ser descrita pela equação de Arrhenius:

$$
\boldsymbol{p}=s \cdot \exp \left\{-\frac{\mathrm{E}}{\mathrm{kT}}\right\}
$$

onde $\boldsymbol{p}$ é a probabilidade de liberação por unidade de tempo, $\boldsymbol{s}$ é o fator de frequência, cujo valor é da ordem da freqüência de vibração da rede cristalina $\left(10^{12}-10^{14} \mathrm{~s}^{-1}\right), E$ é a profundidade da armadilha, ou energia necessária para levar o elétron da armadilha até a banda de condução, $\boldsymbol{k}$ é a constante de Boltzmann $\left(8,617 \times 10^{-5} \mathrm{eV} / \mathrm{K}\right)$ e $\boldsymbol{T}$ é a temperatura. No caso de $E \gg \boldsymbol{k} \boldsymbol{T}_{0}$, com To a temperatura ambiente, os elétrons aprisionados têm probabilidade muito 
pequena de serem liberados e portanto o sistema permanece nesse estado metaestável por um tempo muito longo.

A probabilidade de liberação dos elétrons aumenta com o aumento da temperatura, ou seja, aquecer o material faz com que os elétrons aprisionados passem para a banda de condução mais facilmente (transição c). Uma vez na banda de condução, o elétron fica livre, podendo ser novamente aprisionado ou se recombinar com um buraco que esteja aprisionado no centro $\boldsymbol{R}$ (transição d). Caso esse seja um centro de luminescência, o excesso de energia é liberado na forma de luz (termoluminescência) no processo de recombinação. A intensidade TL durante $\mathrm{o}$ aquecimento é proporcional à taxa de recombinação dos elétrons e buracos em $\boldsymbol{R}$.

Existem alguns modelos matemáticos que explicam o fenômeno da termoluminescência, mas um dos mais simples e conhecidos é o modelo de Randall-Wilkins. Esse modelo se baseia em duas hipóteses. Uma delas é a de que a probabilidade de um elétron livre ser recapturado pelas mesmas armadilhas é desprezível e a outra é a de que o tempo de vida dos portadores de carga livres é pequeno, ou seja, os elétrons livres se recombinam rapidamente nos centros de luminescência emitindo luz. Por esse modelo, a intensidade de luz $I$ em função da temperatura $T$ é dada por:

$$
I(T)=n_{0} \frac{s}{\beta} \exp \left\{-\frac{E}{k T}\right\} \times \exp \left\{-\frac{s}{\beta} \int_{T_{0}}^{T} \exp \left\{-\frac{E}{k T^{\prime}}\right\} d T^{\prime}\right\} \quad 2-2
$$

onde $\boldsymbol{n}_{\boldsymbol{0}}$ é o número inicial de elétrons aprisionados e $\beta$ é a taxa de aquecimento. A Figura 2-3 mostra uma curva calculada por esse modelo. 


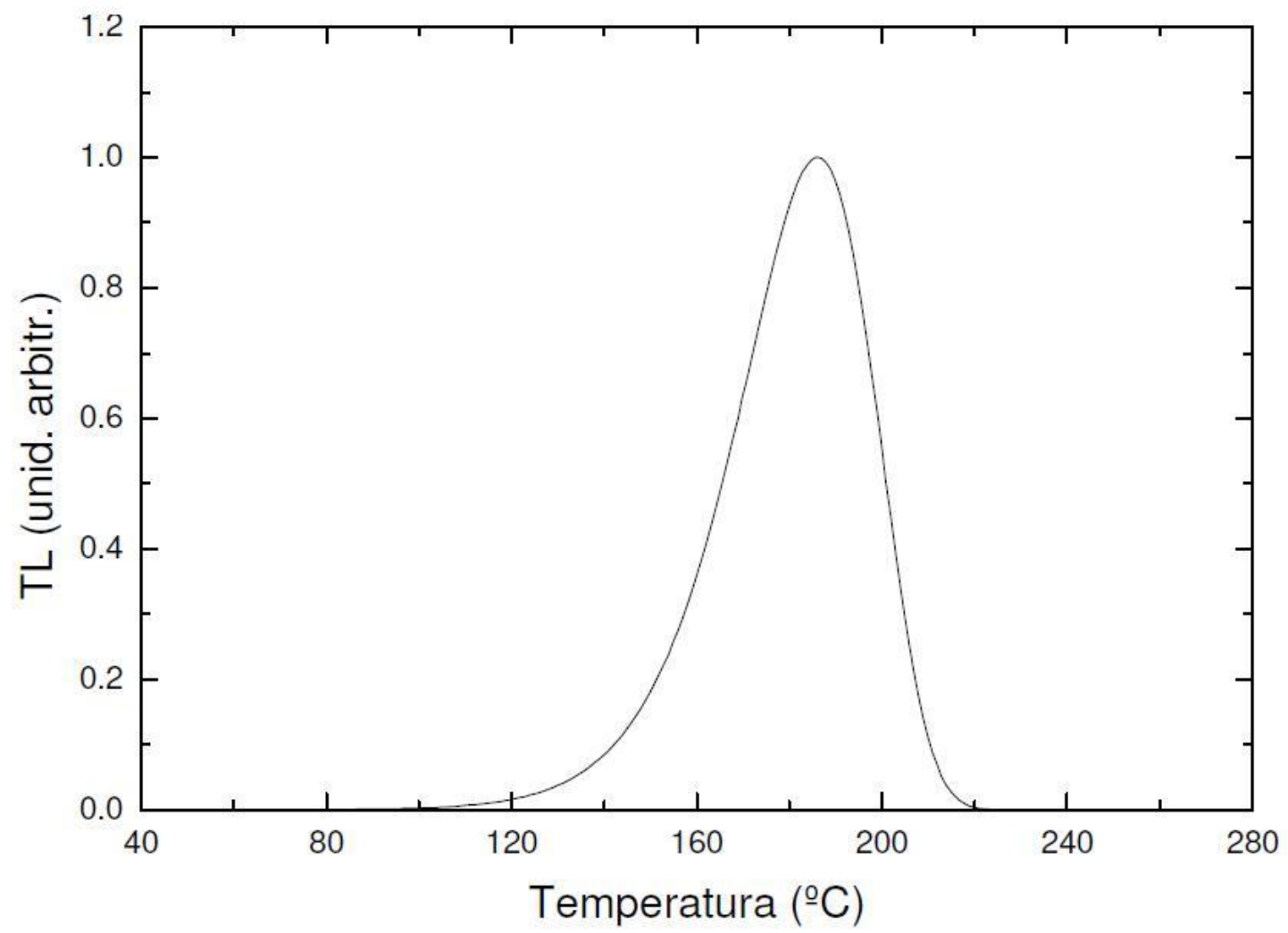

Figura 2-3: Curva de emissão TL calculada a partir do modelo de Randall-Wilkins. Os valores dos parâmetros envolvidos no cálculo foram $E=1,2 \mathrm{eV} ; s=10^{12} \mathrm{~s}^{-1}$ e $\beta=1{ }^{\circ} \mathrm{C} . \mathrm{s}^{-1}$. O valor de $n_{0}$ foi escolhido de modo a normalizar a curva em relação à intensidade de máximo.

Como mostrado na Equação 2-2, essa curva depende de fatores intrínsecos do material como o fator de freqüência $\boldsymbol{s}$ e a profundidade da armadilha $E$, além de fatores controláveis no momento das leituras como a taxa de aquecimento $\beta$. Porém, o fator mais importante para a dosimetria é o número inicial de elétrons aprisionados $\boldsymbol{n}_{\boldsymbol{0}}$, já que esse número é proporcional ao número de ionizações que ocorreram no momento da irradiação. A Figura 2-4 mostra como a curva de emissão TL varia quando no varia, segundo o modelo de Randall-Wilkins. Nota-se que tanto a área sob a curva como o ponto de máximo são proporcionais a $\boldsymbol{n}_{\boldsymbol{0}}$. Conclui-se então que medir um desses dois valores (área ou altura de pico) é uma maneira indireta de se medir a quantidade de elétrons aprisionados no processo de irradiação, ou seja, medir a dose absorvida no material termoluminescente. 


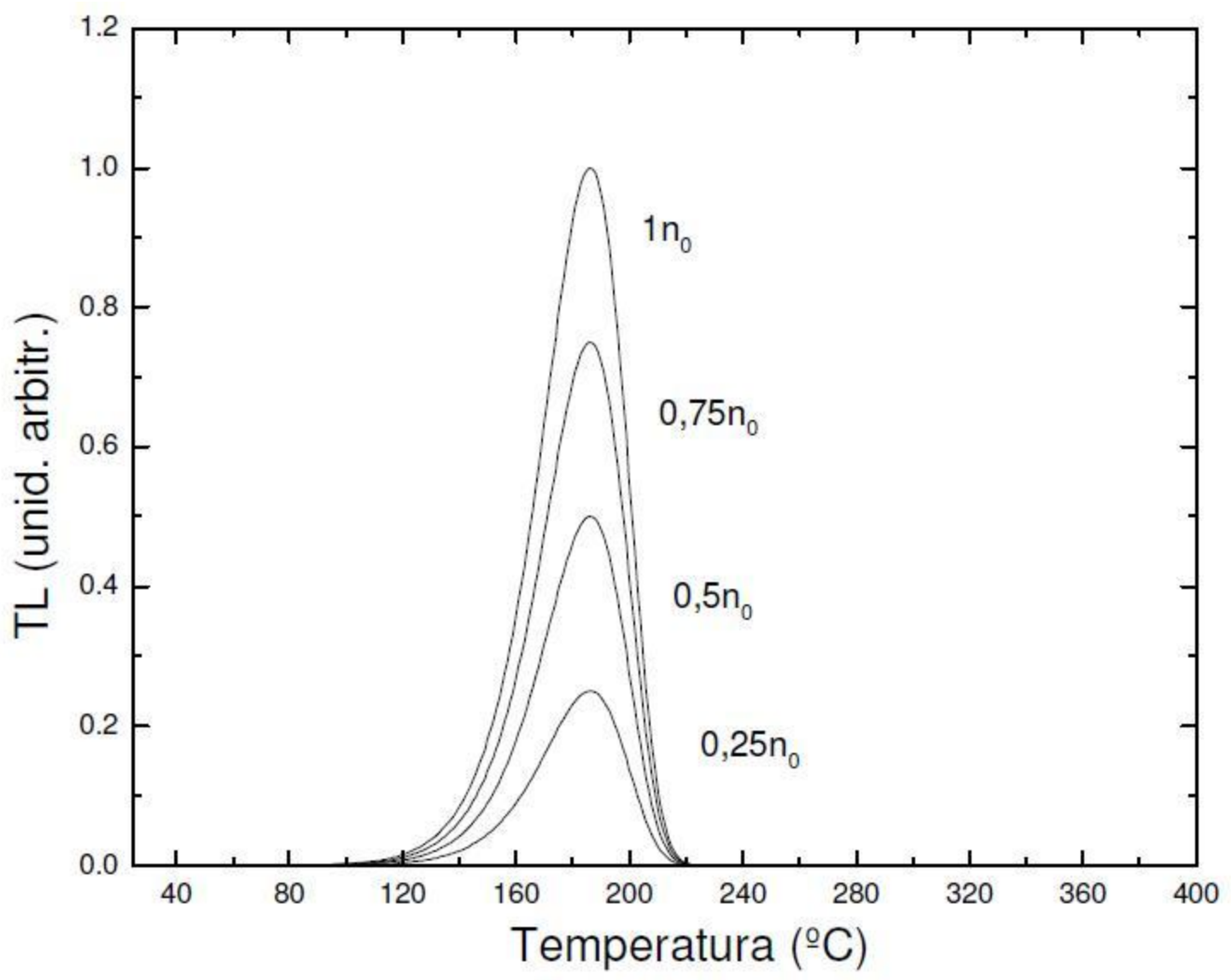

Figura 2-4: Curvas de emissão TL calculadas a partir do modelo de Randall-Wilkins. As diferentes curvas foram calculadas variando o valor de $\mathrm{n}_{0}$ e mantendo os valores dos outros parâmetros fixos $\left(E=1,2 \mathrm{eV} ; s=10^{12} \mathrm{~s}^{-1}\right.$ e $\left.\beta=1^{\circ} \mathrm{C} . \mathrm{s}^{-1}\right)$.

Esse é um modelo simplificado de primeira ordem. Nos materiais estudados ele explica apenas parcialmente o comportamento das curvas de emissão. Alguns materiais como o fluoreto de lítio e a fluorita apresentam mais de um pico de intensidade luminosa (correspondendo a diferentes armadilhas) e vários materiais apresentam curvas que não são completamente explicadas pela aproximação de primeira ordem. Descrições mais completas do fenômeno da termoluminescência podem ser encontradas em [Bos, 2007] e [McKeever, 1985], mas mesmo em modelos mais complexos, a dosimetria continua sendo baseada nas medidas da área ou altura dos picos das curvas de emissão. A relação entre área ou altura de picos e dose nem sempre é de proporcionalidade, e deve ser estudada para cada material.

\subsection{Características dos TLDs}


Desde os primeiros experimentos com dosimetria TL, diversos materiais vem sendo desenvolvidos e utilizados nas dosimetrias de radiações. $O$ desempenho desses dosímetros é ditado por algumas de suas propriedades como linearidade de resposta, dependência energética, faixa de detecção de dose, reprodutibilidade, estabilidade de retenção da informação, dependência direcional, além de outras.

\subsubsection{Linearidade}

A linearidade de resposta, por motivos óbvios, é uma propriedade que se deseja em qualquer dosímetro. Seria muito interessante se a relação entre a intensidade do sinal TL e a dose absorvida pelos TLDs fosse linear. Infelizmente a maioria dos materiais termoluminescentes apresenta uma não linearidade nessa relação para doses acima de certo valor. A supralinearidade, ou sublinearidade, não impossibilita o uso dos TLDs, mas requer correções e calibrações cuidadosas para que os erros nas medidas sejam minimizados.

\subsubsection{Estabilidade}

A estabilidade de retenção da informação de um dosímetro TL está relacionada com a capacidade de que as cargas aprisionadas no material não sejam liberadas (antes da leitura) por calor ambiente, por iluminação ou por outro meio. Em relação a isso, é importante conhecer as características do dosímetro para sua correta utilização. Dependendo do material pode ser necessário um esquema diferente de leitura ou uma proteção contra a luz.

\subsubsection{Dependência Energética}

Visando a aplicação dos TLDs na dosimetria em radioterapia, seria interessante ter um dosímetro que apresentasse uma variação com a energia equivalente à do tecido humano (materiais chamados de "tecido equivalentes"). Como isso não é verdade para todos os materiais TL e para todas as faixas de energia, é necessário estudar o seu comportamento com a energia (eficiência em energia ou dependência energética). Basicamente, a resposta do dosímetro a fótons depende dos coeficientes de interação e de absorção de energia do material $\left(\mu\right.$ e $\mu_{a b}$ ), que determinam a quantidade de energia do feixe que é absorvida no volume sensível do dosímetro para cada energia de fóton. Se 
esses coeficientes variarem com a energia do feixe de radiação, pode ocorrer uma variação na resposta TL desses materiais. Além disso, a quantidade de luz TL emitida pelo dosímetro pode não ser proporcional à energia absorvida para todas as energias de fótons [Loncol, 1996; Marczewska, 2001]. Fatos que contribuem para essa não-linearidade vão da presença de pequenas quantidades de impurezas relacionadas à $T L$ e de número atômico muito distinto da matriz, à distribuição não homogênea das ionizações produzidas pela radiação no volume sensível do material dosimétrico, produzindo, em algumas situações, mudanças na curva térmica de emissão TL [McKeever, 1985].

\subsubsection{Tratamento Térmico}

Para manter alguma dessas propriedades durante as reutilizações dos dosímetros, é importante realizar um tratamento térmico pré-irradiação. Esse tratamento visa estabilizar e esvaziar as armadilhas do material após a leitura, restabelecendo assim a condição inicial do dosímetro [Hufton, 1984]. O procedimento adotado para o tratamento térmico depende do material e influi sensivelmente na sua resposta TL. Portanto, um rígido controle na execução desse tratamento é necessário para garantir a reprodutibilidade das medidas com os TLDs.

\subsection{LiF:Mg,Ti}

O Fluoreto de lítio é hoje, e há mais de 50 anos, o material mais estudado e utilizado como dosímetro TL. Dentre as diversas características que fazem dele um ótimo dosímetro estão o baixo número atômico efetivo $(8,14)$, a falta de sensibilidade à luz, a resistência química e mecânica, a facilidade de ser produzido em diferentes versões (como os dosímetros produzidos pela Harshaw Chemical Company (hoje pertencente ao grupo Saint-Gobain): TLD100, TLD-600 e TLD-700, que têm diferentes concentrações de ${ }^{6} \mathrm{Li}$ e ${ }^{7} \mathrm{Li}$ ) e a disponibilidade em diversos formatos (pastilhas, pó e etc) [Mckeever, 1985].

A curva de emissão do LiF:Mg,Ti consiste de vários picos de intensidade luminosa, mas o pico dosimétrico (pico 5) aparece na temperatura de 
aproximadamente $200^{\circ} \mathrm{C}^{1}$ e geralmente vem acompanhado de outro pico (pico 4) de temperatura mais baixa [Moscovitch e Horowitz, 2007]. A taxa de decaimento do sinal desse grupo dosimétrico (picos 4 e 5) já foi estudado por diversos autores e os resultados apresentados compreendem uma grande faixa, mas valores como $5-10 \%$ ao ano são os mais representativos. A linearidade de resposta TL em função da dose absorvida se mantém na faixa de $10^{-5}$ a $10 \mathrm{~Gy}$, sendo que a saturação de sinal ocorre por volta de $10^{3} \mathrm{~Gy}$ [Mckeever, 1985].

O uso desse material como dosímetro em feixes de radiação mista (nêutron e fótons) também é bem documentado [Busuoli et al, 1970; Nash e Johnson, 1977; Budd et al, 1979; Youssian et al, 1998 e Kry et al, 2007]. O TLD-100 e, principalmente, a variação TLD-600 apresentam alta sensibilidade a nêutrons enquanto o TLD-700, por possuir grande enriquecimento do isótopo 7 do lítio, cuja seção de choque é muito pequena para interações com esse tipo de radiação, é praticamente insensível. Para a medida em feixes mistos podem ser utilizados pares TLD-600/TLD-700 [Esposito et al, 2008] ou mesmo a análise da relação entre os picos 4 e 5 da curva de emissão do TLD-100 [Youssian, 1998].

Por serem tão estudados e conhecidos, nesse trabalho os dosímetros de LiF:Mg,Ti assumiram, em alguns experimentos, o papel de dosímetros padrão, sendo utilizados para correção de alterações no sistema de leitura ou para determinação da dose devido a fótons em irradiações com feixes mistos.

\subsection{Fluorita Natural}

O fluoreto de cálcio $\left(\mathrm{CaF}_{2}\right)$ é um material encontrado na natureza como o mineral fluorita. Tentativas de produzir um dosímetro TL com esse material foram feitas primeiro por uma empresa belga, mas a partir de estudos de Okuno, 1970 e Cruz, 1972 a fluorita natural brasileira também passou a ser empregada na produção de TLDs [Trzesniak, 1985]. Por ser natural e abundante, esse material é uma opção muito barata e acessível de dosímetro termoluminescente.

\footnotetext{
${ }^{1}$ As temperaturas de pico dependem das taxas de aquecimento, e por isso são apresentadas aqui sempre com valores aproximados.
} 
Na curva de emissão TL da fluorita brasileira estão presentes três picos de luminosidade importantes. O pico 1 tem uma meia vida muito pequena à temperatura ambiente e só é detectado quando a leitura é feita em um tempo muito curto após a irradiação. O pico 2 é bem estável e aparece por volta de $200^{\circ} \mathrm{C}$. O pico 3 é o mais estável, corresponde a uma temperatura de cerca de $280^{\circ} \mathrm{C}$ e é considerado como o pico dosimétrico. A faixa de resposta linear desse pico com a dose vai de $10^{-5}$ a cerca de 50 Gy e a saturação ocorre por volta de $10^{3}$ Gy [Mckeever, 1985].

Um ponto importante nos dosímetros de fluorita é a alta sensibilidade à luz UV [Okuno e Watanabe, 1972]. Fato que sugere que ela possa ser utilizada em técnicas de luminescência oticamente estimulada (OSL) [Yoshimura e Yukihara, 2006] ou dosimetria UV. Além disso, esse material também apresenta sensibilidade a nêutrons [Dielhof et al, 1988].

\section{7 $\mathrm{CaSO}_{4}: \mathrm{Dy}$}

Desde a década de $60 \circ \mathrm{CaSO}_{4}$ dopado com terras raras (Dy, Tm ou $\mathrm{Sm}$ ) vem sendo utilizado como material termoluminescente [Bjarngard, 1967, Yamashita et al, 1968 e Becker, 1972].

A curva de emissão (para todos esses dopantes) apresenta o pico dosimétrico em aproximadamente $250^{\circ} \mathrm{C}$. Outro pico (de temperatura baixa) pode ser visto em $180^{\circ} \mathrm{C}$, mas seu sinal apresenta decaimento muito rápido à temperatura ambiente. A faixa de doses onde esse material apresenta variação linear de resposta é de $10^{-4}$ a $10^{2}$ Gy e o sinal satura com $10^{4}$ Gy [Campos e Lima, 1986]. Assim como a fluorita, esse material também apresenta sensibilidade à luz, sendo que o sinal pode decair até $95 \%$ após 5 dias de exposição à luz de uma lâmpada fluorescente [Tuyn e Lakshmanan, 1983].

Duas grandes vantagens dos dosímetros de $\mathrm{CaSO}_{4}$ :Dy são 0 baixo custo para a produção dos dosímetros e a alta sensibilidade a fótons [Campos e Lima, 1986]. Esse material também apresenta sensibilidade a nêutrons. Isso ocorre por causa da reação dessas partículas com o ${ }^{164}$ Dy [Yamashita el al, 1971 e Weng e Chen, 1973]. 
Um problema que o uso desse material como dosímetro apresenta é a forte dependência energética para fótons de baixa energia, pois seu número atômico efetivo é de 15,3 [Mckeever, 1985]. Para tentar reduzir esse problema, o dosímetro passou a ser produzido associando o $\mathrm{CaSO}_{4}$ :Dy a uma matriz de Teflon [Pradhan e Bhatt, 1982] ou NaCl [Morato et al, 1982].

\section{$2.8 \mathrm{Mg}_{2} \mathrm{SiO}_{4}: \mathrm{Tb}$}

$\mathrm{O}$ dosímetro termoluminescente de $\mathrm{Mg}_{2} \mathrm{SiO}_{4}: \mathrm{Tb}$ foi descrito pela primeira vez na década de 70. Desde essa época ele já se mostrou um material bastante promissor, pois apresenta uma alta sensibilidade TL para fótons, além de estabilidade química [Prokié e Yukihara, 2008]. Apesar dessas vantagens, muito pouco foi publicado sobre esse material [McKeever, 1985].

A curva de emissão do $\mathrm{Mg}_{2} \mathrm{SiO}_{4}: \mathrm{Tb}$ apresenta o pico dosimétrico na temperatura de aproximadamente $210^{\circ} \mathrm{C}$. A resposta TL desse material é linear com a dose absorvida na faixa de $10^{-5}$ a 4 Gy e o nível de saturação é da ordem de $10^{3} \mathrm{~Gy}$. Se os dosímetros desse material ficarem protegidos da luz, o decaimento de seu sinal é menor que 3\% em 3 meses, mas em apenas 6 horas de exposição à luz ambiente o sinal termoluminescente desvanece até $10 \%$ [Prokié e Yukihara, 2008].

Um fato importante sobre esse material é justamente a alta sensibilidade à luz [Becker, 1973 e Toryu et al, 1973]. Essa alta sensibilidade faz do $\mathrm{Mg}_{2} \mathrm{SiO}_{4}: \mathrm{Tb}$ um bom material para dosimetria ultra violeta [Lakshmanan e Vohra, 1978] e também dosimetria OSL [Mittani et al, 2007], mas exige sempre alguma proteção contra luz para que ela não afete as medidas.

Essas características dependem muito da técnica de produção do dosímetro utilizada (temperatura e duração do processo de sinterização, agentes químicos utilizados, etc), mas os dosímetros estudados nesse trabalho apresentam comportamento muito semelhante aos descritos.

\section{$2.9 \mathrm{Al}_{2} \mathrm{O}_{3}: \mathrm{C}$}

O cristal "puro" de óxido de alumínio $\left(\mathrm{Al}_{2} \mathrm{O}_{3}\right)$ não apresenta sensibilidade TL, mas ao introduzir vacâncias de oxigênio na estrutura do cristal, grandes 
melhorias são alcançadas nas suas características dosimétricas [Akselrod, 1993]. As principais características observadas nesses dosímetros são a alta sensibilidade TL; curva de emissão simples (apresentando um único pico em aproximadamente $180^{\circ} \mathrm{C}$ ); baixo decaimento do sinal TL (se guardado no escuro perde-se menos de $5 \%$ ao ano) e número atômico efetivo $(10,2)$ relativamente baixo quando comparado a outros materiais. A faixa de resposta linear em função da dose vai de $10^{-7}$ a aproximadamente $1 \mathrm{~Gy}$, variando de acordo com a concentração de carbono no cristal [Yang et al, 2008].

Em relação à dosimetria $T L$, alguns problemas são apresentados pelo dosímetro de $\mathrm{Al}_{2} \mathrm{O}_{3}: \mathrm{C}$. A diminuição da eficiência de luminescência quando a temperatura aumenta (thermal quenching) e a alta sensibilidade à luz [Moscovitch et al, 1993, Mckeever et al, 1995 e Kortov, 1994] são os principais. A resposta do pico dosimétrico também sofre variações com a dose absorvida, indicando mecanismos de competição envolvendo o preenchimento de armadilhas de carga mais profundas [Yukihara, 2003].

A forte sensibilidade à luz do $\mathrm{Al}_{2} \mathrm{O}_{3}: \mathrm{C}$ faz dele um ótimo material para dosimetria OSL, principalmente porque, nessa técnica, o efeito de thermal quenching é evitado, fazendo com que a sensibilidade OSL seja muito maior que a sensibilidade TL.

\subsection{Especificação dos feixes de fótons de alta energia}

Diferentemente dos feixes de fótons com energia da ordem de alguns keVs, que são descritos por meio de sua energia efetiva ou equivalente ou da espessura de suas camadas semi-redutoras (CSR) em materiais padrão, a especificação dos feixes de fótons de alta energia é um pouco mais complexa. Informações como energia média e espessura da CSR para esses feixes são difíceis de medir na rotina das clínicas de radioterapia. Mesmo que as medidas fossem fáceis de realizar, essas são informações que não têm quase nenhuma utilidade na prática.

Uma maneira de especificar os feixes de fótons de alta energia é com o índice $T R_{20,10}$ [IAEA, 2001]. Esse índice é a razão entre as doses absorvidas nas profundidades de 20 e $10 \mathrm{~cm}$ em um simulador de água, medidas com a 
distância fonte-detector fixa e igual a $100 \mathrm{~cm}$ e um tamanho de campo de $10 \mathrm{~cm} \times 10 \mathrm{~cm}$ no plano do detector. Apesar de ser bem estabelecida, a especificação dos pelo $\operatorname{TPR}_{20,10}$ não é muito intuitiva e é comum encontrar na literatura feixes identificados pela aceleração nominal dos elétrons [Mobit, 1996] (feixes de aceleração nominal de $18 \mathrm{MV}$, por exemplo) ou pela energia nominal máxima de seus fótons [Morlotti, 2007] (feixes de raios $X$ com energia máxima de $18 \mathrm{MeV}$. É interessante notar que, no jargão da radioterapia, também é comum denominar o feixe de fótons apenas pela energia potencial necessária para acelerar os elétrons até que esses tenham energia igual à dos elétrons que incidem no alvo. Desse modo, um feixe de fótons gerados por um feixe de elétrons de $6 \mathrm{MeV}$, é chamado de "feixe de fótons de $6 \mathrm{MV}$ ". Essa denominação é incorreta, pois MV não é unidade de energia e o feixe não possui apenas fótons de $6 \mathrm{MeV}$.

O principal problema com essas denominações mais simples é que elas trazem pouca informação sobre os aspectos dosimétricos dos feixes. Feixes com mesma denominação, mas originados em aceleradores de diferentes fabricantes geralmente apresentam grandes diferenças de penetração e distribuição de dose. Além disso, uma vez que algumas das correções feitas nas medidas dosimétricas nas clínicas dependem de parâmetros obtidos na literatura, utilizar apenas a denominação pela aceleração nominal, ignorando as reais propriedades de penetração do feixe pode acarretar em variações de até $2 \%$ nos valores desses parâmetros [Andreo, 1986].

\subsection{Geradores de feixes clínicos de fótons de Alta Energia}

A evolução da radioterapia nas últimas décadas se deve, em grande parte, ao desenvolvimento dos geradores de feixes de fótons de alta energia. Desde a década de 50 , unidades de Cobalto 60 e bétatrons foram bastante utilizados [Johns e Cunninghan, 1969]. A partir de 70, essas unidades passaram a ser substituídas por aceleradores lineares e, atualmente, essas são as máquinas mais encontradas nos centros de radioterapia. Nesse trabalho foram utlilizados feixes de fótons de alta energia gerados em aceleradores lineares clínicos e em unidades de Cobalto 60. 


\subsubsection{Unidades de Cobalto 60}

As unidades de cobalto, assim como unidades de outros radionuclídeos, são basicamente um recipiente de chumbo ou outro material de alto número atômico e alta densidade, no interior do qual é colocada a fonte radioativa, e um mecanismo controlado à distância para deslocar a fonte para uma posição em frente a uma abertura que possibilite a saída do feixe de radiação. A fonte de ${ }^{60} \mathrm{Co}$ utilizada consiste de cilindros envolvidos por duas cápsulas de aço inoxidável, vedadas com solda [Johns e Cunninghan, 1969].

A fonte de ${ }^{60} \mathrm{Co}$ decai, emitindo uma partícula $\beta^{-}\left(E_{\max }=0,32 \mathrm{MeV}\right)$, para ${ }^{60} \mathrm{Ni}$ em um estado excitado. A desexcitação ocorre instantaneamente pela emissão de dois fótons (1,17 MeV e 1,33 MeV). As partículas $\beta$ são absorvidas pelo material do encapsulamento e os fótons gama são os principais constituintes do feixe útil. Além desses raios gama, o feixe é constituído por fótons de baixa energia e elétrons (produzidos pelas interações do feixe primário com os materiais do cabeçote da unidade). O espectro de fótons gerado em uma unidade típica de ${ }^{60} \mathrm{Co}$ pode ser visto na Figura 2-5. O gráfico apresentado foi obtido por simulação de Monte Carlo [Mora, 1999].

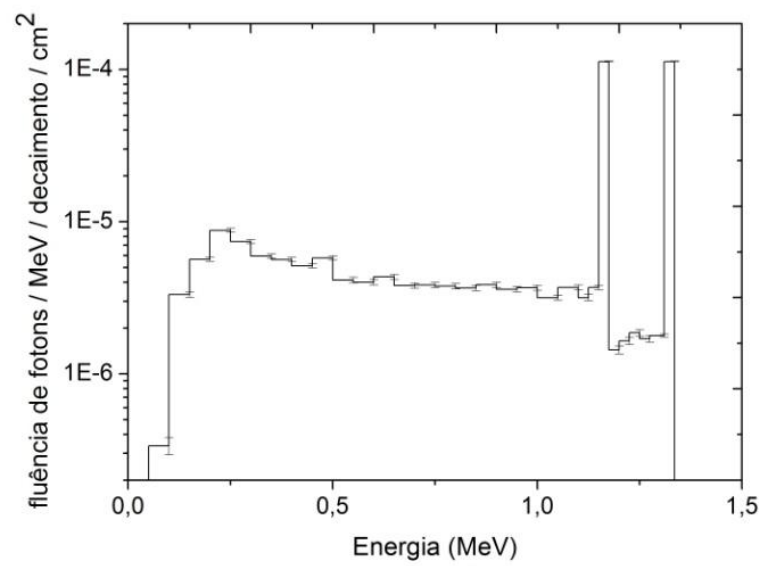

Figura 2-5: Espectro de fótons simulado no eixo central de um campo de $10 \times 10 \mathrm{~cm}^{2}$ e distância fonte detector de $100 \mathrm{~cm}$. O espectro corresponde ao de uma unidade de cobalto Eldorado 6 e leva em consideração o encapsulamento da fonte, o sistema de colimação e o espalhamento no ar.

\subsubsection{Aceleradores Lineares Clínicos}

Os aceleradores são equipamentos que obedecem a duas condições básicas para promoverem a aceleração de partículas. A primeira é que as 
partículas a serem aceleradas têm que ter carga elétrica. A segunda é que um campo elétrico na direção de aceleração das partículas deve ser provido [Podgorsak, 2006].

Os aceleradores lineares clínicos, encontrados no Brasil, possuem um tubo acelerador, onde elétrons, gerados em um "canhão de elétrons", são acelerados por ondas de radiofrequência até atingirem energias cinéticas da ordem de 4 a $25 \mathrm{MeV}$.

Para gerar o feixe de fótons, o feixe de elétrons acelerados é direcionado a um alvo para produção de raios-X. Pela interação dos elétrons com o material do alvo, o feixe de fótons de Bremsstrahlung é gerado.

O espectro de fótons gerados nos aceleradores lineares apresenta uma distribuição contínua até a energia máxima dos fótons, que é igual à energia cinética dos elétrons incidentes no alvo. Na realidade, apenas uma parcela bem pequena dos fótons terá energia igual à energia máxima possível. Os espectros dos feixes utilizados nesse trabalho podem ser vistos na Figura 2-6. Esses espectros também foram gerados por simulações de Monte Carlo e correspondem aos aceleradores dos mesmos fabricantes dos aceleradores utilizados. [Sheikh-Bagheri e Rogers, 2002]. 


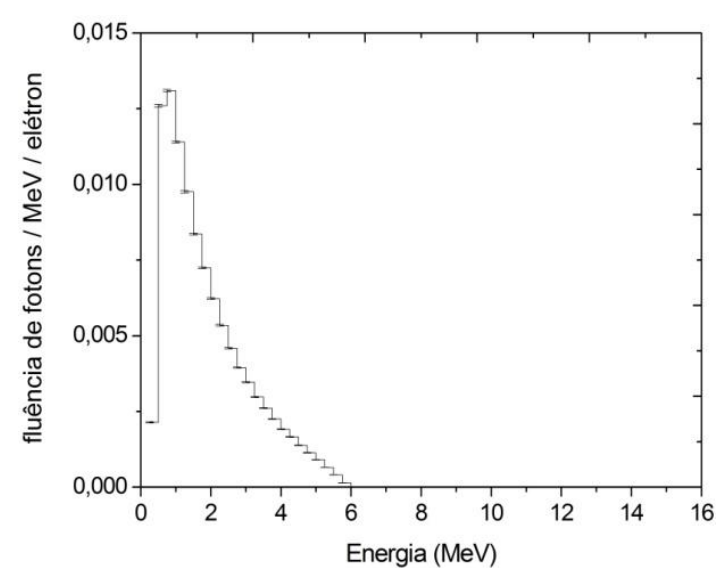

(a)

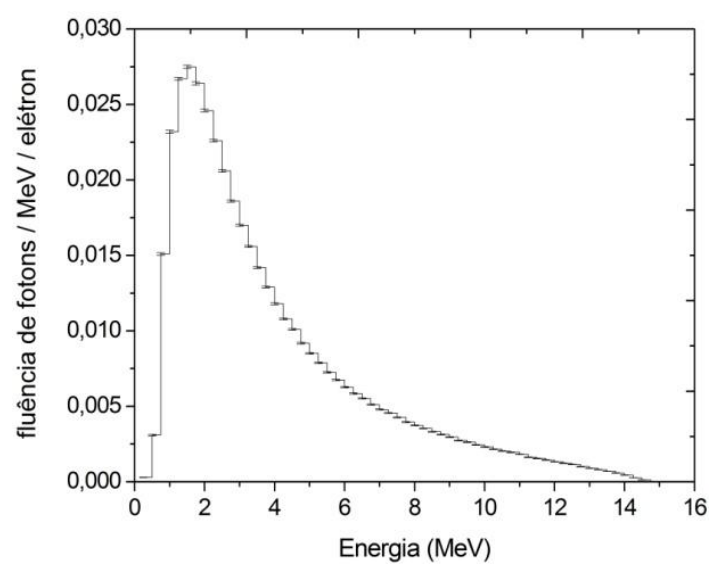

(c)

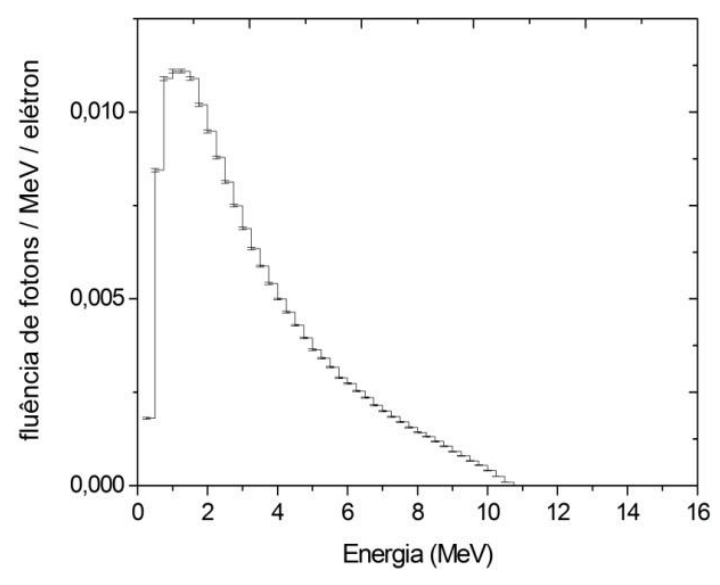

(b)

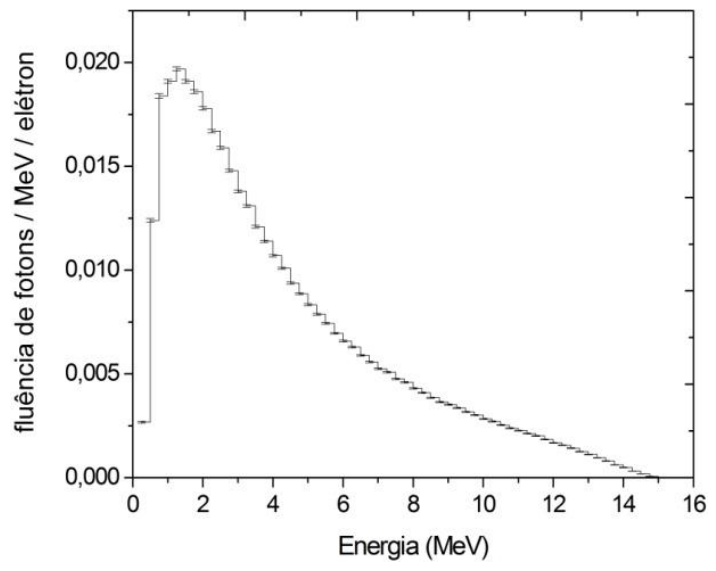

(d)

Figura 2-6: Espectro de fótons simulado para diferentes aceleradores lineares: Três aceleradores da Varian de potencial de aceleração nominal de 6 MV (a), 10 MV (b) e 15 MV (c) e um acelerador da Siemens com potencial de aceleração nominal de $18 \mathrm{MV}$ (d).

\subsection{Contaminação de nêutrons no feixe de fótons}

Um fato que gera problemas para a dosimetria experimental dos feixes de raios $X$ e que também pode interferir na dose recebida pelo paciente é que os feixes que possuem fótons com energia maior que $10 \mathrm{MeV}$, apresentam contaminação por nêutrons gerados por reações $(\gamma, n)$ em materiais atingidos pelo feixe. $O$ espectro desses nêutrons é formado basicamente por nêutrons rápidos com energia média de $0,4 \mathrm{MeV}$, logo após saírem do cabeçote do acelerador [Rivera, 2008 e Facure et al, 2005].

Existem normas internacionais como a IEC 60601-2-1 [IEC, 1998] que determinam que "a dose absorvida devida a nêutrons não deve exceder um máximo de 0,05 e uma média de 0,02\% da dose absorvida devida aos raios $X$ ". Além disso, nota-se na Figura 2-6 que a parcela de fótons com energia maior 
que $10 \mathrm{MeV}$, mesmo no feixe de potencial de aceleração nominal de $18 \mathrm{MV}$ é pequena, ou seja, a dose absorvida devido a nêutrons nos experimentos realizados nesse trabalho deve ser praticamente desprezível. Mesmo assim, para a realização das medidas com os TLDs, é necessário um teste de sensibilidade desses dosímetros a nêutrons, pois no caso de uma alta sensibilidade a esse tipo de radiação a resposta TL poderia ser afetada.

\subsection{Monte Carlo}

Fazer uma simulação com o método de Monte Carlo significa utilizar uma série de procedimentos estatísticos e matemáticos para representar sistemas naturais ou artificiais (físicos, matemáticos, químicos ou biológicos). Como requisitos, esses sistemas devem ser estatisticamente aleatórios e poderem ser descritos por funções de densidade de probabilidade [Guimarães, 2005].

Para o transporte de radiação, por exemplo, partículas são geradas aleatoriamente em geometrias definidas pelo usuário e, por meio das funções densidade de probabilidade, todos os eventos ocorridos entre a geração e a absorção de cada partícula são calculados. Para estimar uma grandeza por esse método, cada partícula gerada tem sua história calculada e a incerteza final depende do número de histórias ou de partículas simuladas. Para reduzir as incertezas a níveis aceitáveis, às vezes é necessário um longo tempo de cálculo, mesmo contando com os computadores e processadores modernos.

$\mathrm{Na}$ literatura é possível encontrar vários códigos computacionais que utilizam o método de Monte Carlo para simular o transporte de radiação. Alguns dos mais conhecidos são o EGS [Kawrakou et al, 2010], MCNP [Brown et al, 2003], GEANT [Agostinelli et al, 2003], FLUKA [Battistoni et al, 2007] e o PENELOPE [Salvat et al, 2006]. Todos os códigos apresentam algumas limitações e dificuldades. Nesse trabalho, o PENELOPE foi o código escolhido para as simulações. 


\section{MATERIAIS E MÉTODOS}

\subsection{Dosímetros TL}

Foram estudados dosímetros TL de cinco materiais diferentes. Cada tipo de dosímetro exige um manejo e apresenta propriedades distintas. As principais características dos dosímetros utilizados vão descritas a seguir, e estão resumidas na Tabela 3-1.

\subsubsection{LiF:Mg,Ti (TLD-100)}

Os dosímetros, produzidos pela Harshaw Chemical Company, tem o formato de paralelepípedo de dimensões $3,1 \times 3,1 \times 0,9 \mathrm{~mm}^{3}$. Sua curva de emissão (Figura 3-1) pode apresentar vários picos quando o material é aquecido. $O$ agrupamento dos picos 5 e 4, mostrado na figura, é utilizado para dosimetria, pois é mais estável, intenso e seu sinal não decai à temperatura ambiente.

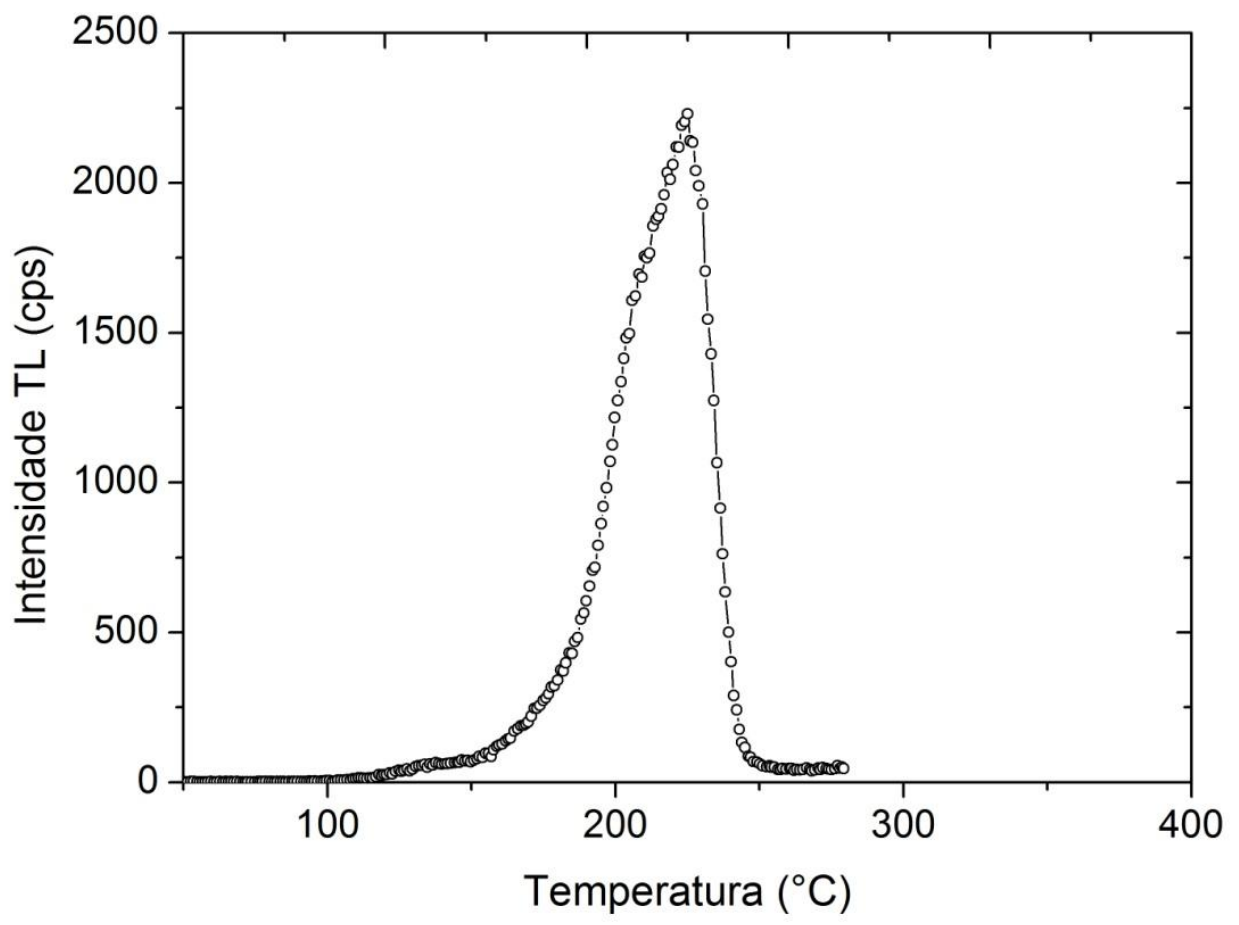

Figura 3-1: Curva de emissão do LiF:Mg, Ti obtida 24 horas após irradiação com ${ }^{60} \mathrm{Co}$ e dose de $10 \mathrm{mGy}$. A leitura foi feita com aquecimento de $5^{\circ} \mathrm{C} / \mathrm{s}$ até $280^{\circ} \mathrm{C}$. 


\subsubsection{Fluorita Natural}

Os dosímetros desse material foram produzidos, no Laboratório de Dosimetria do IFUSP, para uso nesse projeto, pela da compactação do pó de $\mathrm{CaF}_{2}$ natural (fluorita verde) com o aglutinante $\mathrm{NaCl}$. A pastilha tem formato cilíndrico, diâmetro médio de 5,0 $\mathrm{mm}$, espessura média de $0,84 \mathrm{~mm}$ e massa média de $42 \mathrm{mg}$. A curva de emissão (Figura 3-2) apresenta dois picos úteis para uso em dosimetria. A resposta desses dosímetros é bastante alterada no caso de exposição à luz.

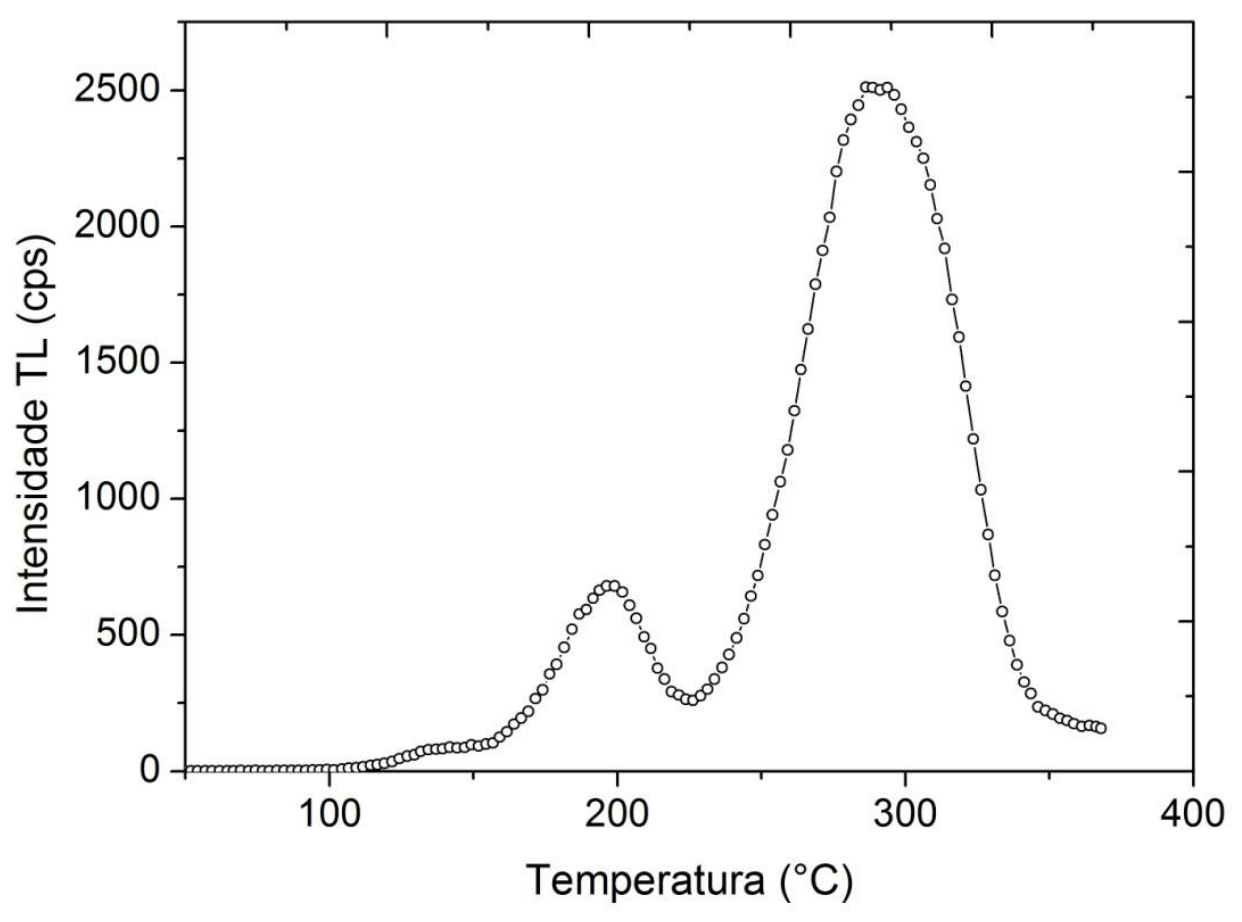

Figura 3-2: Curva de emissão do $\mathrm{CaF}_{2}$ obtida 24 horas após irradiação com ${ }^{60} \mathrm{Co}$ e dose de $10 \mathrm{mGy}$. A leitura foi feita com aquecimento de $5^{\circ} \mathrm{C} / \mathrm{s}$ até $380^{\circ} \mathrm{C}$.

\subsection{3 $\mathrm{CaSO}_{4}: \mathrm{Dy}$}

Os dosímetros utilizados foram desenvolvidos e produzidos pelo LMD/IPEN pela de mistura do fósforo $\mathrm{CaSO}_{4}$ :Dy e de pó de Teflon (na proporção de 1:4). As pastilhas são cilíndricas com $6,0 \mathrm{~mm}$ de diâmetro médio, $0,80 \mathrm{~mm}$ de espessura média e massa média de $50 \mathrm{mg}$. A curva de emissão (Figura 3-3) apresenta dois picos, sendo que o primeiro apresenta forte decaimento quando exposto à luz. A presença do Teflon impede que a leitura desse dosímetro seja feita até temperaturas muito altas. 


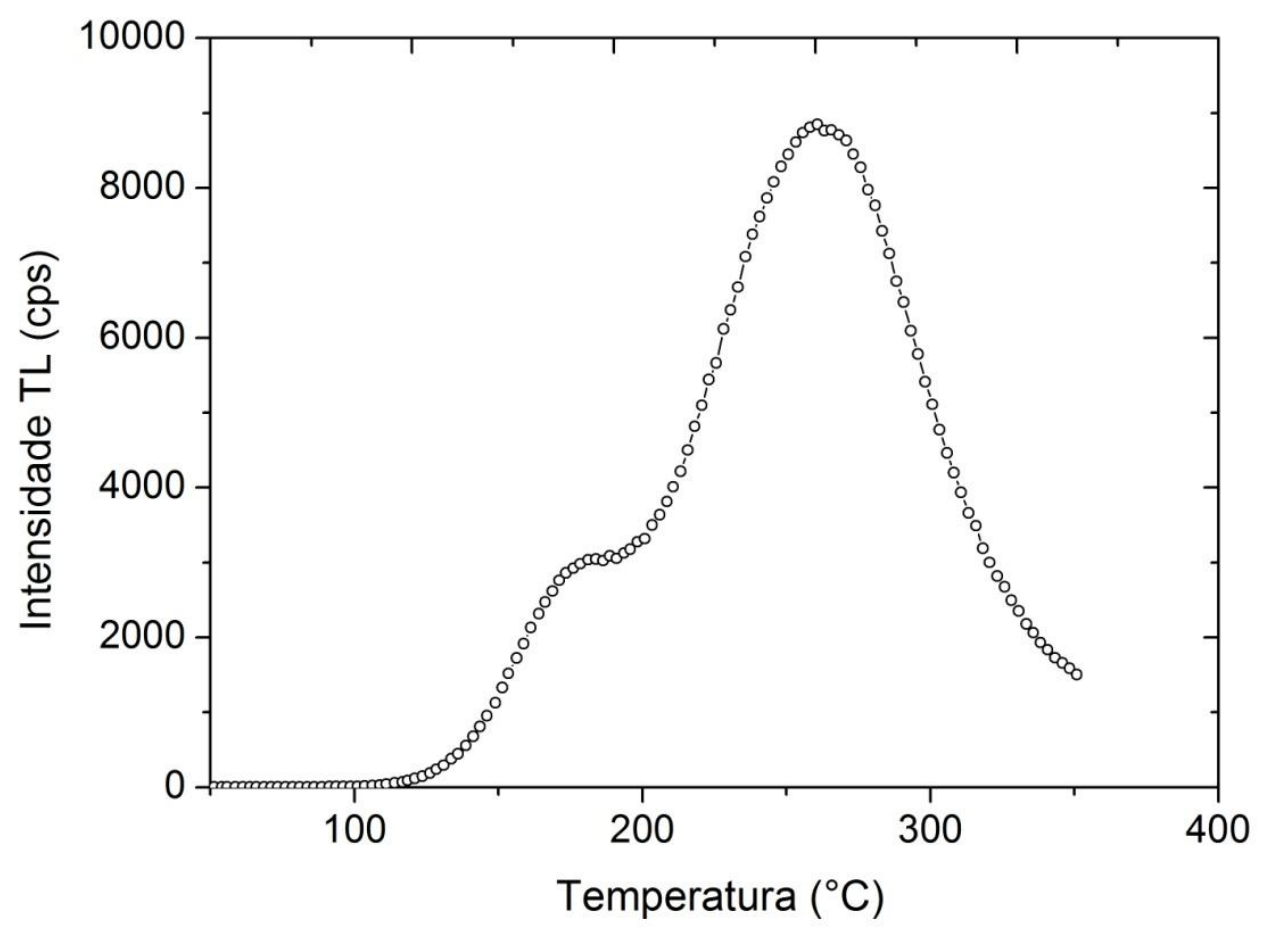

Figura 3-3: Curva de emissão do $\mathrm{CaSO}_{4}$ :Dy obtida 24 horas após irradiação com ${ }^{60} \mathrm{Co}$ e dose de 10 mGy. A leitura foi feita com aquecimento de $5^{\circ} \mathrm{C} / \mathrm{s}$ até $350^{\circ} \mathrm{C}$.

\subsection{4 $\mathrm{Mg}_{2} \mathrm{SiO}_{4}: \mathrm{Tb}$}

Fabricados pela Kasei Optonix, os dosímetros de $\mathrm{Mg}_{2} \mathrm{SiO}_{4}: \mathrm{Tb}$ encontram-se na forma de pó encapsulado em um invólucro de vidro cilíndrico com diâmetro de 2,0 mm e altura de 15 mm. A curva de emissão (Figura 3-4) apresenta um único pico em aproximadamente $215^{\circ} \mathrm{C}$. A exposição direta à luz, também nesse material, causa um considerável decaimento do sinal TL. 


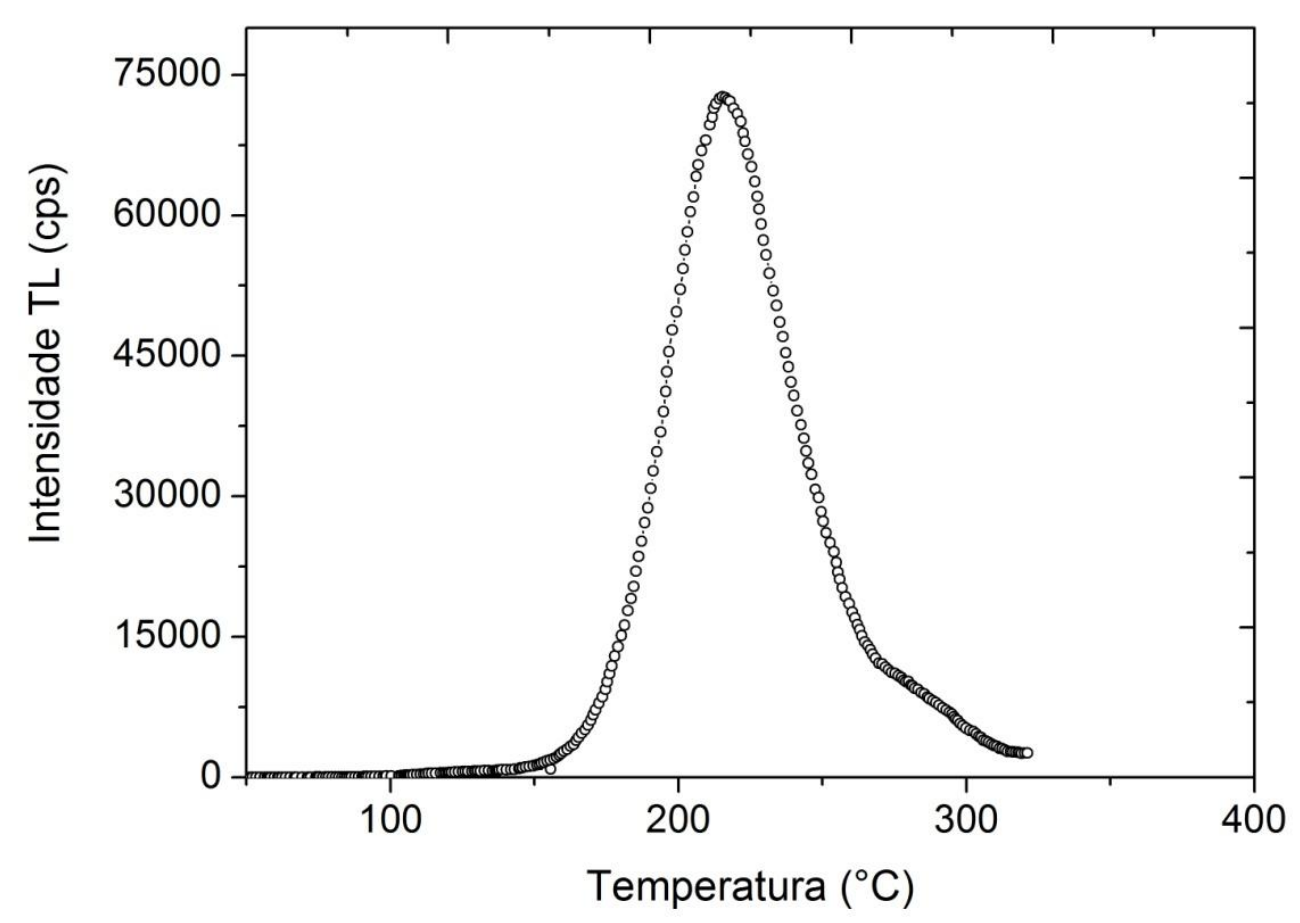

Figura 3-4: Curva de emissão do $\mathrm{Mg}_{2} \mathrm{SiO}_{4}$ : $\mathrm{Tb}$ obtida 24 horas após irradiação com ${ }^{60} \mathrm{Co}$ e dose de $10 \mathrm{mGy}$. As leituras foram feitas com aquecimento de $5^{\circ} \mathrm{C} / \mathrm{s}$ até $320^{\circ} \mathrm{C}$.

\subsection{5 $\mathrm{Al}_{2} \mathrm{O}_{3}: \mathrm{C}$}

Os dosímetros de óxido de alumínio utilizados foram crescidos no Urals Polytechnic Institute (Rússia). São cristais cilíndricos com diâmetro médio de $5,0 \mathrm{~mm}$ e espessura média de $1,0 \mathrm{~mm}$. Esse material é muito estudado para uso em dosimetria OSL, mas também apresenta alta sensibilidade quando utilizado como dosímetro TL. Sua curva de emissão (Figura 3-5) apresenta um pico bem definido e de temperatura relativamente baixa (por volta de $170{ }^{\circ} \mathrm{C}$ ). Para possibilitar uma maior homogeneidade de aquecimento, as leituras foram tomadas com uma taxa de aquecimento menor do que a usada com os outros materiais. Esse procedimento foi motivado pelo fato do cristal ter massa maior e apresentar o pico de emissão em temperatura mais baixa que os demais dosímetros.

Uma característica que exige bastante cuidado no manejo desses dosímetros é a alta sensibilidade à luz. A exposição à luz pode interferir no sinal TL do $\mathrm{Al}_{2} \mathrm{O}_{3}: \mathrm{C}$ de três maneiras: decaimento do sinal, transferência de 
cargas aprisionadas em armadilhas profundas (PTTL) e aumento do sinal devido a iluminação com radiação UV [Akselrod, 1993].

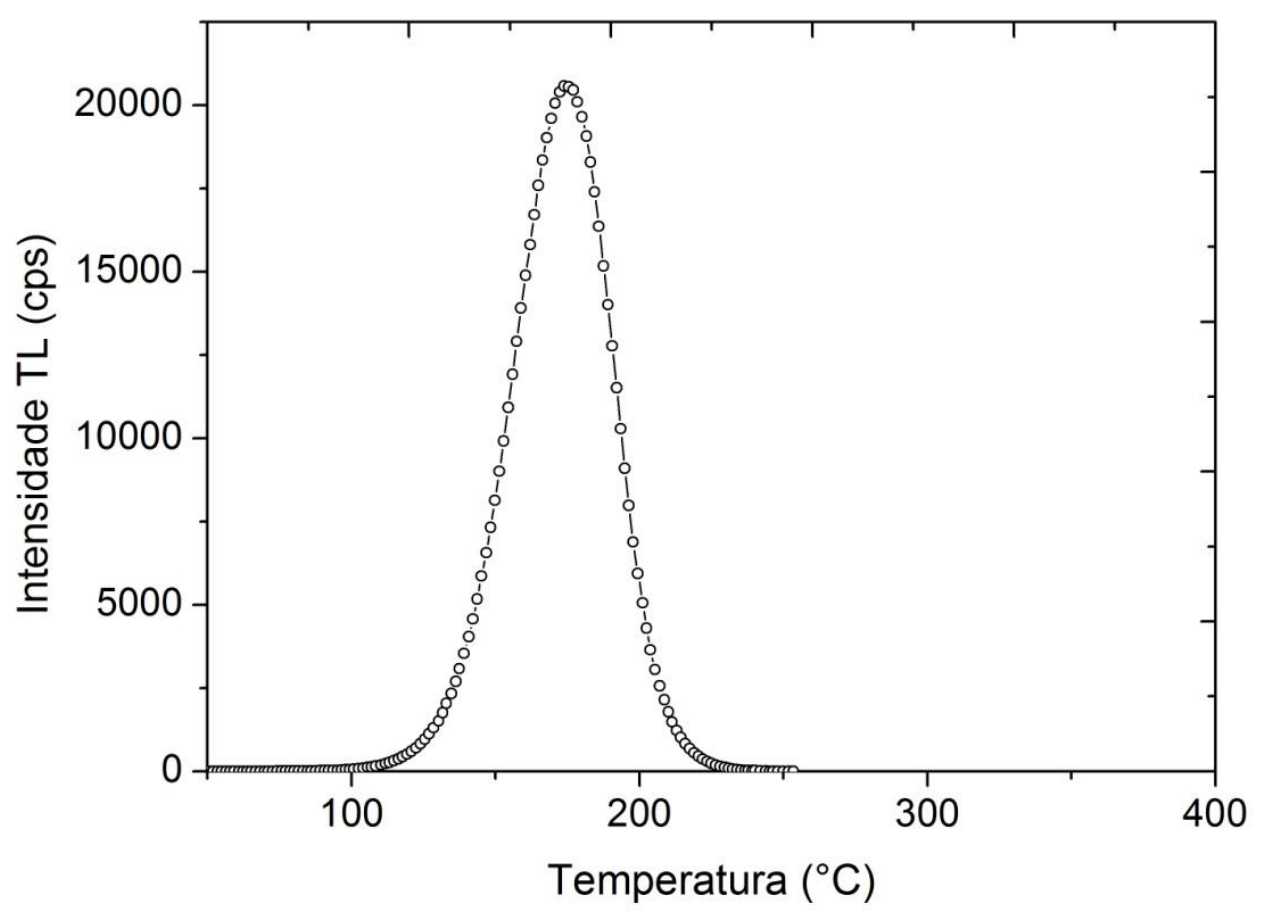

Figura 3-5: Curva de emissão do $\mathrm{Al}_{2} \mathrm{O}_{3}: \mathrm{C}$ obtida 24 horas após irradiação com ${ }^{60} \mathrm{Co}$ e dose de $10 \mathrm{mGy}$. A leitura foi feita com aquecimento de $1^{\circ} \mathrm{C} / \mathrm{s}$ até $240{ }^{\circ} \mathrm{C}$.

Tabela 3-1: Resumo das características dos dosímetros estudados.

\begin{tabular}{|c|c|c|c|c|c|c|}
\hline \multirow[b]{2}{*}{ Material } & \multirow[b]{2}{*}{ Formato } & \multirow{2}{*}{$\begin{array}{l}\text { Tratamento } \\
\text { Térmico pré } \\
\text { irradiação }\end{array}$} & \multicolumn{2}{|c|}{ Leituras } & \multirow{2}{*}{$\begin{array}{l}\text { Temperatura } \\
\text { do(s) pico(s) } \\
\text { dosimétrico(s) }\end{array}$} & \multirow{2}{*}{$\begin{array}{c}\text { Sensível à } \\
\text { Luz }\end{array}$} \\
\hline & & & $\begin{array}{c}\text { Taxa de } \\
\text { Aquecimento }\end{array}$ & $\begin{array}{c}\text { Temperatura } \\
\text { Máxima }\end{array}$ & & \\
\hline LiF:Mg,Ti & paralelepípedo & $\begin{array}{c}1 \text { hora a } \\
400^{\circ} \mathrm{C}+ \\
2 \text { horas a } \\
100^{\circ} \mathrm{C}\end{array}$ & $5^{\circ} \mathrm{C} / \mathrm{s}$ & $280^{\circ} \mathrm{C}$ & $225^{\circ} \mathrm{C}$ & não \\
\hline Fluorita & $\begin{array}{l}\text { pastilha } \\
\text { cilíndrica }\end{array}$ & $\begin{array}{c}20 \text { min. a } \\
400^{\circ} \mathrm{C}\end{array}$ & $5^{\circ} \mathrm{C} / \mathrm{s}$ & $380^{\circ} \mathrm{C}$ & $\begin{array}{l}195^{\circ} \mathrm{C} \\
285^{\circ} \mathrm{C}\end{array}$ & $\operatorname{sim}$ \\
\hline $\mathrm{CaSO}_{4}: \mathrm{Dy}$ & $\begin{array}{l}\text { pastilha } \\
\text { cilíndrica }\end{array}$ & $\begin{array}{c}3 \text { horas a } \\
300{ }^{\circ} \mathrm{C}\end{array}$ & $5^{\circ} \mathrm{C} / \mathrm{s}$ & $350^{\circ} \mathrm{C}$ & $\begin{array}{l}180^{\circ} \mathrm{C} \\
260^{\circ} \mathrm{C}\end{array}$ & $\operatorname{sim}$ \\
\hline $\mathrm{Al}_{2} \mathrm{O}_{3}: \mathrm{C}$ & $\begin{array}{l}\text { cristal } \\
\text { cilíndrico }\end{array}$ & $\begin{array}{l}15 \text { min. a } \\
900^{\circ} \mathrm{C}\end{array}$ & $1^{\circ} \mathrm{C} / \mathrm{s}$ & $240^{\circ} \mathrm{C}$ & $170^{\circ} \mathrm{C}$ & $\operatorname{sim}$ \\
\hline $\mathrm{Mg}_{2} \mathrm{SiO}_{4}: \mathrm{Tb}$ & $\begin{array}{c}\text { pó } \\
\text { encapsulado }\end{array}$ & $\begin{array}{l}1 \text { hora a } \\
300^{\circ} \mathrm{C}\end{array}$ & $5^{\circ} \mathrm{C} / \mathrm{s}$ & $320^{\circ} \mathrm{C}$ & $215^{\circ} \mathrm{C}$ & $\operatorname{sim}$ \\
\hline
\end{tabular}




\subsection{Seleção de Dosímetros}

A precisão em Dosimetria TL requer dosímetros com pouca variação de resposta quando irradiados com uma mesma dose. Essa característica não é garantida em um lote de dosímetros qualquer, pois fatores como concentração de dopantes, opacidade à luz emitida e geometria podem variar de dosímetro para dosímetro e acabar influenciando na dispersão da resposta.

A dispersão de cada lote pode ser dada pelo desvio padrão das medidas TL, tomando o cuidado para que os dosímetros sejam submetidos, todos de uma vez, às mesmas condições de irradiação, tratamento térmico e leitura. As medidas iniciais dos lotes dos diferentes dosímetros apresentaram dispersões da ordem de $10 \%$ do valor médio.

Para reduzir a dispersão, foi feito um processo de seleção. Esse processo consiste em escolher, dentro dos lotes, subconjuntos de dosímetros que apresentem coeficiente de variação (desvio padrão relativo à média), menores do que os dos lotes iniciais.

Como o desvio padrão de um conjunto de dosímetros tem uma componente aleatória e outra sistemática, a melhor seleção que pode ser feita é aquela em que se excluem os dosímetros com comportamento sistemático diferente dos demais. Dessa maneira, os grupos selecionados são aqueles cuja dispersão se deve predominantemente ao erro estatístico.

O processo de seleção foi feito usando duas irradiações por lote. As irradiações foram feitas na fonte de ${ }^{60} \mathrm{Co}$ do Laboratório de Dosimetria e em cada uma a dose absorvida nos dosímetros foi de aproximadamente $10 \mathrm{mGy}$. Após cada irradiação, foram feitos histogramas das leituras TL. Os histogramas tinham o mesmo número de faixas e a posição de cada dosímetro nestas faixas foi acompanhada. Assim, foi possível definir três grupos, de acordo com a região do histograma (alta, média ou baixa). Os dosímetros que ocuparam faixas extremas (altas ou baixas) nos dois histogramas de leituras foram excluídos do lote. 
Uma seleção melhor poderia ser feita utilizando mais irradiações, porém com apenas duas, a dispersão obtida para cada grupo já foi considerada satisfatória.

\subsection{Irradiações em feixes clínicos}

Os grupos dos cinco materiais termoluminescentes estudados foram irradiados em cinco diferentes feixes de fótons de alta energia. Para isso foram utilizados uma fonte clínica de ${ }^{60} \mathrm{Co}$ e três aceleradores lineares de elétrons.

A fim de obter curvas de resposta TL em função da dose absorvida em água, os diferentes grupos foram irradiados, em cada feixe, com doses conhecidas entre 0,200 e 2,00 Gy. Essa faixa de doses foi escolhida por estar na parte linear da curva de resposta de quase todos os TLDs estudados, serem valores facilmente obtidos com os geradores de feixes clínicos e abranger valores de dose comumente empregados em teleterapia fracionada.

O processo de irradiação consistia em posicionar, com o auxilio de um suporte, alguns dosímetros no interior de um objeto simulador e irradiá-los com a dose desejada. Todas as doses foram verificadas pela da medida com câmara de ionização, e apresentaram incerteza da ordem de $1 \%$.

\subsubsection{Fontes de radiação utilizadas}

Para o processo de seleção dos dosímetros, irradiações preliminares e calibração para o experimento com nêutrons, o feixe de fótons utilizado era originado em uma fonte de ${ }^{60} \mathrm{Co}$ pertencente ao Laboratório de Dosimetria do IFUSP. A fonte pertencia a um serviço de radioterapia e foi doada ao IFUSP por estar com atividade abaixo da recomendada para tratamentos de pacientes. A atividade da fonte era de 4,420 Ci em 01/10/2008.

Outra fonte de ${ }^{60} \mathrm{Co}$, esta pertencente ao Hospital-1, foi utilizada para as medidas de dependência energética. Essa fonte é parte de uma máquina Alcyon II da CGR que é projetada para ser usada em tratamentos de radioterapia. Ela possui uma distância fonte isocentro de $80 \mathrm{~cm}$ e a atividade em janeiro de 2011 era de aproximadamente $2600 \mathrm{Ci}$. 
No hospital-2, foram utilizados dois aceleradores lineares clínicos. Um Varian CLINAC iX e um Varian CLINAC 2100. Estes aceleradores possuem distância foco-isocentro de $100 \mathrm{~cm}$ e fornecem feixes de raios- $X$ com energias máximas de 6 ou $15 \mathrm{MeV}$ e 6 ou $10 \mathrm{MeV}$, respectivamente.

As medidas em feixes de potencial de aceleração nominal de $18 \mathrm{MV}$ foram realizadas no acelerador clínico Primus, da Siemens, pertencente ao hospital-3. Esse acelerador é capaz de gerar feixes de raios- $X$ com energias máximas de 6 ou $18 \mathrm{MeV}$, mas nesse trabalho, só foi utilizado o feixe de maior energia.

A Fonte utilizada para realizar os experimentos com nêutrons foi uma fonte de AmBe também pertencente ao Laboratório de Dosimetria do IFUSP. No ponto de medida o fluxo de nêutrons térmicos era de $(6,2 \pm 2) \times 10^{3}$ e o de epitérmicos $(2,3 \pm 6) \times 10^{3}$ nêutrons. $\mathrm{cm}^{-2} \cdot \mathrm{s}^{-1}$ [Maidana, 2011].

\subsubsection{Câmaras de ionização}

Para verificar as doses depositadas em água, nos volumes ocupados pelos dosímetros termoluminescentes, nas irradiações em feixes clínicos foram utilizados conjuntos dosimétricos pertencentes aos próprios hospitais. Todos os conjuntos consistem de eletrômetros e câmaras de ionização tipo farmer com volume sensível de $0,6 \mathrm{~cm}^{3}$.

No Hospital-1 a câmara era da marca IBA, modelo FC65-G e o eletrômetro Standard Imaging, modelo: MAX4000; no hospital-2 foi utilizada uma câmara PTW 30013 e eletrômetro PTW Unidos E; no hospital-3, a câmara também era da marca IBA modelo FC65-G e o eletrômetro Standard Imaging CDX-2000A.

Todos os conjuntos dosimétricos estavam devidamente calibrados. As calibrações foram feitas em feixe de ${ }^{60} \mathrm{Co}$ de um laboratório de padrão secundário, rastreável a um laboratório de padrão primário, conforme recomendações dos protocolos internacionais de dosimetria [IAEA, 2001 e Almond et al, 1999]. 


\subsubsection{Objeto simulador}

O objeto simulador utilizado nas irradiações clínicas consiste de uma caixa com paredes de PMMA, de dimensões $20 \times 20 \times 15 \mathrm{~cm}^{3}$ (Figura 3-6 (b)), preenchida de água e com uma cavidade própria para acomodar uma câmara de ionização tipo farmer. Essa cavidade é construída de maneira que o volume sensível da câmara possa ficar no centro da caixa, a 5 ou $10 \mathrm{~cm}$ de profundidade. Esse objeto simulador atende as recomendações do protocolo de dosimetria TRS-398 da Agência Internacional de Energia Atômica [IAEA, 2001].

\subsubsection{Suporte para dosímetros TL}

O suporte de TLDs utilizado foi desenvolvido no Laboratório de Dosimetria do IFUSP (Figura 3-6 (a)). Esse suporte possui geometria semelhante à de uma câmara de ionização tipo farmer e tem a finalidade de utilizar dosímetros TL em locais onde esse tipo de câmara pode ser inserida (simuladores de água líquida, água sólida ou mesmo medidas no ar utilizando a capa de equilíbrio eletrônico da câmara).

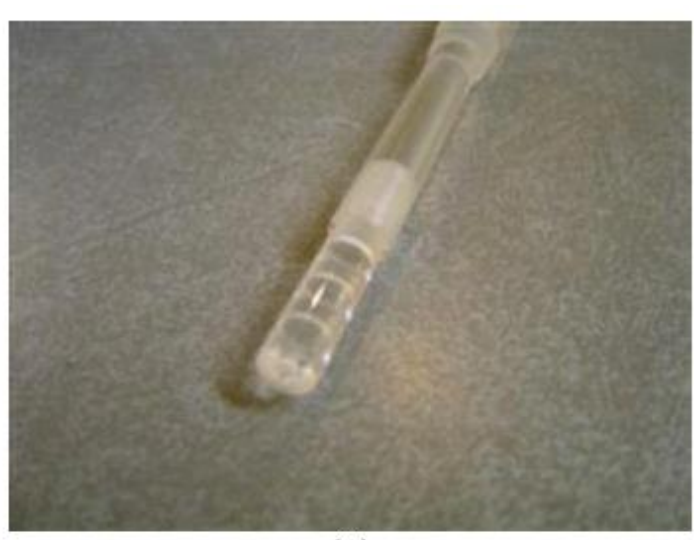

(a)

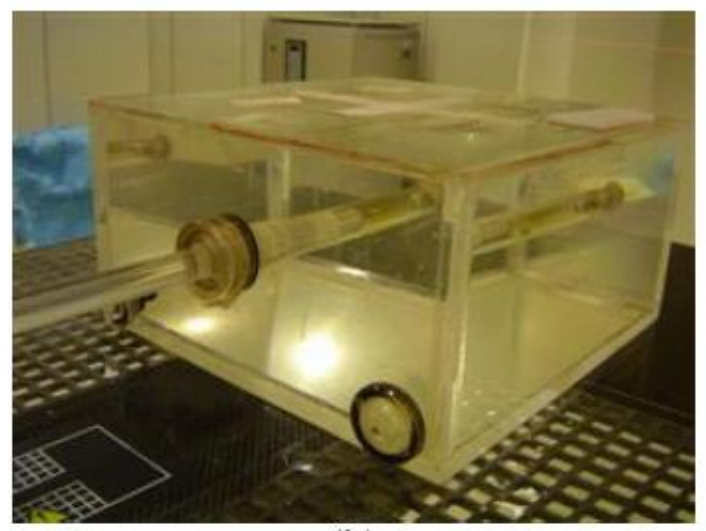

(b)

Figura 3-6: (a) suporte com formato da câmara de ionização tipo farmer. (b) suporte posicionado no objeto simulador.

O suporte é feito de PMMA transparente e possui um espaço onde se inserem diferentes ponteiras. Essas ponteiras também foram feitas em PMMA transparente e possuem, cada uma, três compartimentos onde podem ser colocados os dosímetros. Para $\circ \mathrm{Mg}_{2} \mathrm{SiO}_{4}: \mathrm{Tb}$, que tem formato de pó encapsulado em um cilindro de vidro, a ponteira tem espaço apenas para dois dosímetros. 
Nessas ponteiras (Figura 3-7), os dosímetros ficam acomodados em uma bandeja de PMMA dentro de uma bainha opaca. As extremidades das bandejas foram cobertas com fita isolante líquida para completar a vedação de luz.
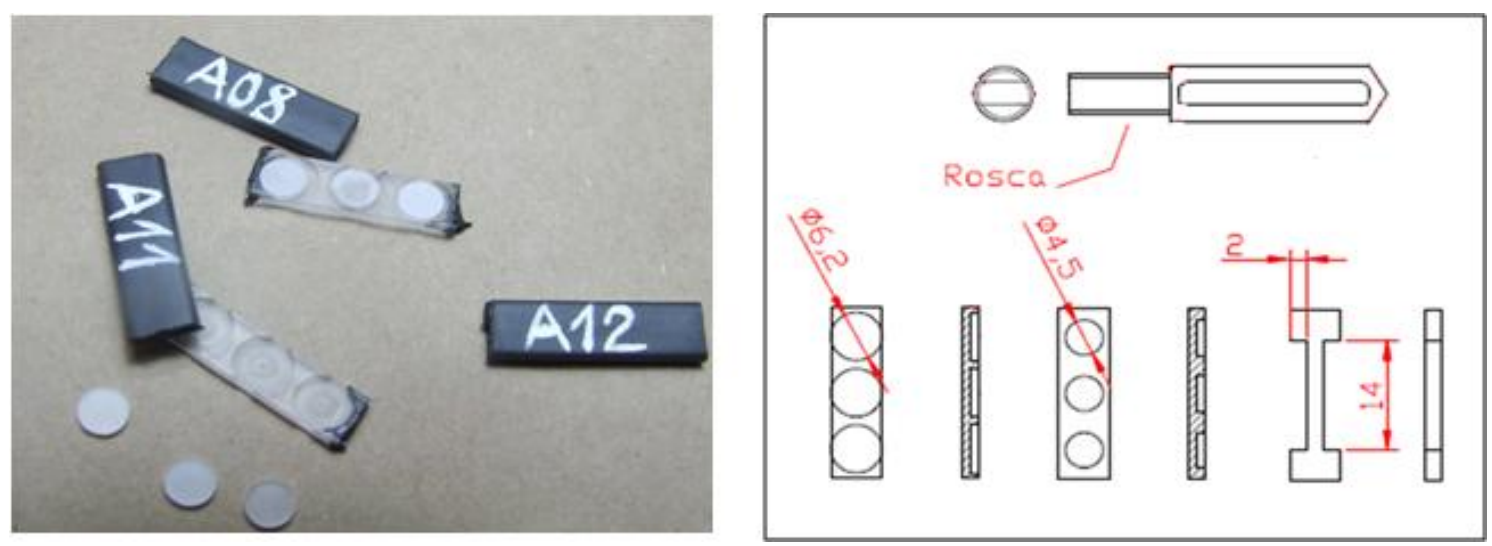

Figura 3-7: Ponteira e bainha de vedação de luz para a pastilha de $\mathrm{Al}_{2} \mathrm{O}_{3}: \mathrm{C}$ e o projeto das demais ponteiras.

Foi feito um teste que consistiu em deixar algumas ponteiras, com dosímetros previamente irradiados, expostas a luz ambiente. Depois dessa exposição, os dosímetros foram lidos para verificar se houve algum decaimento do sinal TL. As leituras foram comparadas com as de um grupo controle e não houve diferença entre as respostas. Assim sendo, a vedação de luz nas ponteiras foi considerada satisfatória para o uso nesse trabalho.

\subsubsection{Geometria das Irradiações Clínicas}

Para as irradiações em feixes clínicos, o objeto simulador foi posicionado a $100 \mathrm{~cm}$ da fonte de radiação no caso dos aceleradores lineares, e a $80 \mathrm{~cm}$ no caso da fonte de ${ }^{60} \mathrm{Co}$. O campo de radiação media, na superfície do objeto, $10 \times 10 \mathrm{~cm}^{2}$ e o suporte de dosímetros foi posicionado a $5 \mathrm{~cm}$ de profundidade para o feixe de ${ }^{60} \mathrm{Co}$ e a $10 \mathrm{~cm}$ para os demais feixes.

Essa geometria de irradiação é a geometria sugerida pelo protocolo de dosimetria TRS-398, da Agência Internacional de Energia Atômica [IAEA, 2001], para a determinação, com câmaras de ionização cilíndricas, da dose absorvida na água em feixes de fótons de alta energia.

Como o suporte para os dosímetros TL tem as mesmas dimensões de uma câmara de ionização tipo farmer (cilíndrica), as irradiações dos TLDs e 
das câmaras puderam ser feitas na mesma geometria, garantindo que a dose absorvida em água, medida pela câmara de ionização era equivalente à dose que se pretendia medir com os TLDs, ou seja, a dose que seria absorvida naquele volume de água, caso os TLDs não estivessem presentes.

\subsection{Leituras TL}

\subsubsection{Sistemas de leitura}

A leitura de todos os TLDs foi realizada em um sistema de leitura de termoluminescência construído no Laboratório de Dosimetria do IFUSP. Esse sistema detecta a luz emitida pelo dosímetro e a sua temperatura a cada instante.

O sistema possui um porta-amostra, cujo aquecimento pode ser controlado, onde são colocados, um por vez, os dosímetros a serem lidos. Esse porta-amostra fica em uma câmara escura onde os fótons emitidos pelo dosímetro aquecido são detectados por uma fotomultiplicadora EMI 9789B. O sinal de saída é amplificado por um pré-amplificador SR445 (DC $300 \mathrm{MHz}$ ) e contado como pulsos no contador SR400. A contagem de pulsos é enviada a um computador junto com a informação da temperatura obtida com um termopar.

O software que gerencia o sistema também foi desenvolvido no Laboratório de Dosimetria do IFUSP na plataforma Labview e, por meio dele, pode-se controlar a taxa de aquecimento, intervalo de temperatura e tempo de integração das contagens. O programa também realiza a aquisição dos dados. No arquivo de saída encontram-se o tempo em segundos, a temperatura em o $\mathrm{C}$, a taxa de contagem de fótons (fótons por segundo) e o número total de fótons contados a cada intervalo de amostragem.

\subsubsection{Filtros ópticos}

No sistema de leitura de termoluminescência utilizado é possível adicionar filtros ópticos entre o dosímetro a ser "lido" e a entrada da válvula fotomultiplicadora. Nesse trabalho foram usados 5 diferentes filtros: Schott KG 1, Corning 4-70, Corning 5-58, e dois filtros neutros, Oriel, com transmissão de 
$1 \%$ e $10 \%$. O filtro Schott KG 1 foi utilizado em todas as leituras e filtra, principalmente, os fótons de infravermelho, originados pela incandescência das amostras e do próprio porta-amostra. Os filtros Corning 4-70 e 5-58 são filtros coloridos e apresentam transmissão de fótons na faixa do azul e violeta respectivamente. Os filtros neutros foram utilizados nas leituras em que os dosímetros haviam sido irradiados com doses altas (irradiações em feixes clínicos). O objetivo desses filtros é reduzir a intensidade de luz que chega a fotomultiplicadora, mantendo a taxa de contagens abaixo do limite estabelecido pelo fabricante.

\subsubsection{Correção para alterações no sistema de leitura}

A eficiência da leitura de sinal TL pode ser influenciada por diversos fatores. A perda de eficiência da válvula fotomultiplicadora, sujeira acumulada nos filtros e variações na tensão de alimentação são ocorrências que podem causar alterações durante um mesmo processo de medidas. Além disso, se as medidas não forem feitas no mesmo momento, variações na posição do termopar e alterações no porta-amostra podem ocorrer, e acabar influenciando as respostas das leituras.

Como nesse trabalho as análises dependem de medidas feitas em datas diferentes, foi necessário adotar uma medida de correção para as possíveis alterações de eficiência de leitura. A estratégia foi utilizar um grupo de dosímetros de LiF:Mg,Ti como grupo controle.

Esse grupo foi todo irradiado com a mesma dose (1,80 Gy $\pm 1 \%$ no feixe de potencial de aceleração nominal de $6 \mathrm{MV}$ ) e, toda vez que uma medida de qualquer um dos materiais estudados foi feita, alguns desses dosímetros foram lidos e sua resposta foi considerada como um fator de normalização. Desse modo foi possível anular as alterações na resposta devido a variações no equipamento. O LiF:Mg,Ti foi escolhido como o dosímetro controle por causa da estabilidade e confiabilidade de suas características dosimétricas.

\subsection{Irradiações com Nêutrons}

Para verificar a possível influência da contaminação de nêutrons nas respostas dos dosímetros irradiados com os feixes de potencial de aceleração 
nominal de 10, 15 e $18 \mathrm{MV}$, todos os dosímetros foram irradiados pelo feixe de uma fonte de AmBe. A intenção dessa irradiação foi verificar se os dosímetros são sensíveis a nêutrons e se ocorrem alterações no comportamento das curvas de emissão em comparação com as curvas obtidas após uma irradiação com fótons gama.

A fonte de AmBe geralmente é utilizada como padrão de calibração para as medidas dos nêutrons de contaminação de feixes gerados em aceleradores por possuir um espectro de nêutrons semelhante ao espectro encontrado ao redor do cabeçote desses aparelhos [Rivera, 2008]. Como nesse trabalho os dosímetros irradiados foram posicionados no centro do objeto simulador de água, com espessura suficiente para termalizar os nêutrons, as irradiações na fonte de $\mathrm{AmBe}$ foram feitas utilizando um suporte de parafina que também termaliza os nêutrons rápidos, sendo que, no ponto de medida o fluxo térmico era de $(6,2 \pm 2) \times 10^{3}$ e o epitérmico $(2,3 \pm 6) \times 10^{3}$ nêutrons. $\mathrm{cm}^{-2} \cdot \mathrm{s}^{-1}$. Nas irradiações, os dosímetros ficaram expostos durante um tempo longo ( 36 horas para os dosímetros de sulfato de cálcio e $\sim 14$ horas para os demais) e as leituras foram feitas logo em seguida.

Como o feixe da fonte de AmBe também possui fótons, foi necessário monitorar a dose referente a esse tipo de radiação. Para isso foi utilizado o TLD-700, que é um dosímetro de fluoreto de lítio, também produzido pela Harshaw Chemical Company. A diferença entre o TLD-700 e o TLD-100 (estudado nesse trabalho) está na composição isotópica do lítio. Enquanto o TLD-100 apresenta o lítio na sua proporção natural $\left(7,5 \%\right.$ de ${ }^{6} \mathrm{Li}$ e $92,5 \%$ de $\left.{ }^{7} \mathrm{Li}\right)$, o TLD-700 é enriquecido com ${ }^{7} \mathrm{Li}\left(99,93 \%\right.$ de ${ }^{7} \mathrm{Li}$ e $0,07 \%$ de $\left.{ }^{6} \mathrm{Li}\right)$. Esse enriquecimento resulta no fato de o TLD-700 não ser sensível a nêutrons, atuando assim como medidor da dose referente apenas aos fótons gama presentes no feixe.

Para determinar a dose no ar medida pelo TLD-700, foi feita uma irradiação de calibração na fonte de ${ }^{60} \mathrm{Co}$ onde os dosímetros receberam 5 doses diferentes (entre 5 e $100 \mathrm{mGy}$ ) e a reta de calibração foi traçada. Retas de calibração no ${ }^{60} \mathrm{Co}$ e nessa faixa de doses também foram feitas para os dosímetros dos cinco materiais estudados. Com o auxilio dessas retas foi 
possível estimar a resposta desses dosímetros para a mesma dose absorvida devida a fótons, que foi medida com o TLD-700, e relacionar essa resposta com a resposta obtida na irradiação com a fonte de AmBe.

\subsection{Simulações com Monte Carlo}

Para as simulações com o método Monte Carlo foi utilizado o código computacional PENELOPE (versão 2006). Esse código realiza simulações de transporte de elétrons e fótons em materiais arbitrários para uma gama de energias, desde centenas de eVs até GeVs. Um pacote de geometria, chamado PENGEOM é responsável pela interação dos feixes de fótons/elétrons com volumes homogêneos delimitados por superfícies quadráticas (planos, esferas, cilindros, etc.). Com o auxílio desde pacote, é possível recriar a geometria utilizada em uma medida experimental para realizar uma simulação [Salvat et al, 2006].

Nas simulações realizadas nesse trabalho, o objetivo foi encontrar a razão entre a dose absorvida nos diferentes dosímetros estudados e a dose absorvida em água nas mesmas situações de irradiação. A comparação dos resultados experimentais obtidos com as simulações permitiria diferenciar possíveis efeitos de deposição de energia e de mecanismos TL. Vale ressaltar que o código PENELOPE não simula a criação e transporte de nêutrons. Como foram utilizados feixes de fótons com energia máxima de 10, 15 e $18 \mathrm{MeV}$, que podem interagir com os materiais de alto número atômico, presentes no cabeçote dos aceleradores, gerando nêutrons, divergências entre os resultados das simulações e experimentos poderiam indicar uma apreciável resposta dos dosímetros a nêutrons que contaminem o feixe terapêutico.

Nesse trabalho, foi simulada uma geometria que reproduz fielmente o arranjo experimental usado nas medidas feitas nos hospitais. Os espectros das fontes simuladas foram obtidos na literatura [Mora,1999 e Sheikh-Bagheri e Rogers, 2002] e correspondem aos espectros de feixes gerados em máquinas clínicas do mesmo modelo e fabricante dos utilizados para as irradiações. Para obter a dose absorvida na água, o material dos dosímetros foi substituído por 
água e as simulações foram todas repetidas. Em todos os casos, o campo de radiação na superfície do objeto simulador foi um círculo de diâmetro $10 \mathrm{~cm}$.

O material dos dosímetros foi simulado com o programa auxiliar MATERIAL [Salvat et al, 2006]. Nesse programa é possível "criar" os materiais usando as suas composições químicas e densidade ou utilizar os materiais do banco de dados existente [Berger, 1992]. A Tabela 3-2 mostra os materiais simulados e algumas de suas propriedades.

Em todas as simulações, o transporte de elétrons foi terminado em $10 \mathrm{keV}$, o corte para transporte de fótons foi configurado como $1 \mathrm{keV}$ e a criação de fótons de bremsstrahlung e raios delta com energia maior que essas energias foi simulada explicitamente. Uma vez que a partícula apresenta a energia de corte, o programa considera que ela deposita toda essa energia localmente.

O número de histórias por simulação variou entre 15 e 50 milhões, dependendo da energia do feixe e tipo de dosímetro. A incerteza na dose absorvida simulada foi da ordem de $1 \%$.

Tabela 3-2: Propriedades dos materiais simulados.

\begin{tabular}{|c|c|c|c|}
\hline Dosímetro & $\begin{array}{l}\text { Material } \\
\text { Simulado }\end{array}$ & $\begin{array}{c}\text { Densidade } \\
\left(\mathrm{g} / \mathrm{cm}^{3}\right)\end{array}$ & fonte \\
\hline TLD-100 & $\mathrm{LiF}$ & 2,64 & [Berger, 1992] \\
\hline Fluorita & $\begin{array}{c}\mathrm{CaF}_{2}+ \\
\text { aglutinante } \\
\underset{\mathrm{NaCl}}{ }\end{array}$ & 2,55 & [Guimarães, 2005] \\
\hline $\mathrm{CaSO}_{4}: \mathrm{Dy}$ & $\mathrm{CaSO}_{4}$ & 4,93 & [Nunes, 2008] \\
\hline $\mathrm{Mg}_{2} \mathrm{SiO}_{4}: \mathrm{Tb}$ & $\mathrm{Mg}_{2} \mathrm{SiO}_{4}$ & 3,12 & [Yasuda, 2000] \\
\hline $\mathrm{Al}_{2} \mathrm{O}_{3}: \mathrm{C}$ & $\mathrm{Al}_{2} \mathrm{O}_{3}$ & 3,97 & [Berger, 1992] \\
\hline
\end{tabular}




\subsection{Análise de Dados}

\subsubsection{Irradiações em feixes clínicos}

A análise dos dados das medidas das irradiações em feixes clínicos seguiu o mesmo padrão para os cinco materiais estudados. Como foi dito na seção 2.3, em cada feixe, os dosímetros foram irradiados com cinco doses diferentes, equivalentes a doses absorvidas em água de 0,200, 0,500, 1,00, 1,80 e 2,00 Gy. Além desses, um grupo de cada material também foi utilizado para medir a radiação de fundo. Para cada valor de dose, dois ou três dosímetros foram irradiados e a resposta TL assumida foi igual à média das respostas com a incerteza igual ao desvio padrão dessa média. Vale ressaltar que nesse trabalho a resposta TL atribuída a cada um dos dosímetros foi a altura do pico da curva de intensidade de luz. Para a fluorita o pico utilizado foi o pico 3, para o sulfato de cálcio o pico 2 e para o fluoreto de lítio o pico 5.

Uma importante análise a ser feita é uma comparação qualitativa do formato das curvas de emissão. Analisar globalmente as curvas de emissão TL (posição, presença e formato de picos, altura relativa entre picos) quando os materiais são irradiados com diferentes feixes de fótons pode indicar alguma dependência com a energia sem que a resposta $T L$ seja necessariamente alterada.

Para a análise das respostas $T L$, foram traçadas curvas de calibração (resposta TL em função da dose absorvida em água) para todos os feixes e materiais. Para os dosímetros que apresentaram resposta linear ao longo dessa faixa de dose, um ajuste linear dos pontos medidos foi feito e o coeficiente angular das diferentes retas ajustadas foi considerado como um importante parâmetro para quantificar a dependência energética desse dosímetro. O coeficiente linear dos ajustes, para esses casos, foi da ordem da resposta TL dos dosímetros que não foram irradiados (medida da radiação de fundo), por essa razão, ele não foi considerado nas análises.

Outra maneira de estudar a linearidade da resposta TL em função da energia do feixe e também da dose absorvida em água, é pela razão entre a resposta TL (líquida, ou seja, subtraída a contribuição de radiação de fundo) e 
a dose absorvida na água. Essa razão pode ser chamada de sensibilidade relativa, uma vez que expressa em cps.Gy ${ }^{-1}$ o "tamanho" da resposta (cps) que o dosímetro terá para um certo valor de dose medido (Gy), nas condições empregadas para leitura.

Em um gráfico da sensibilidade relativa em função da dose absorvida na água, é esperada uma reta paralela ao eixo da dose absorvida para os dosímetros que apresentem resposta $T L$ linear em função da dose na faixa estudada. Ao se comparar esse tipo de gráfico para diferentes feixes, esperase observar o mesmo comportamento das curvas caso não haja dependência energética na resposta dos dosímetros.

Para analisar quantitativamente a dependência energética, a partir das respostas TL medidas, foi definido um fator de dependência energética $\boldsymbol{F}_{\boldsymbol{C o}}^{\boldsymbol{X}}$ como sendo a razão entre o coeficiente angular da reta de calibração de um feixe qualquer $\mathrm{X}$ e o coeficiente angular da reta de calibração do feixe de ${ }^{60} \mathrm{Co}$ :

$$
F_{C o}^{X}=\frac{\text { coef.angular }(X)}{\text { coef.angular }(C o)}
$$

Se o dosímetro tiver os valores de $\boldsymbol{F}_{\boldsymbol{C} o}^{\boldsymbol{X}}$ próximos de 1 , significa que a sua resposta não muda com a energia do feixe, ou melhor, se $\boldsymbol{F}_{C o}^{X}$ é igual a 1 , a resposta dos dosímetros quando irradiados com uma certa dose em um feixe de ${ }^{60} \mathrm{Co}$ é igual a resposta desse mesmo dosímetro quando irradiado com a mesma dose em um outro feixe $X$. Essa quantificação é feita geralmente na literatura pela razão entre as sensibilidades para um determinado valor de dose. A razão entre os coeficientes angulares amplia a definição de fator de dependência energética.

No caso dos dosímetros cuja resposta $T L$ em função da dose absorvida na água não apresentou comportamento linear, o fator de dependência energética $\mathrm{F}_{\mathrm{Co}}^{\mathrm{X}}$ foi calculado como a média das dependências energéticas de cada ponto de dose medido:

$$
F_{C o}^{X}=\frac{1}{N} \sum_{i=1}^{i=N} \frac{\left(T L\left(D_{i}\right) / D_{i}\right)_{X}}{\left(T L\left(D_{i}\right) / D_{i}\right)_{C o}}
$$


onde $\boldsymbol{D}_{\boldsymbol{i}}$ é a dose absorvida na água em uma das medidas, $\left(\boldsymbol{T} \boldsymbol{L}\left(\boldsymbol{D}_{\boldsymbol{i}}\right)\right)_{X}$ é a resposta TL do dosímetro quando irradiado em um feixe $X$ com dose $D_{i}$ e $N$ é o total de pontos medidos (nesse trabalho $\boldsymbol{N}$ foi igual a 5). Nesse caso, valores de $\boldsymbol{F}_{\boldsymbol{C o}}^{\boldsymbol{X}}$ próximos de 1 também indicam resposta independente da energia (desde que não ocorram variações no formato das curvas de sensibilidade relativa). No caso de $\boldsymbol{F}_{\boldsymbol{C o}}^{\boldsymbol{X}}$ apresentar valores diferentes de 1 não é possível chegar a uma conclusão, pois isso pode acontecer se existir uma dependência energética, se existir diferença de formato nas curvas de sensibilidade relativa ou ambas as coisas. Para uma análise conclusiva, no caso de não linearidade entre a resposta TL e a dose absorvida, é necessário associar o calculo de $\boldsymbol{F}_{C o}^{X}$ pela equação 3-2 e a análise das curvas de sensibilidade relativa.

\subsubsection{Irradiações com nêutrons}

Para as medidas da influência da contaminação por nêutrons dos feixes clínicos de fótons, a análise dos dados foi semelhante às análises realizadas no estudo de dependência energética. A resposta TL utilizada continuou sendo a altura dos picos dosimétricos, sendo que o valor adotado foi a média de vários dosímetros irradiados na fonte de $\mathrm{AmBe}$ e a incerteza foi o desvio padrão dessa média.

Para avaliar a contribuição dos fótons gama durante a irradiação com a fonte de AmBe para a resposta de cada dosímetro, a dose no ar devido a esse tipo de radiação foi medida com o TLD-700 que havia sido calibrado em um feixe de ${ }^{60} \mathrm{Co}$. A partir do valor da dose absorvida medida pelo TLD-700 a altura de pico das curvas de emissão dos demais dosímetros foi estimada. Essa estimativa foi feita utilizando, de modo invertido, as curvas de calibração para o feixe de ${ }^{60} \mathrm{Co}$, ou seja, o sinal TL esperado foi obtido a partir de um valor conhecido de dose, determinado com os dosímetros de TLD-700. Também nesse caso, as curvas de emissão foram analisadas em busca de alguma alteração que indicasse a presença de nêutrons. 


\subsubsection{Simulações Monte Carlo}

Para análise dos resultados das simulações, também foi interessante estabelecer um fator de dependência energética das simulações $f s_{C o}^{X}$ como sendo:

$$
f s_{C o}^{X}=\frac{\left(D_{T L D} / D_{\text {água }}\right)_{X}}{\left(D_{T L D} / D_{\text {água }}\right)_{C o}}
$$

onde $\left(\boldsymbol{D}_{T L D}\right)_{X}$ é a dose depositada do dosímetro termoluminescente quando irradiado em um feixe qualquer $\boldsymbol{X}$ e $\left(\boldsymbol{D}_{\text {água }}\right)_{X}$ é a dose depositada no volume de água igual ao volume do dosímetro quando este é irradiado pelo mesmo feixe $X$ de radiação e nas mesmas condições. A razão $\left(\boldsymbol{D}_{T L D} / \boldsymbol{D}_{\text {água }}\right)$ é o análogo da sensibilidade relativa (definida na seção 2.7.1), pois representa a relação entre dose absorvida no dosímetro e a dose que ele se propõe a medir (dose absorvida na água). A diferença é que, nesse caso, só é levada em consideração a deposição de energia, uma vez que os mecanismos TL não são simulados.

Também nesse caso, valores de $\boldsymbol{f} \boldsymbol{s}_{\boldsymbol{C o}}^{\boldsymbol{X}}$ próximos a 1 indicam que, ao variar a energia, a sensibilidade relativa dos dosímetros não se altera. Somado às outras análises já descritas, a análise de $\boldsymbol{f} \boldsymbol{s}_{C o}^{X}$ é de grande ajuda para chegar às conclusões desse trabalho. 


\section{RESULTADOS}

\subsection{Seleção dos dosímetros estudados}

A Tabela 4-1 apresenta os resultados do processo de seleção dos dosímetros estudados. Como pode ser visto, após realizar essa seleção, a dispersão da resposta do grupo quando irradiado com uma mesma dose foi consideravelmente reduzida.

Tabela 4-1: Resultados da seleção dos dosímetros. A dispersão apresentada é em relação à média das medidas.

\begin{tabular}{cccccc}
\hline \multirow{2}{*}{ Material } & \multicolumn{2}{c}{ Lote inicial } & \multicolumn{2}{c}{ Grupo selecionado } & $\begin{array}{c}\text { Redução da } \\
\text { dispersão }\end{array}$ \\
\cline { 2 - 5 } & quantidade & dispersão & quantidade & dispersão & \\
\hline LiF:Mg,Ti & 64 & $4 \%$ & 50 & $3 \%$ & $25 \%$ \\
Fluorita & 111 & $12 \%$ & 78 & $8 \%$ & $33 \%$ \\
$\mathrm{CaSO}_{4}: \mathrm{Dy}$ & 121 & $8 \%$ & 84 & $5 \%$ & $38 \%$ \\
$\mathbf{A l}_{2} \mathrm{O}_{3}: \mathbf{C}$ & 48 & $17 \%$ & 17 & $6 \%$ & $65 \%$ \\
$\mathbf{M g}_{2} \mathrm{SiO}_{4}: \mathrm{Tb}$ & 116 & $12 \%$ & 87 & $8 \%$ & $33 \%$ \\
\hline
\end{tabular}




\subsection{Resposta TL do fluoreto de lítio (TLD-100) em função da energia do feixe}

\subsubsection{Curvas de emissão}

Uma das análises que deve ser feita, quando se estuda a dependência energética de dosímetros TL é em relação a mudanças em suas curvas de emissão. Como vimos no Capítulo 2, pode ocorrer que, ao variar a energia do feixe de fótons, o formato da curva sofra alguma alteração independente de a área sob a curva ou a intensidade máxima variarem. A Figura 4-1 apresenta as curvas de emissão obtidas nas medidas dos dosímetros de LiF:Mg,Ti expostos aos diferentes feixes de fótons. Para facilitar a comparação visual, uma vez que essa é uma análise qualitativa, todas as curvas foram normalizadas em relação ao seu ponto de máximo (altura do pico dosimétrico).

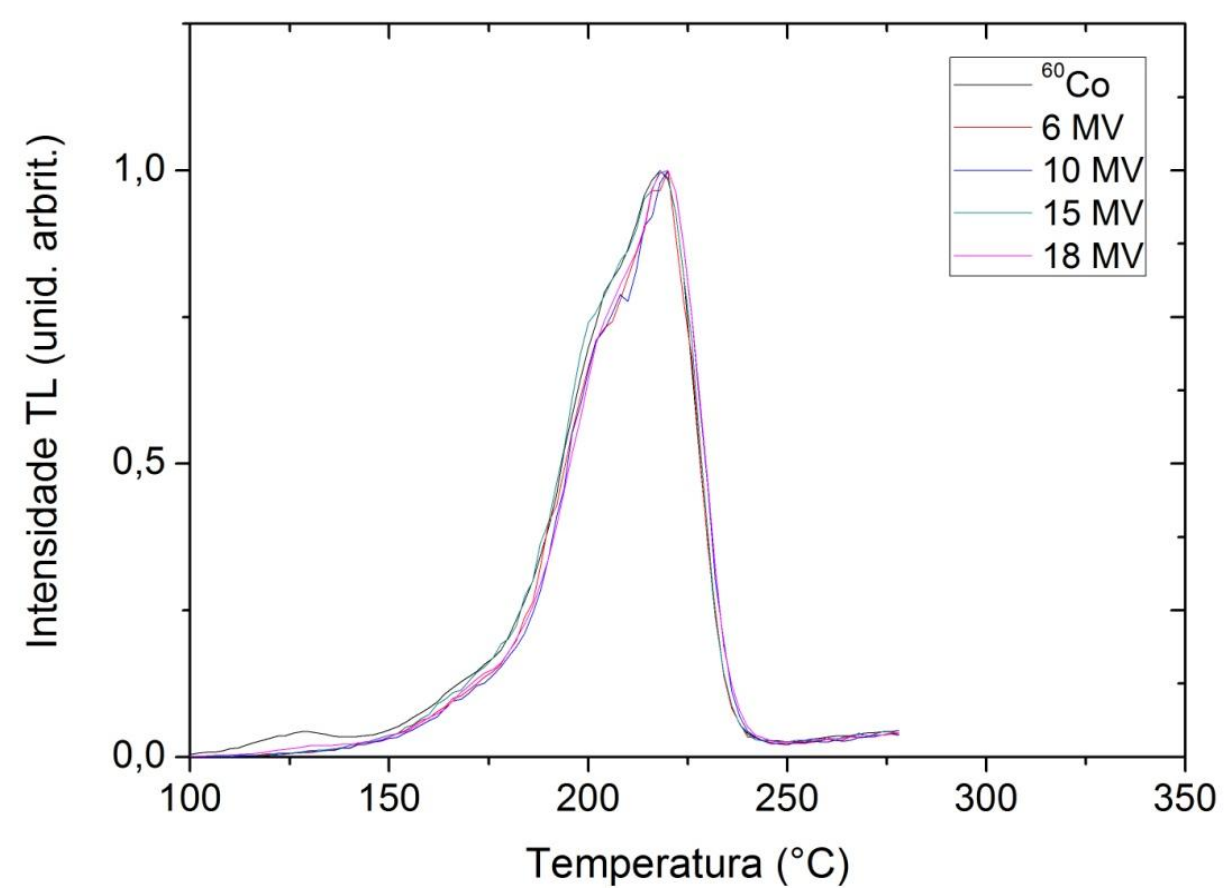

Figura 4-1: Curvas de emissão TL das pastilhas de LiF:Mg,Ti. Todas as curvas foram normalizadas em relação ao seu ponto de máximo e a legenda indica o material da fonte radioativa ou o potencial de aceleração nominal dos feixes de fótons com o qual os dosímetros foram irradiados.

\subsubsection{Resposta TL em função da energia do feixe}

A análise dos dados foi feita conforme descrito na seção 3.7.1. A resposta TL utilizada foi a altura do pico das curvas de emissão e a Figura 4-2 mostra o gráfico dessa resposta em função da dose absorvida em água para os diferentes feixes de fótons estudados. 


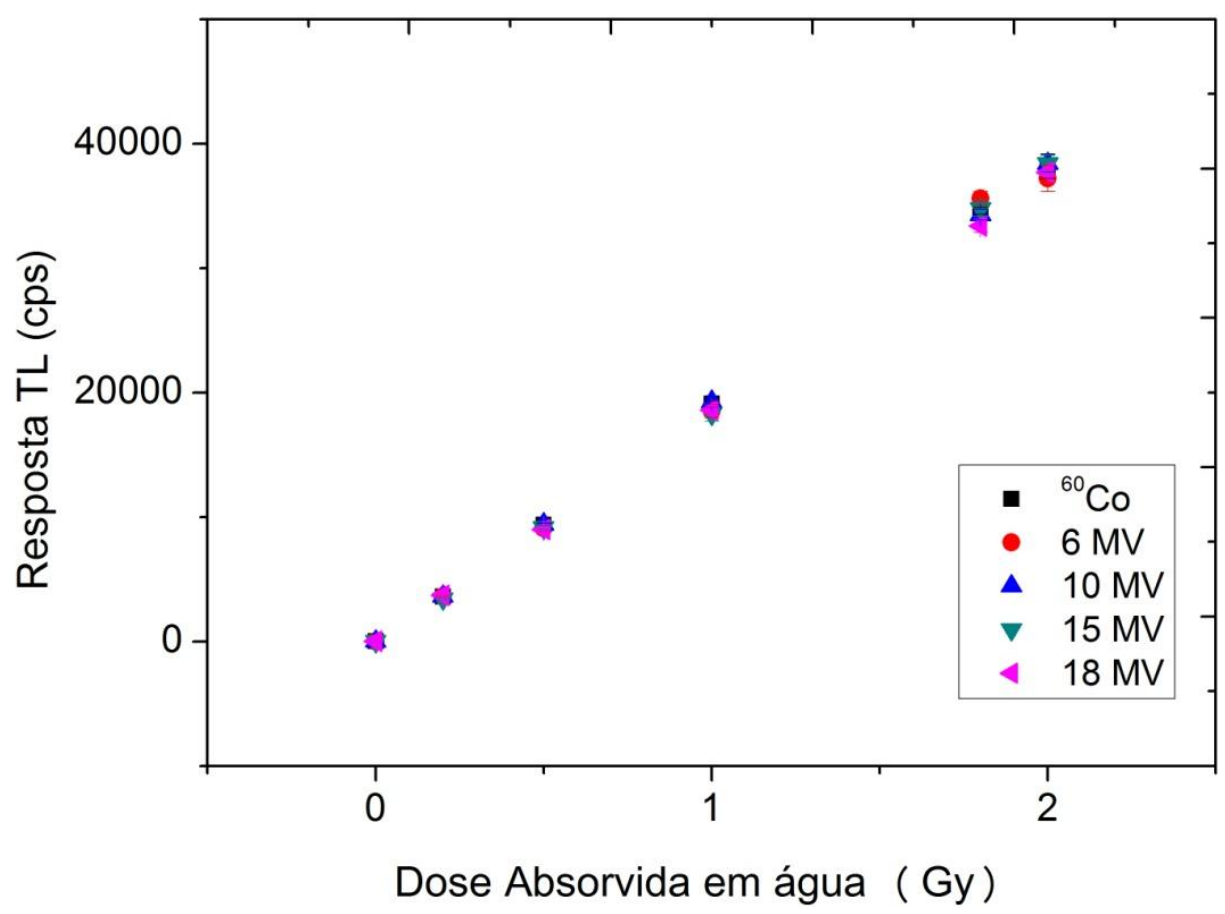

Figura 4-2: Resposta TL dos dosímetros de LiF:Mg,Ti em função da dose absorvida em água para os diversos feixes de radiação utilizados. As leituras foram feitas utilizando os filtros Schott KG 1, Corning 4-70 e Oriel com transmissão de 10\%.

O ajuste linear para uma das curvas de calibração pode ser visto na Figura 4-3, e os coeficientes angulares obtidos estão listados na Tabela 4-2. Os coeficientes lineares dos ajustes tiveram valores da ordem da resposta para radiação de fundo. 


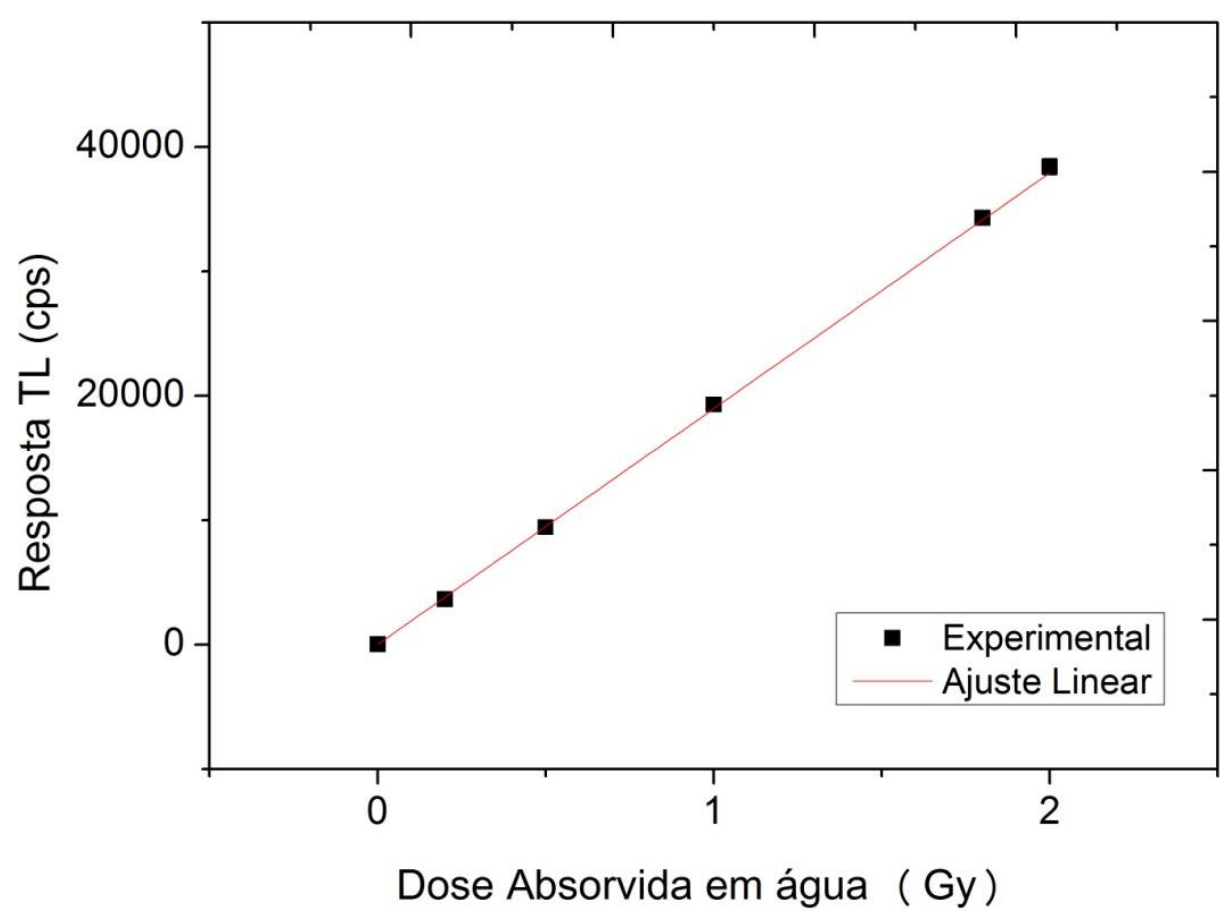

Figura 4-3: Curva de calibração do LiF:Mg,Ti para o feixe de potencial de aceleração nominal de 10 MV. As incertezas apresentadas são menores que os pontos.

Tabela 4-2: Dependência energética do LiF:Mg,Ti

\begin{tabular}{ccccc}
\hline Feixe & TPR $_{20,10}$ & $\begin{array}{c}\text { Coef. Angular } \\
\left(10^{4} \mathrm{cps} \cdot \mathrm{Gy}^{-1}\right)\end{array}$ & $\begin{array}{c}\text { Coef. } \\
\text { Ajuste } \\
\mathrm{R}^{2}\end{array}$ & $F_{C o}^{X}$ \\
\hline${ }^{60} \mathrm{Co}$ & 0,566 & $1,90 \pm 0,01$ & 1,000 & $1,00 \pm 0,01$ \\
$6 \mathrm{MV}$ & 0,673 & $1,89 \pm 0,02$ & 0,998 & $1,00 \pm 0,01$ \\
$10 \mathrm{MV}$ & 0,737 & $1,90 \pm 0,01$ & 1,000 & $1,00 \pm 0,01$ \\
$15 \mathrm{MV}$ & 0,763 & $1,87 \pm 0,02$ & 0,998 & $0,98 \pm 0,01$ \\
$18 \mathrm{MV}$ & 0,778 & $1,864 \pm 0,009$ & 1,000 & $0,98 \pm 0,01$ \\
\hline
\end{tabular}

Para facilitar a análise, o fator de dependência energética $\boldsymbol{F}_{\boldsymbol{C o}}^{X}$ (razão entre o coeficiente angular da reta de calibração de um feixe qualquer $X$ e 0 coeficiente angular da reta de calibração do feixe de ${ }^{60} \mathrm{Co}$ ) foi calculado e também está apresentado na Tabela 4-2.

Além disso, também o gráfico da sensibilidade relativa em função da dose absorvida na água foi traçado para todos os materiais estudados e o do fluoreto de lítio pode ser visto na Figura 4-4. 


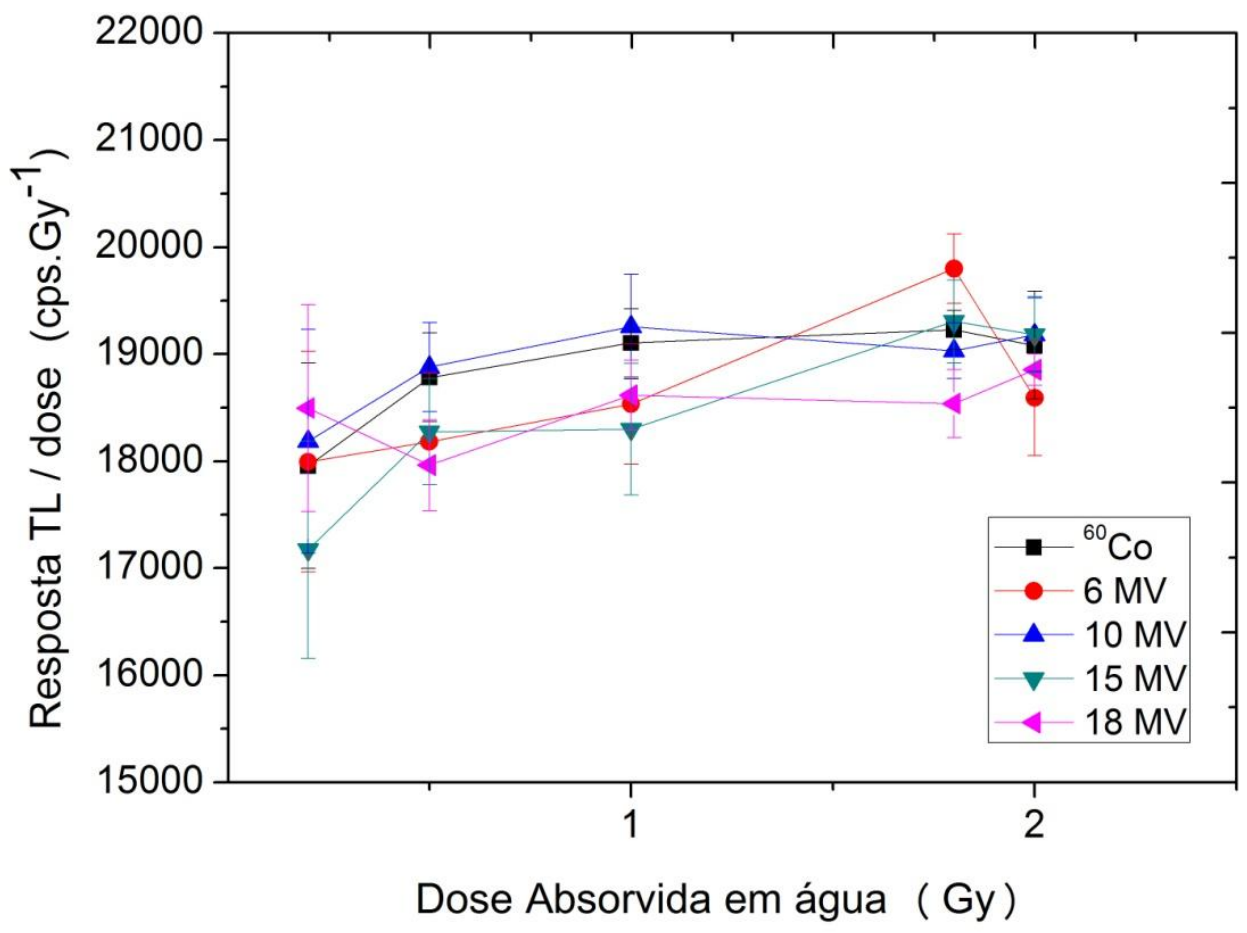

Figura 4-4: Sensibilidade relativa dos dosímetros de fluoreto de lítio em função da dose absorvida na água.

\subsection{Resposta TL da fluorita natural brasileira em função da energia do feixe}

\subsubsection{Curvas de emissão}

A Figura 4-5 apresenta as curvas de emissão obtidas nas medidas dos dosímetros de fluorita natural, normalizadas em relação ao ponto de máximo (altura do pico 3 da curva de emissão). A curva mostrada começa em $150 \stackrel{\circ}{ } \mathrm{C}$, omitindo assim a parte onde se encontraria o pico 1 já que esse pico não é utilizado para dosimetria. 


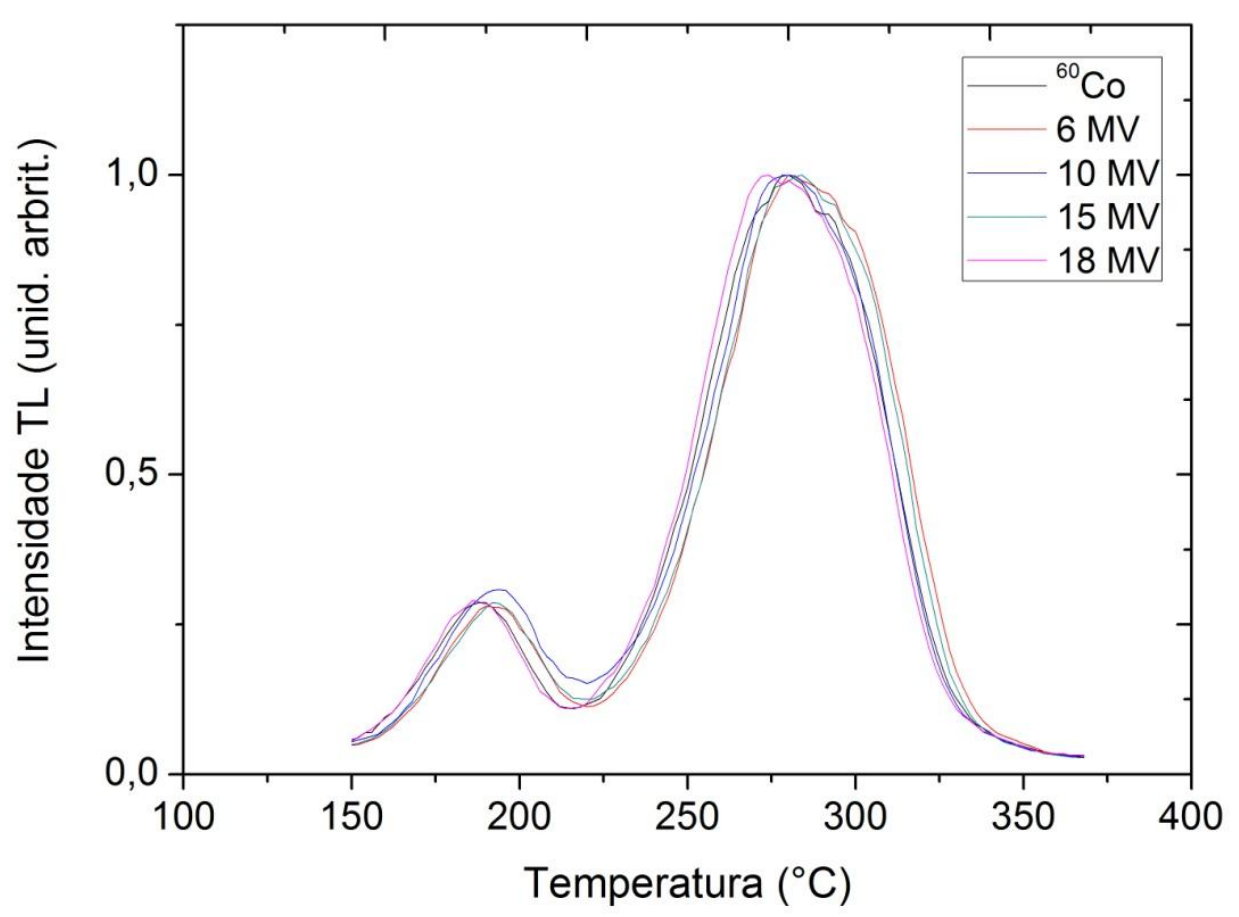

Figura 4-5: Curvas de emissão TL das pastilhas de fluorita natural. Todas as curvas foram normalizadas em relação ao seu ponto de máximo.

\subsubsection{Resposta TL em função da energia do feixe}

No caso dos dosímetros de fluorita, a resposta TL utilizada foi a altura do pico 3 das curvas de emissão. A Figura 4-6 mostra o gráfico dessa resposta em função da dose absorvida em água para os diferentes feixes de fótons estudados. O ajuste linear da curva de calibração para um dos feixes pode ser visto na Figura 4-7 e os coeficientes angulares obtidos estão listados na Tabela 4-3. Os coeficientes lineares dos ajustes tiveram valores da ordem da resposta para radiação de fundo. 


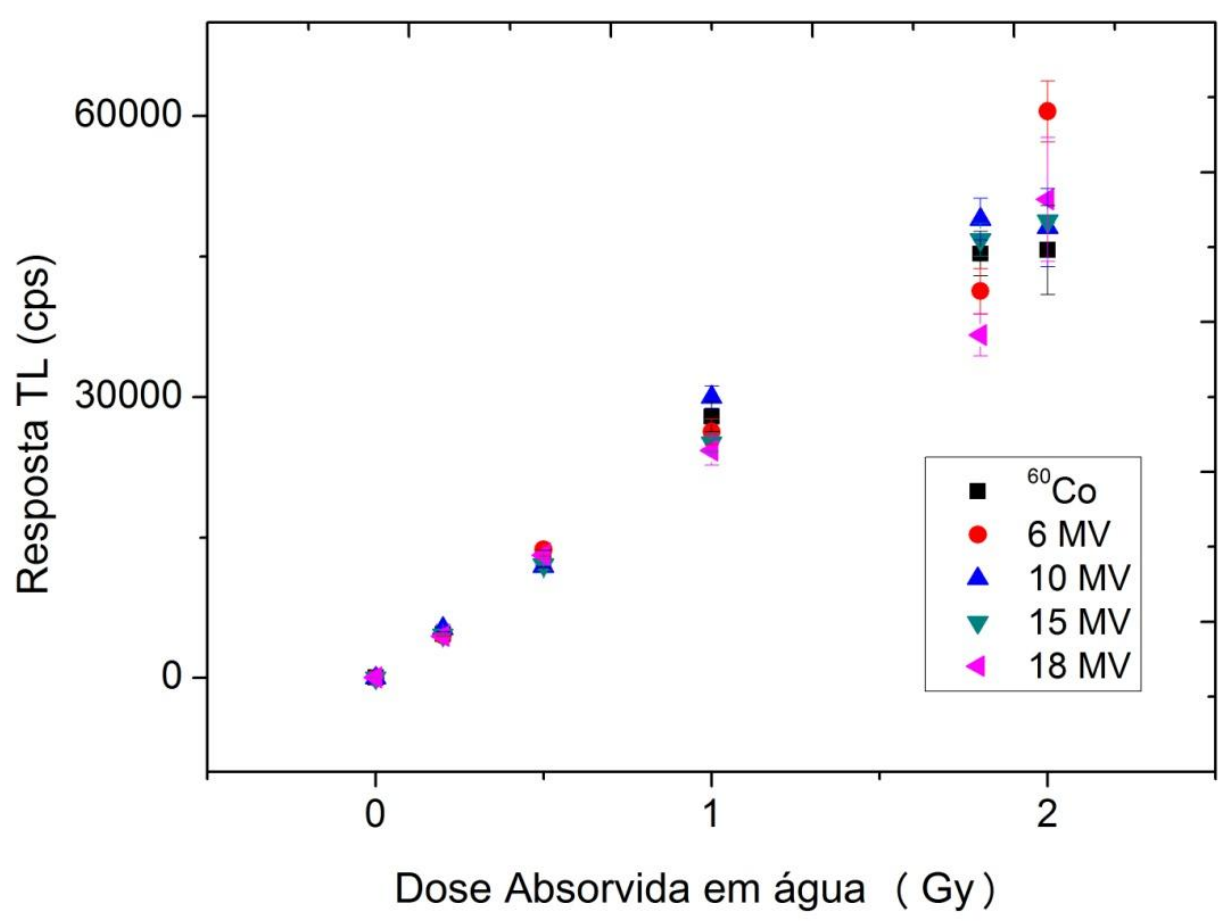

Figura 4-6: Resposta TL dos dosímetros de fluorita natural em função da dose absorvida em água para os diversos feixes de radiação utilizados. As leituras foram feitas usando os filtros Schott KG 1, Corning 5-58 e Oriel com transmissão de 10\%.

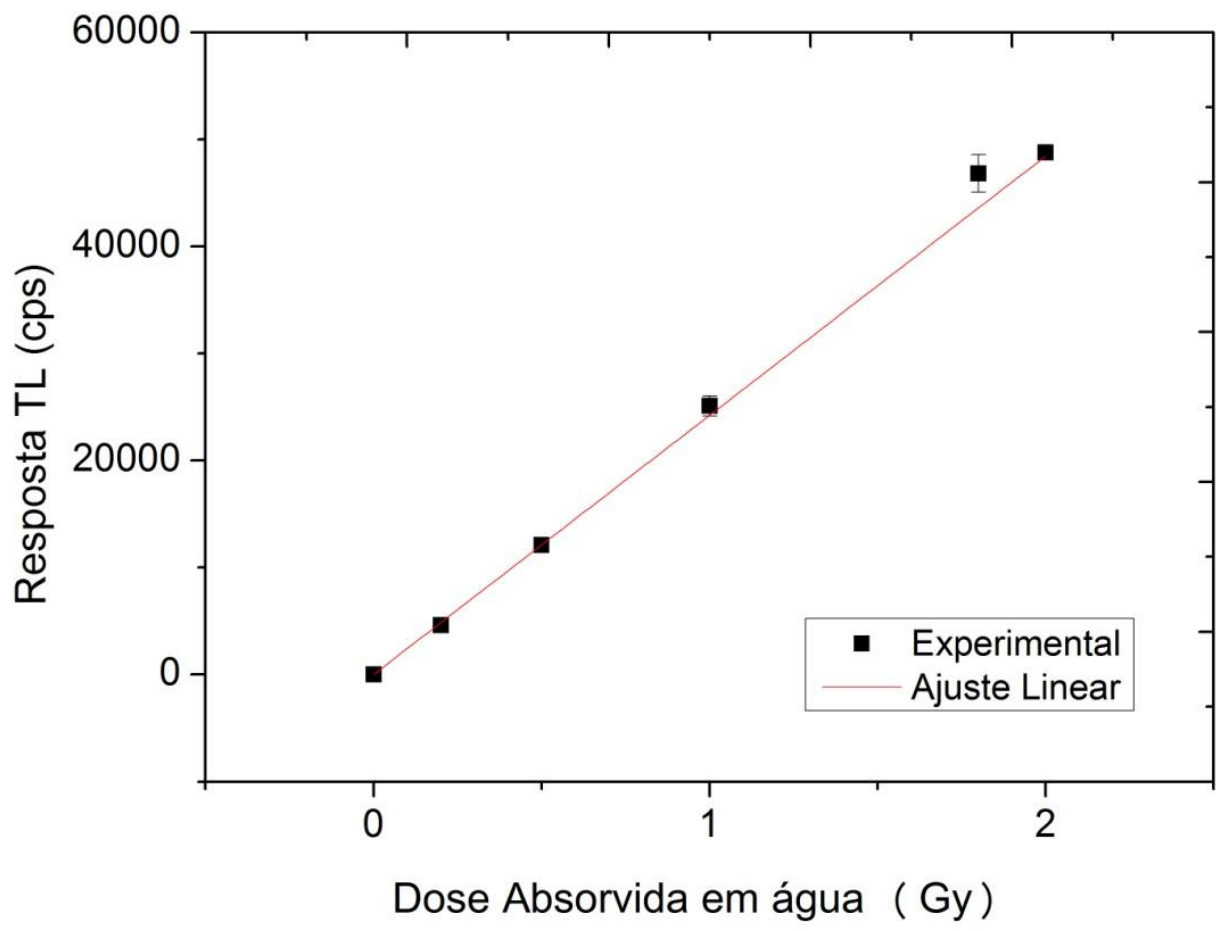

Figura 4-7: Curva de calibração da fluorita natural para o feixe de potencial de aceleração nominal de $15 \mathrm{MV}$. 
Tabela 4-3: Dependência energética da fluorita natural

\begin{tabular}{ccccc}
\hline Feixe & TPR $_{20,10}$ & $\begin{array}{c}\text { Coef. Angular } \\
\left(10^{4} \mathrm{cps} \cdot G y^{-1}\right)\end{array}$ & $\begin{array}{c}\text { Coef. } \\
\text { Ajuste } \\
\mathrm{R}^{2}\end{array}$ & $F_{\text {Co }}^{X}$ \\
\hline${ }^{60} \mathrm{Co}$ & 0,566 & $2,45 \pm 0,06$ & 0,995 & $1,00 \pm 0,03$ \\
$6 \mathrm{MV}$ & 0,673 & $2,45 \pm 0,05$ & 0,987 & $1,00 \pm 0,03$ \\
$10 \mathrm{MV}$ & 0,737 & $2,378 \pm 0,005$ & 1,000 & $0,97 \pm 0,02$ \\
$15 \mathrm{MV}$ & 0,763 & $2,42 \pm 0,01$ & 0,999 & $0,99 \pm 0,02$ \\
$18 \mathrm{MV}$ & 0,778 & $2,37 \pm 0,05$ & 0,988 & $0,97 \pm 0,03$ \\
\hline
\end{tabular}

A Figura 4-8 mostra o gráfico da sensibilidade relativa em função da dose absorvida na água para as pastilhas de fluorita.

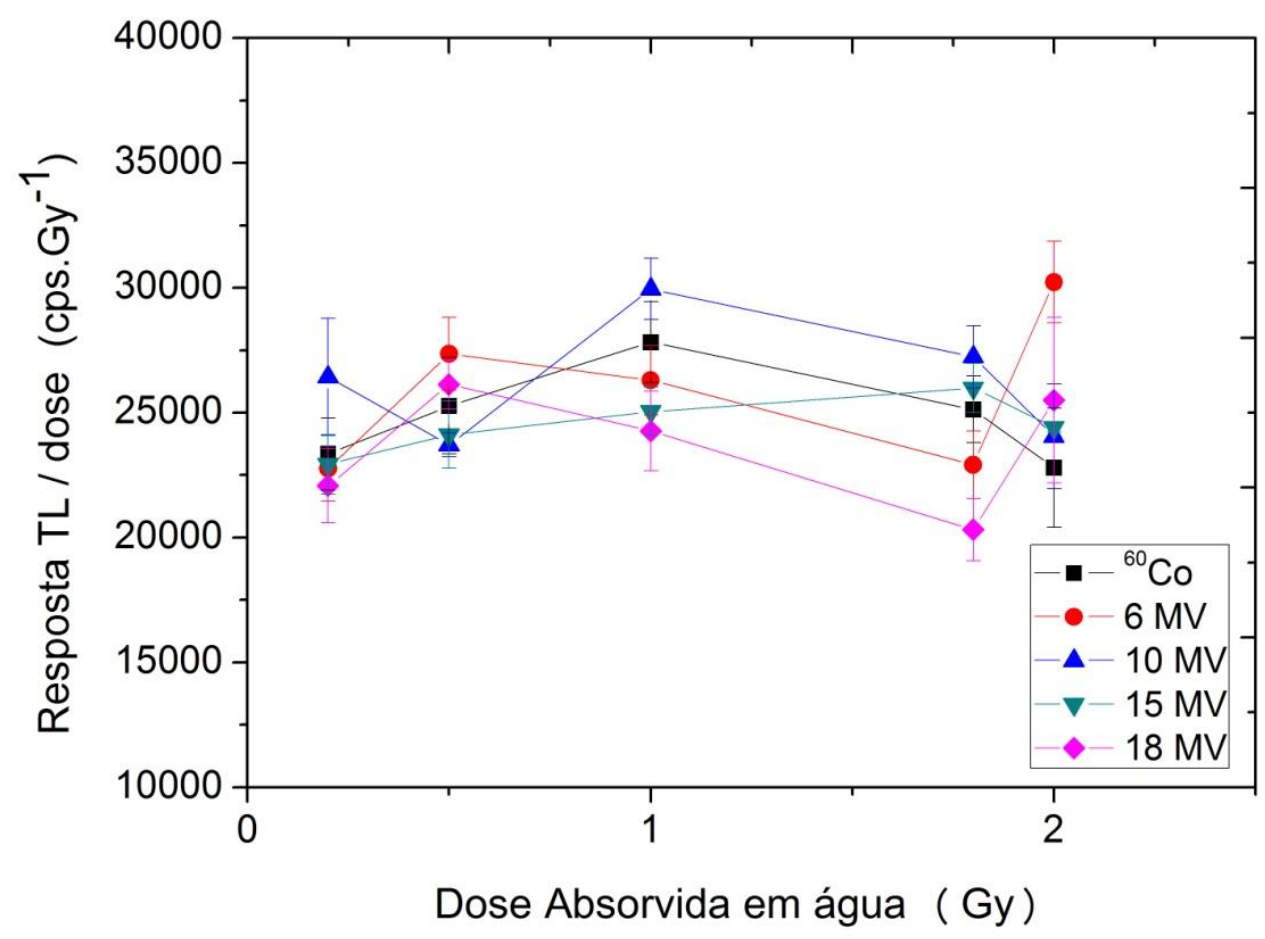

Figura 4-8: Sensibilidade relativa dos dosímetros de fluorita em função da dose absorvida na água.

\subsection{Resposta TL do sulfato de cálcio em função da energia do feixe}

\subsubsection{Curvas de emissão}

A Figura 4-9 apresenta as curvas de emissão obtidas nas medidas dos dosímetros de sulfato de cálcio. Também nesse caso, as curvas foram todas 
normalizadas em relação ao ponto de máximo (altura do pico dosimétrico). Note-se que a temperatura máxima das medidas é $350^{\circ} \mathrm{C}$, pois a matriz desses dosímetros é de material que não suporta temperaturas muito elevadas.

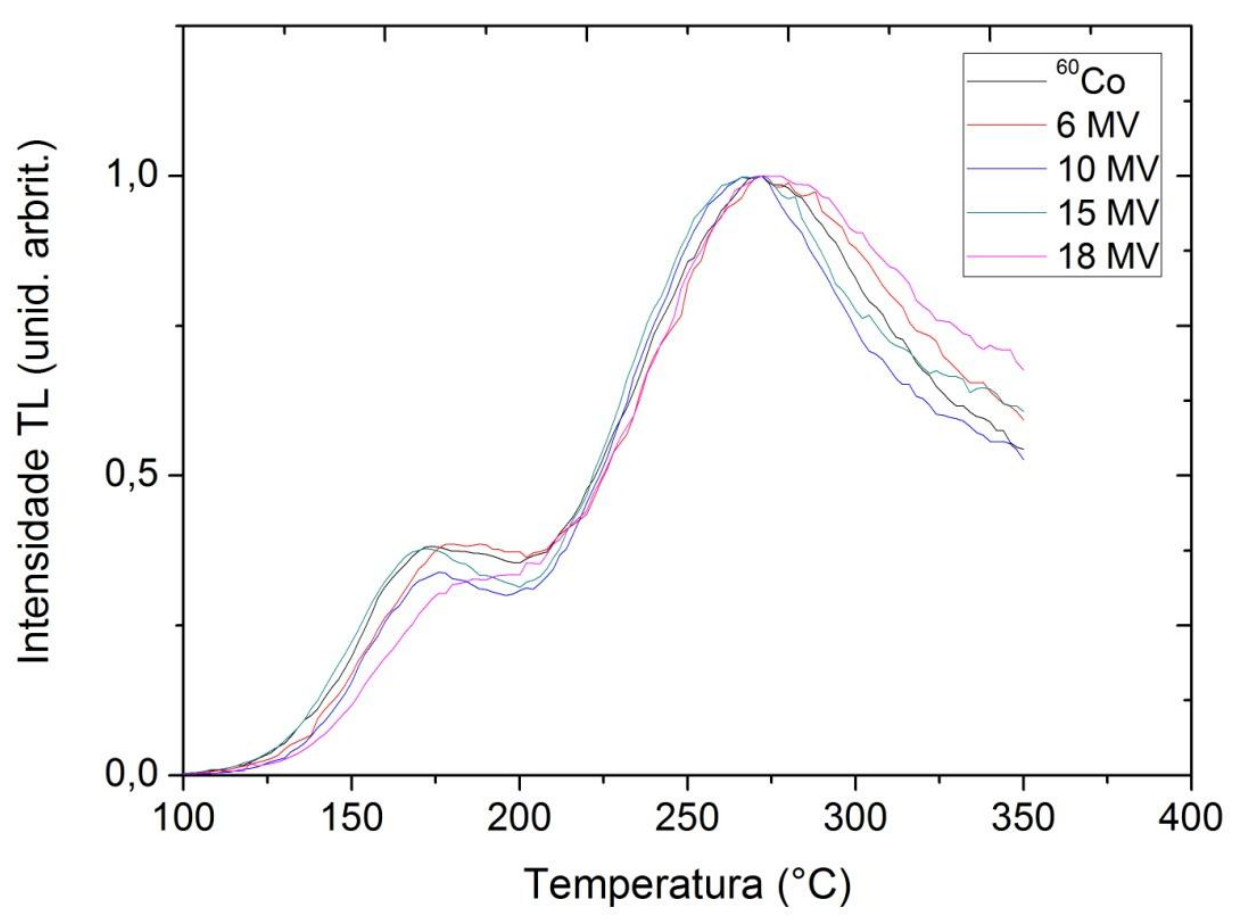

Figura 4-9: Curvas de emissão TL das pastilhas de sulfato de cálcio. Todas as curvas foram normalizadas em relação ao seu ponto de máximo.

\subsubsection{Resposta TL em função da energia do feixe}

Para os dosímetros de sulfato de cálcio, a resposta TL utilizada foi a altura do pico 2 das curvas de emissão. Na Figura 4-10 está o gráfico dessa resposta em função da dose absorvida em água para os diferentes feixes de fótons. O ajuste linear de uma das curvas de calibração pode ser visto na Figura 4-11. Os coeficientes lineares dos ajustes tiveram valores da ordem da resposta para radiação de fundo. Os coeficientes angulares e fatores de dependência energética obtidos estão listados na Tabela 4-4. 


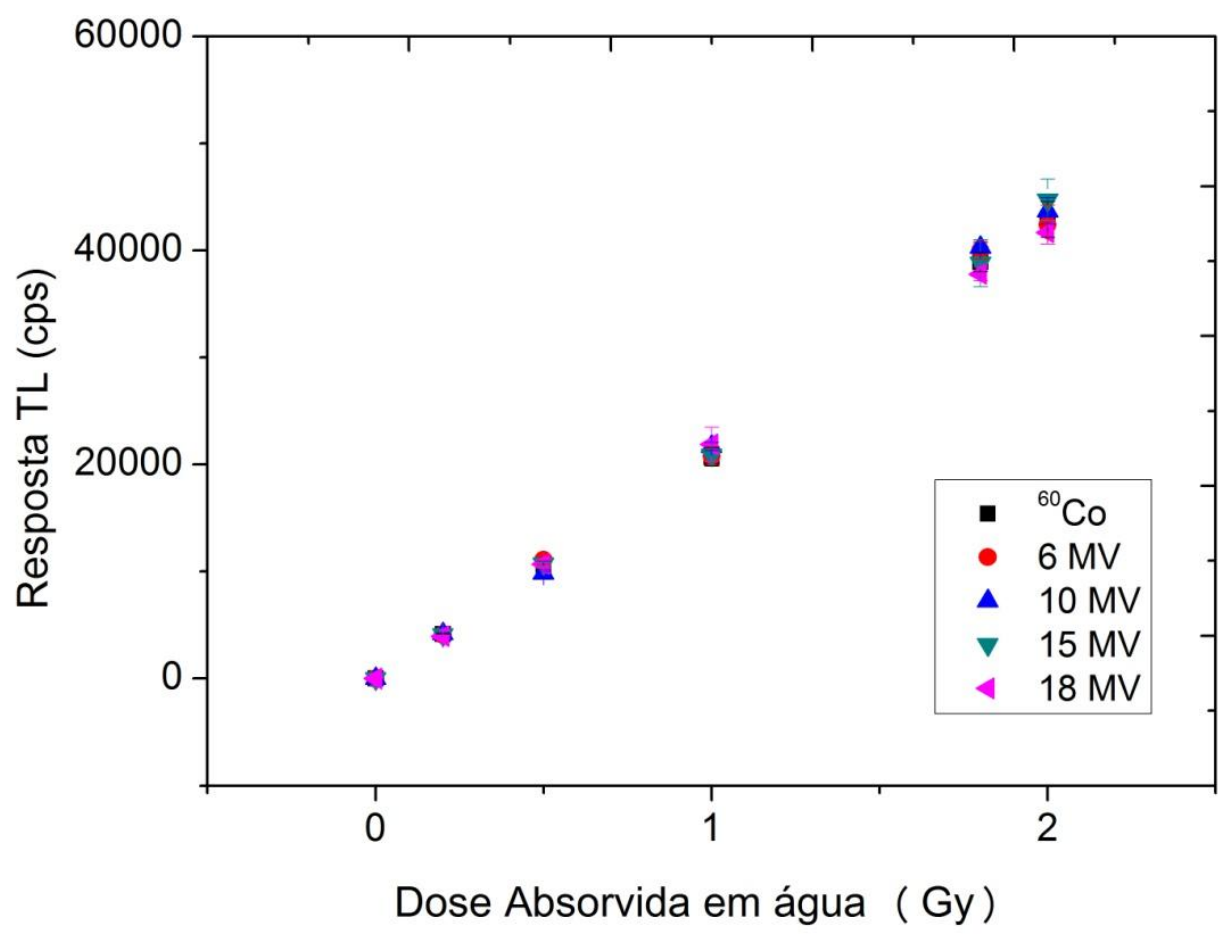

Figura 4-10: Resposta TL dos dosímetros de sulfato de cálcio em função da dose absorvida em água para os diversos feixes de radiação utilizados. As leituras foram feitas usando os filtros Schott KG 1 e Oriel com transmissão de $1 \%$

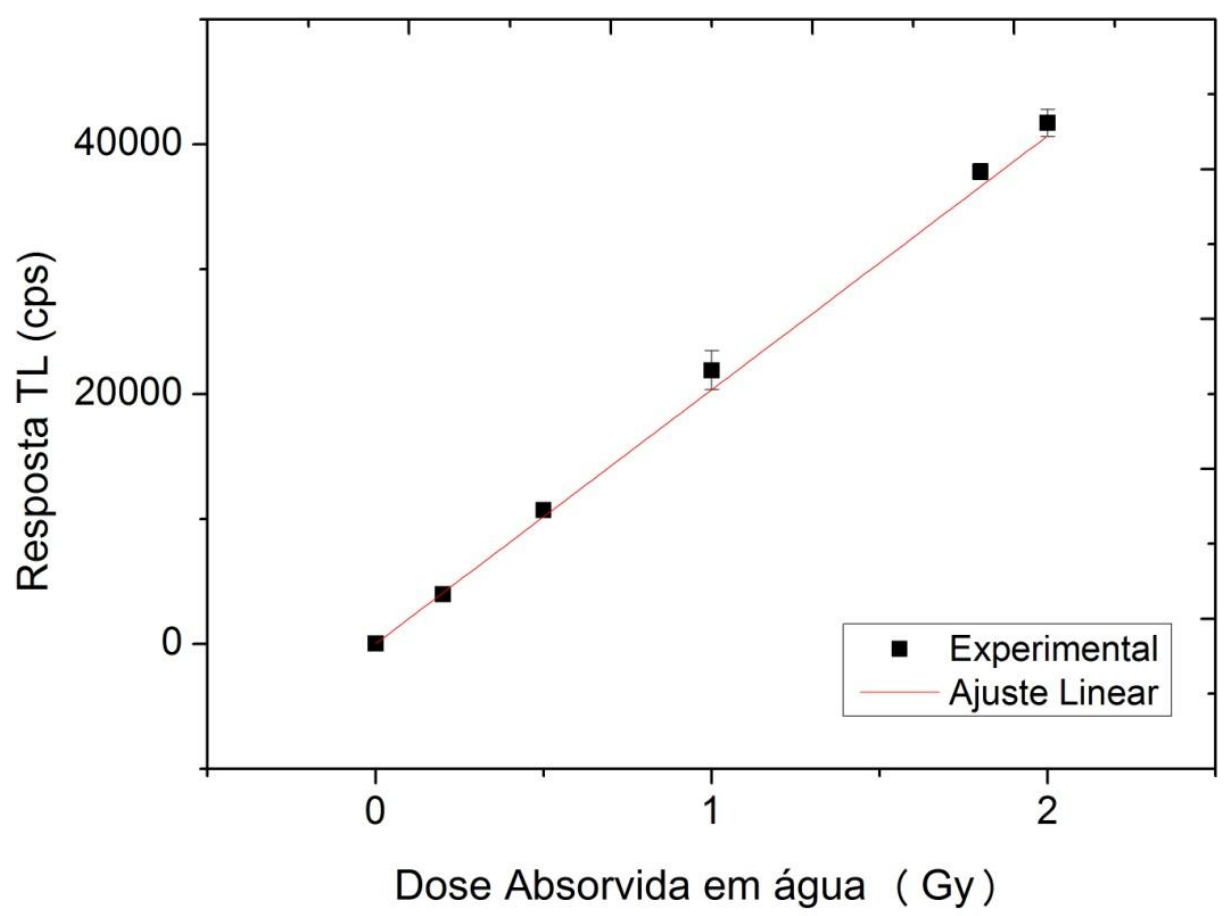

Figura 4-11: Curva de calibração do sulfato de cálcio para o feixe de potencial de aceleração nominal de $18 \mathrm{MV}$. 
Tabela 4-4: Dependência energética de sulfato de cálcio

\begin{tabular}{ccccc}
\hline Feixe & TPR $_{20,10}$ & $\begin{array}{c}\text { Coef. Angular } \\
\left(10^{4} \mathrm{cps} \cdot \mathrm{Gy}^{-1}\right)\end{array}$ & $\begin{array}{c}\text { Coef. } \\
\text { Ajuste } \\
\mathrm{R}^{2}\end{array}$ & $F_{C o}^{X}$ \\
\hline${ }^{60} \mathrm{Co}$ & 0,566 & $2,10 \pm 0,02$ & 1,000 & $1,00 \pm 0,01$ \\
$6 \mathrm{MV}$ & 0,673 & $2,08 \pm 0,02$ & 0,998 & $0,99 \pm 0,01$ \\
$10 \mathrm{MV}$ & 0,737 & $2,16 \pm 0,02$ & 0,997 & $1,03 \pm 0,01$ \\
$15 \mathrm{MV}$ & 0,763 & $2,13 \pm 0,03$ & 0,999 & $1,01 \pm 0,02$ \\
$18 \mathrm{MV}$ & 0,778 & $2,03 \pm 0,02$ & 0,999 & $0,97 \pm 0,01$ \\
\hline
\end{tabular}

A Figura 4-12 mostra o gráfico da sensibilidade relativa em função da dose absorvida na água para as irradiações com as pastilhas de sulfato de cálcio.

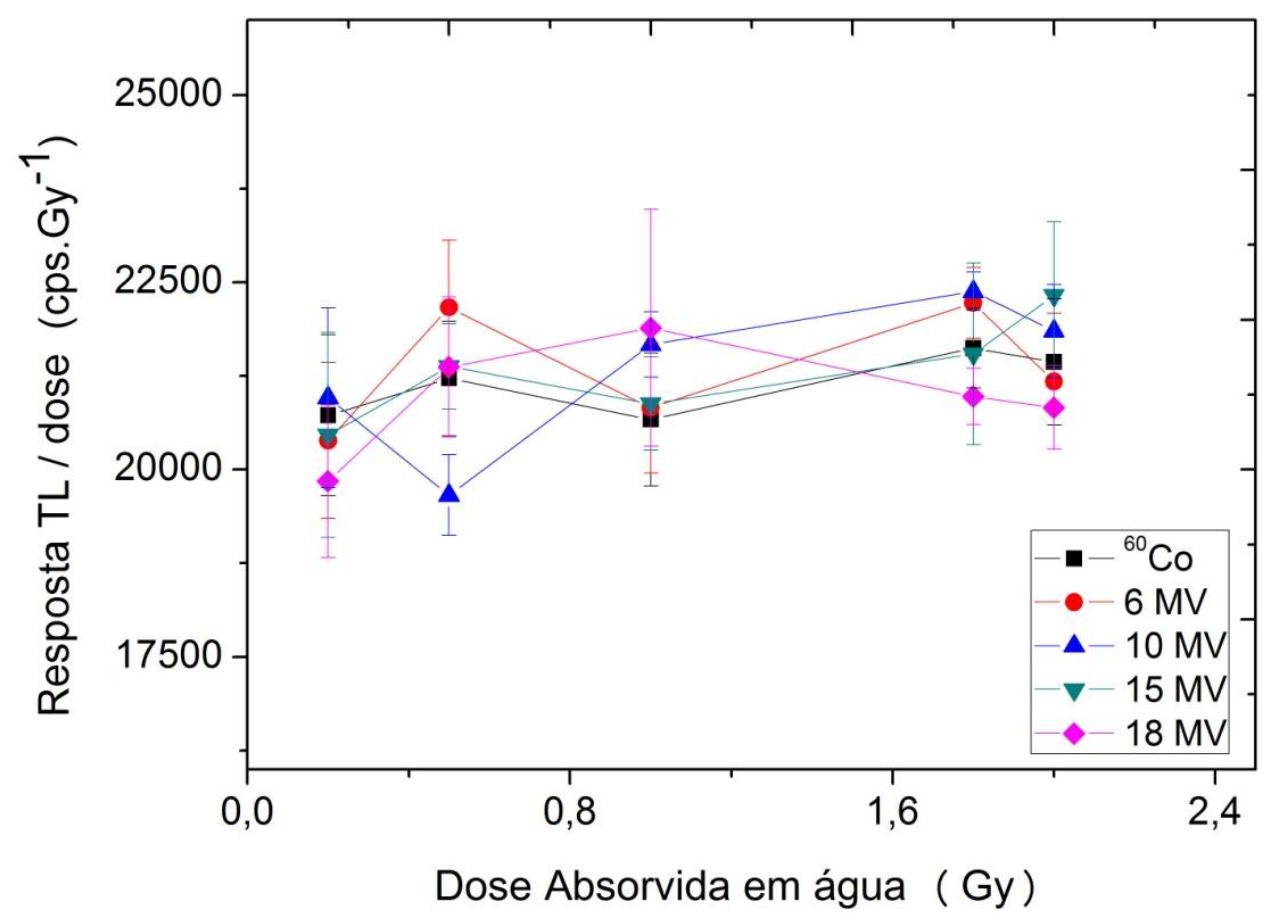

Figura 4-12: Sensibilidade relativa dos dosímetros de sulfato de cálcio em função da dose absorvida na água. 


\subsection{Resposta TL do silicato de magnésio em função da energia do feixe}

\subsubsection{Curvas de emissão}

As curvas de emissão obtidas nas medidas dos dosímetros de silicato de magnésio estão apresentadas na Figura 4-13. Assim como para os outros materiais, elas estão normalizadas em relação ao ponto de máximo (altura do pico dosimétrico).

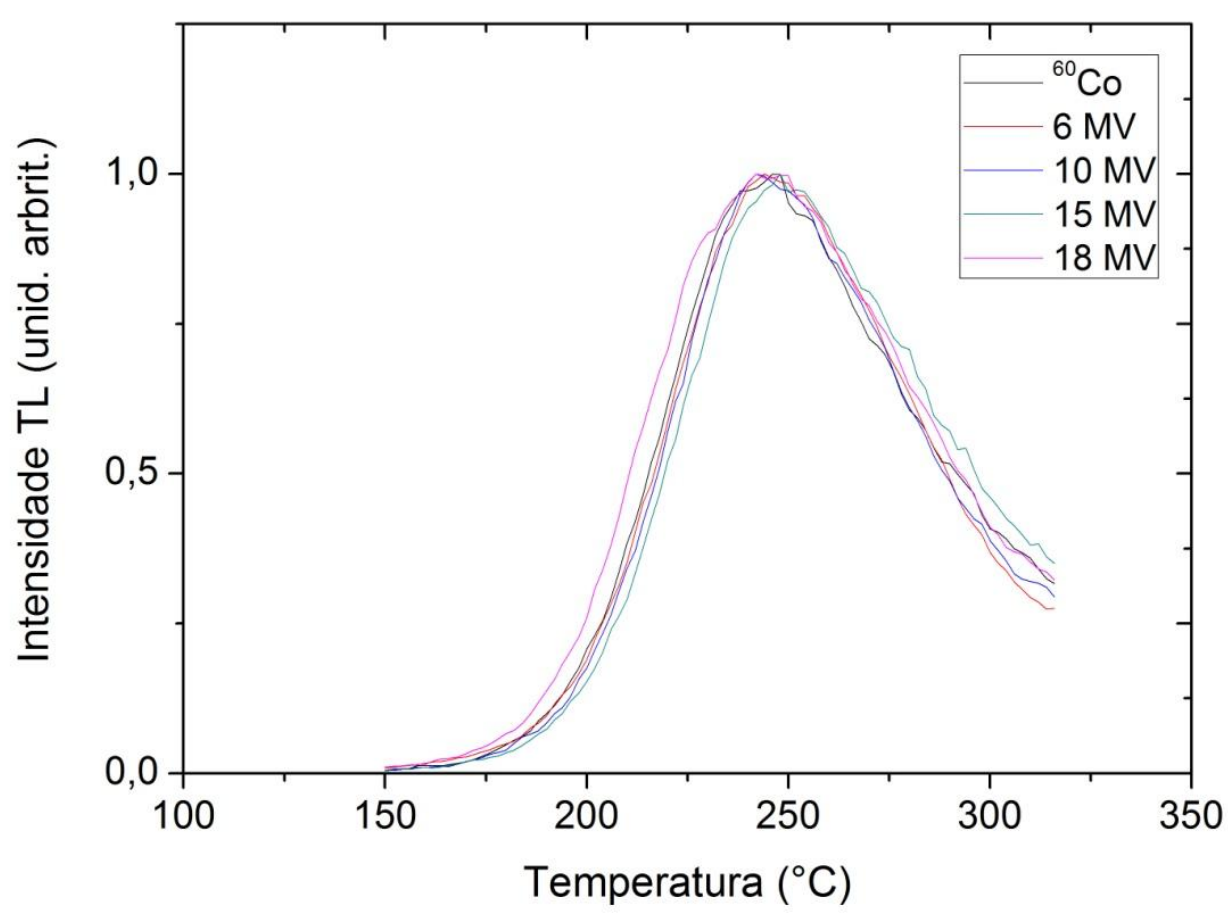

Figura 4-13: Curvas de emissão TL dos dosímetros de silicato de magnésio. Todas as curvas foram normalizadas em relação ao seu ponto de máximo.

\subsubsection{Resposta TL em função da energia do feixe}

Para os dosímetros de silicato de magnésio, a resposta TL utilizada também foi a altura do pico das curvas de emissão. Na Figura 4-14 está demonstrado o gráfico dessa resposta em função da dose absorvida em água para os diferentes feixes de fótons. O ajuste linear de uma das curvas de calibração pode ser visto na Figura 4-15. Os coeficientes lineares dos ajustes tiveram valores da ordem da resposta para radiação de fundo. Os coeficientes 
angulares e fatores de dependência energética obtidos estão listados na Tabela 4-5.

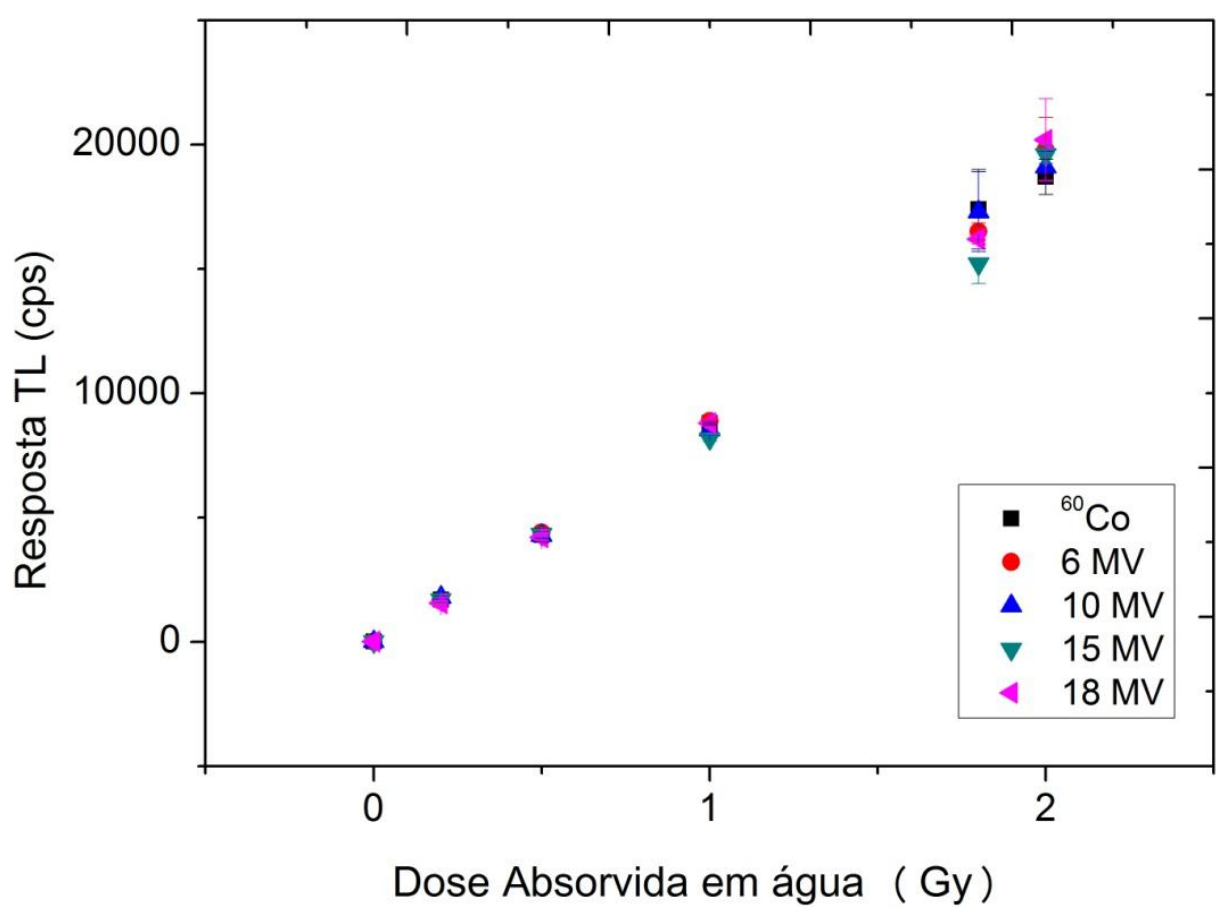

Figura 4-14: Resposta TL dos dosímetros de silicato de magnésio em função da dose absorvida em água para os diversos feixes de radiação utilizados. As leituras foram feitas usando o filtro Schott KG 1 e dois filtros Oriel com transmissão de $10 \%$ e $1 \%$.

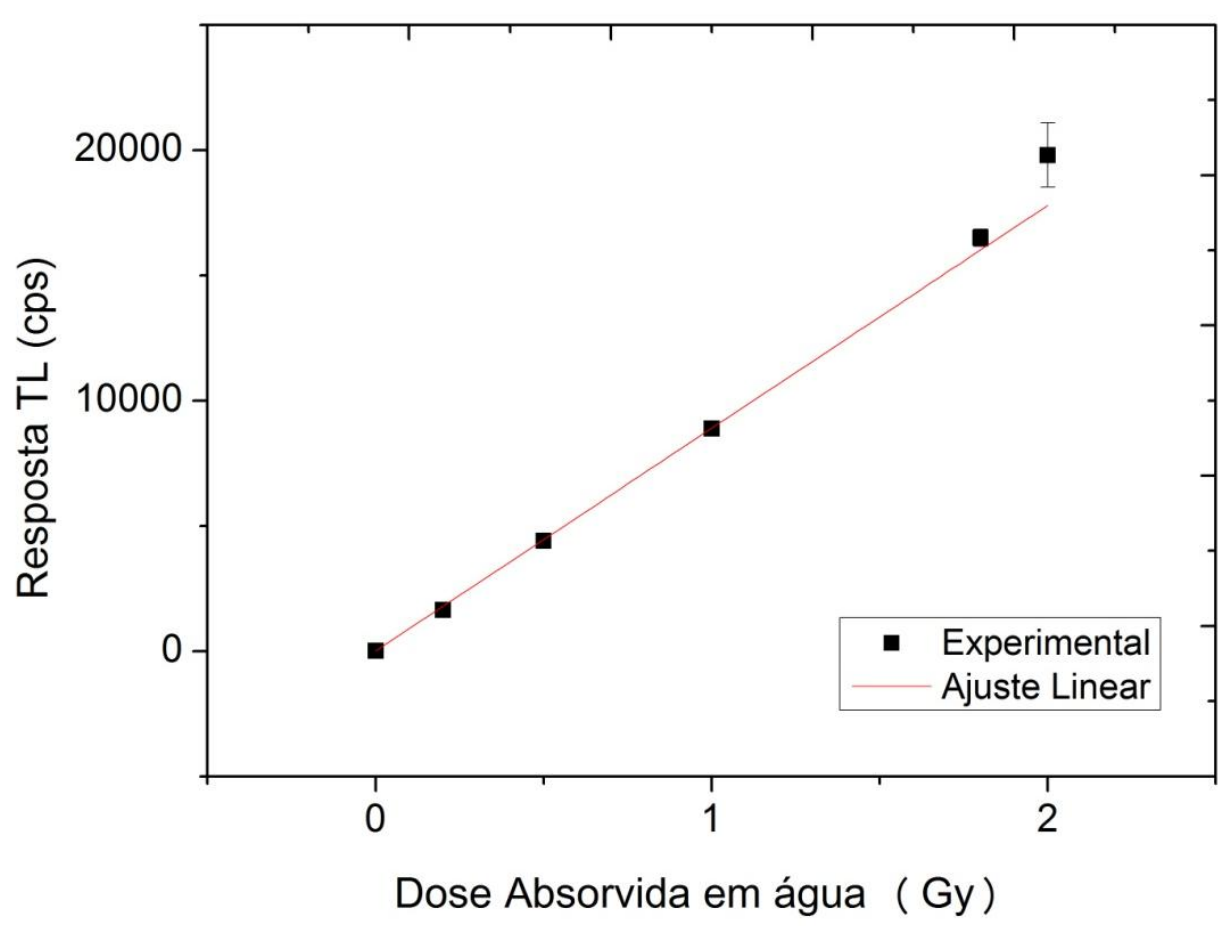

Figura 4-15: Curva de calibração do silicato de magnésio para o feixe de potencial de aceleração nominal de $6 \mathrm{MV}$. 
Tabela 4-5: Dependência energética do silicato de magnésio

\begin{tabular}{ccccc}
\hline Feixe & TPR $_{20,10}$ & $\begin{array}{c}\text { Coef. Angular } \\
\left(10^{3} \mathrm{cps} \cdot G \mathrm{G}^{-1}\right)\end{array}$ & $\begin{array}{c}\text { Coef. } \\
\text { Ajuste } \\
\mathrm{R}^{2}\end{array}$ & $F_{\text {Co }}^{X}$ \\
\hline${ }^{60} \mathrm{Co}$ & 0,566 & $8,82 \pm 0,08$ & 1,000 & $1,00 \pm 0,01$ \\
$6 \mathrm{MV}$ & 0,673 & $8,89 \pm 0,06$ & 1,000 & $1,01 \pm 0,01$ \\
$10 \mathrm{MV}$ & 0,737 & $8,85 \pm 0,14$ & 0,997 & $1,00 \pm 0,02$ \\
$15 \mathrm{MV}$ & 0,763 & $8,60 \pm 0,09$ & 0,993 & $0,97 \pm 0,01$ \\
$18 \mathrm{MV}$ & 0,778 & $8,76 \pm 0,07$ & 0,998 & $0,99 \pm 0,01$ \\
\hline
\end{tabular}

A Figura 4-16 apresenta o gráfico da sensibilidade relativa em função da dose absorvida na água para os dosímetros de silicato de magnésio.

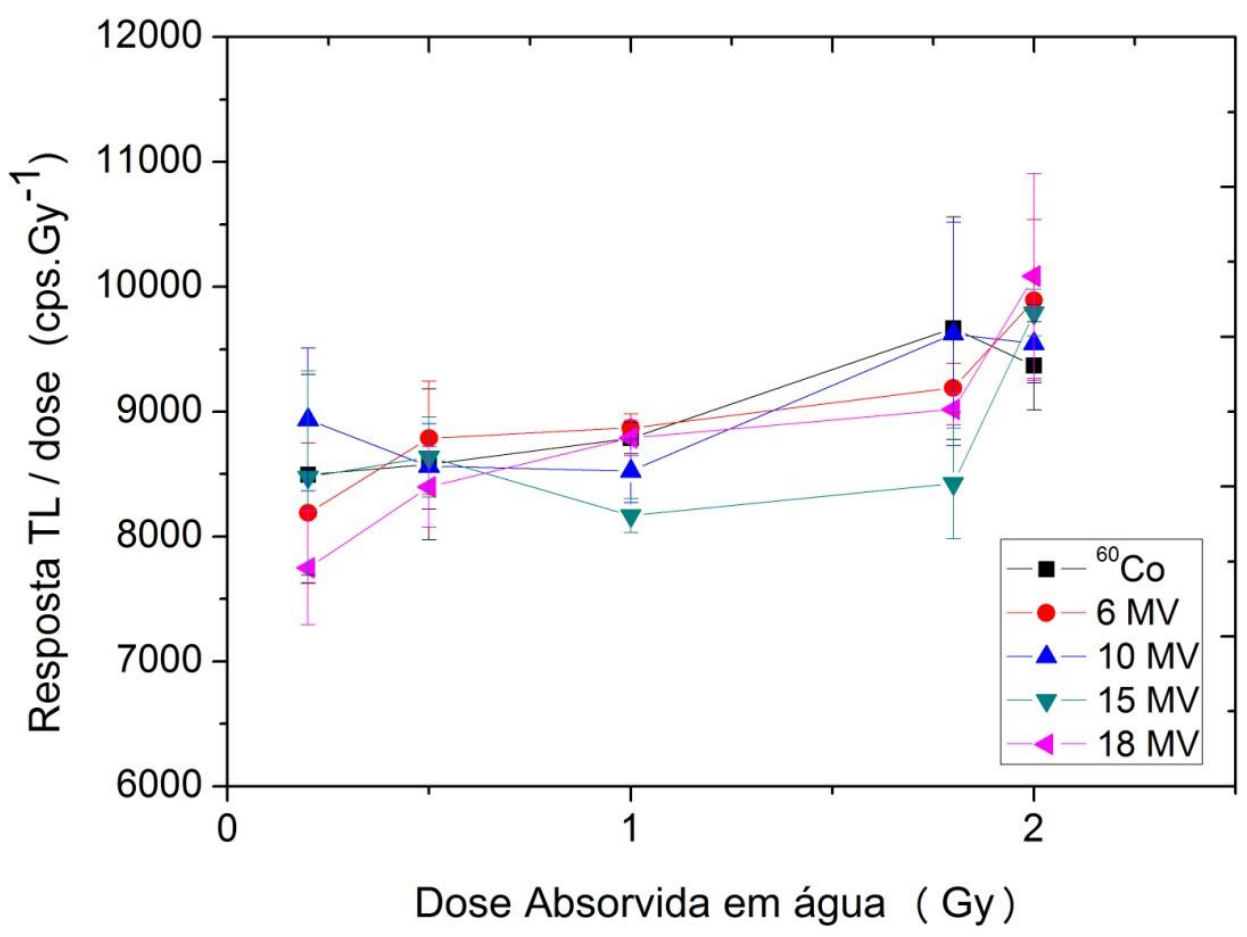

Figura 4-16: Sensibilidade relativa dos dosímetros de silicato de magnésio em função da dose absorvida na água. 


\subsection{Resposta TL do óxido de alumínio em função da energia do feixe}

\subsubsection{Curvas de emissão}

Na Figura 4-17: Curvas de emissão TL dos dosímetros de óxido de alumínio. Todas as curvas foram normalizadas em relação ao seu ponto de máximo. podem ser vistas as curvas de emissão obtidas nas medidas dos dosímetros de óxido de alumínio. Para facilitar a análise, também nesse caso, elas estão todas normalizadas em relação ao ponto de máximo (altura do pico dosimétrico).

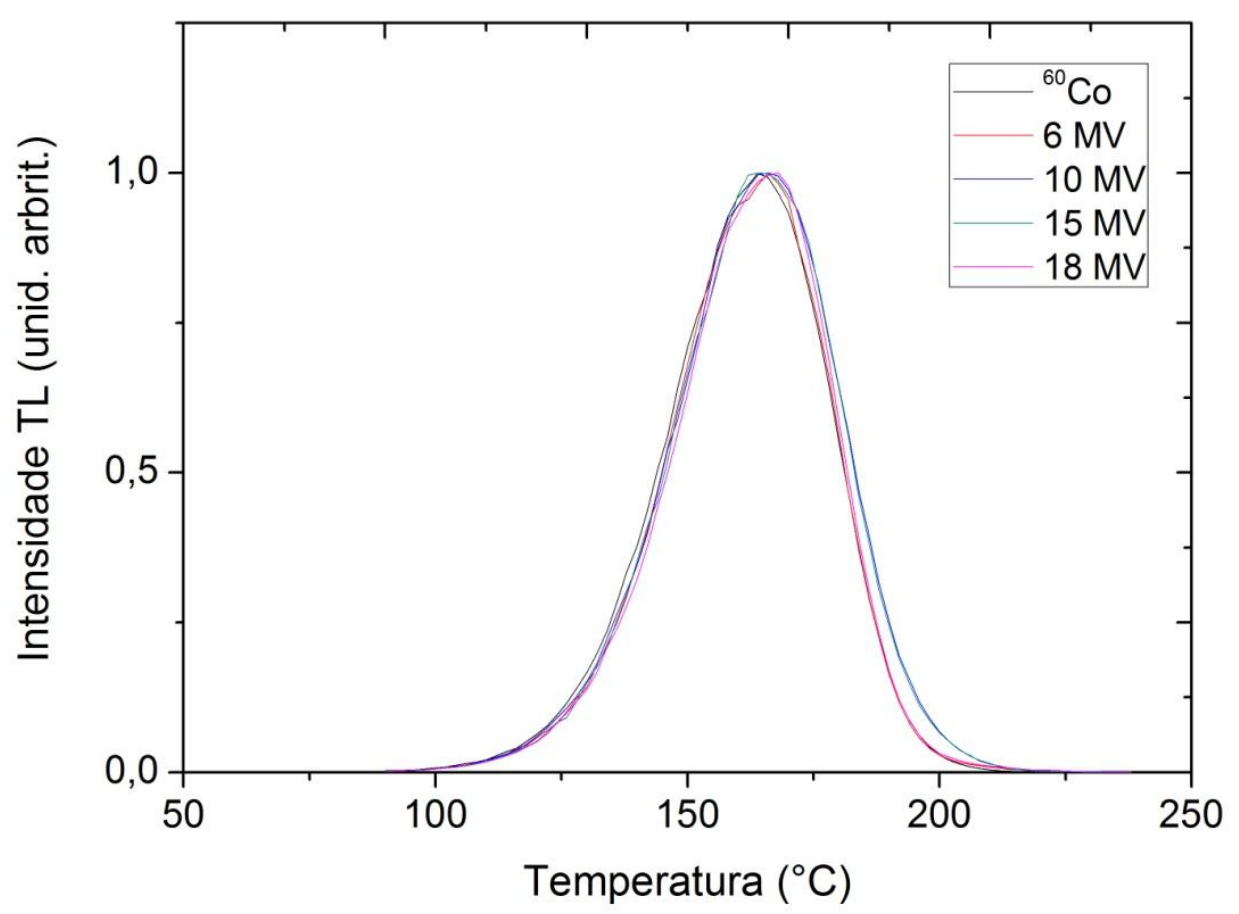

Figura 4-17: Curvas de emissão TL dos dosímetros de óxido de alumínio. Todas as curvas foram normalizadas em relação ao seu ponto de máximo.

\subsubsection{Resposta TL versus energia do feixe}

Mais uma vez a altura do pico das curvas de emissão foi utilizada como o valor da resposta TL. O resultado dessa resposta em função da dose absorvida em água pode ser visto na Figura 4-18. É sabido que o óxido de alumínio pode apresentar uma não linearidade de resposta na faixa de doses estudada [Akselrod, 1993 e Yang et al, 2008]. Esse fato fica evidenciado na 
Figura 4-19 e também na Figura 4-20, na qual foi traçado o mesmo gráfico que na Figura 4-18, porém com escalas logarítmicas. A reta mostrada na Figura 4-20 representa uma dependência linear entre dose e resposta, pois foi traçada com coeficiente angular igual a 1.

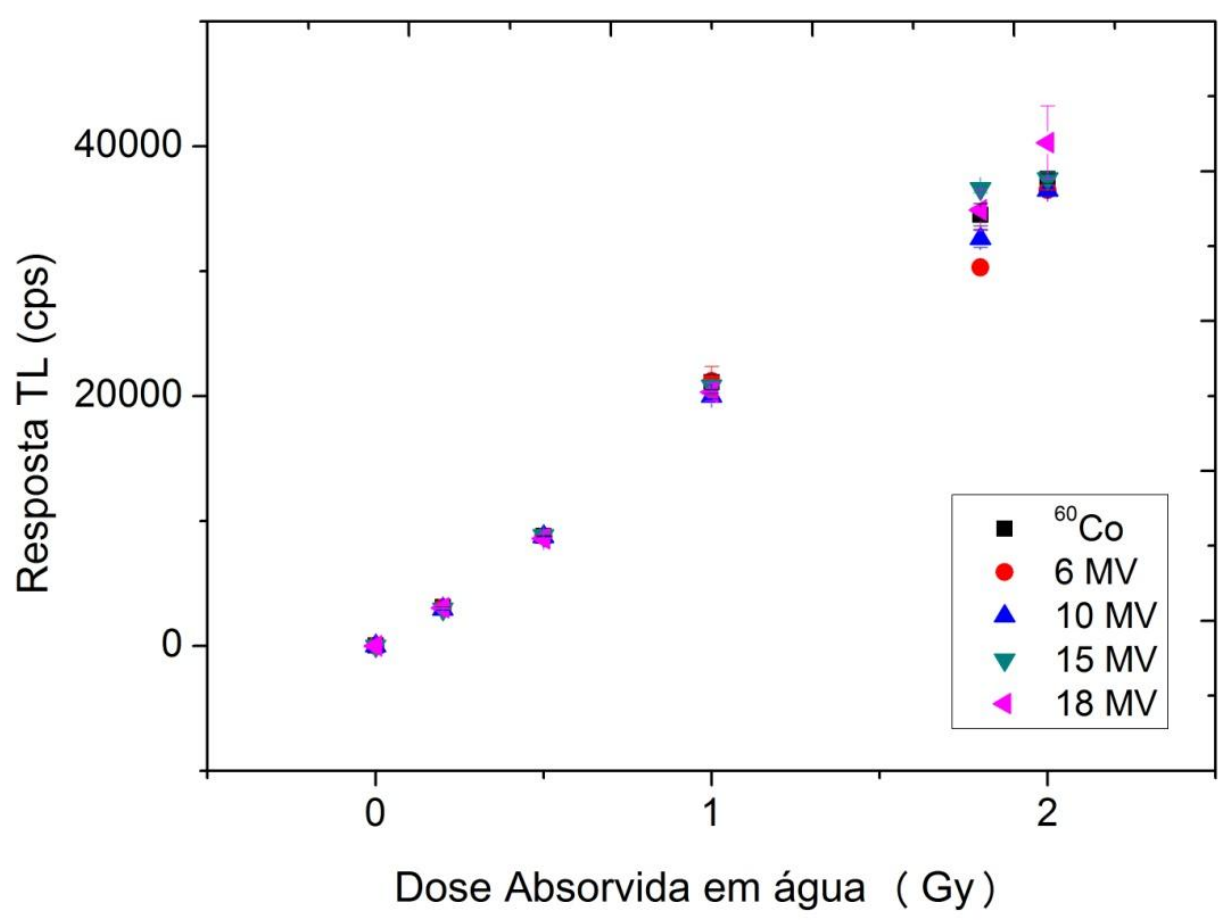

Figura 4-18: Resposta TL dos dosímetros de óxido de alumínio em função da dose absorvida em água para os diversos feixes de radiação utilizados. As leituras foram feitas utilizando os filtros Schott KG 1, Corning 4-70 e Oriel com transmissão de 1\%. 


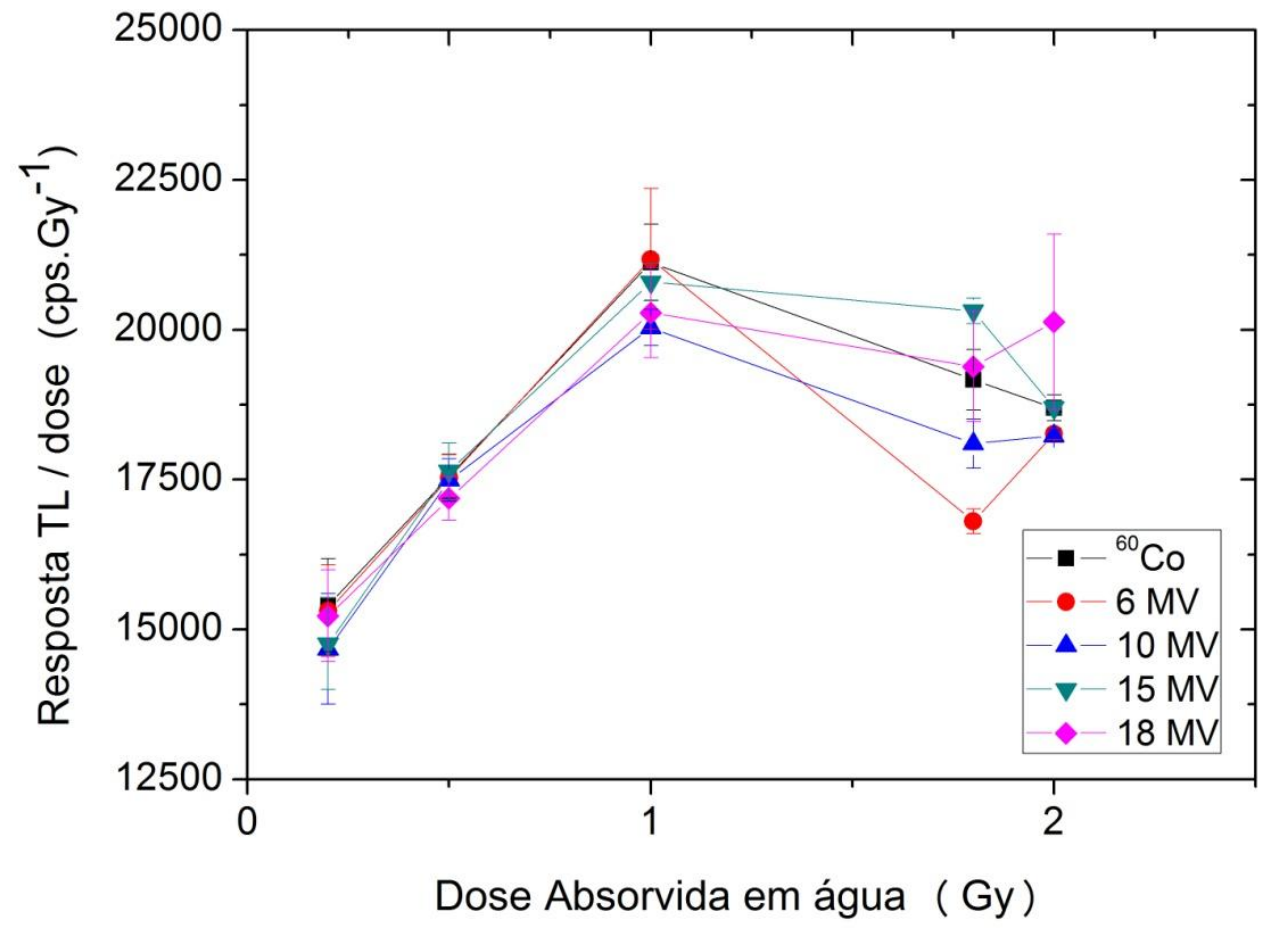

Figura 4-19: Sensibilidade relativa dos dosímetros de óxido de alumínio em função da dose absorvida na água.

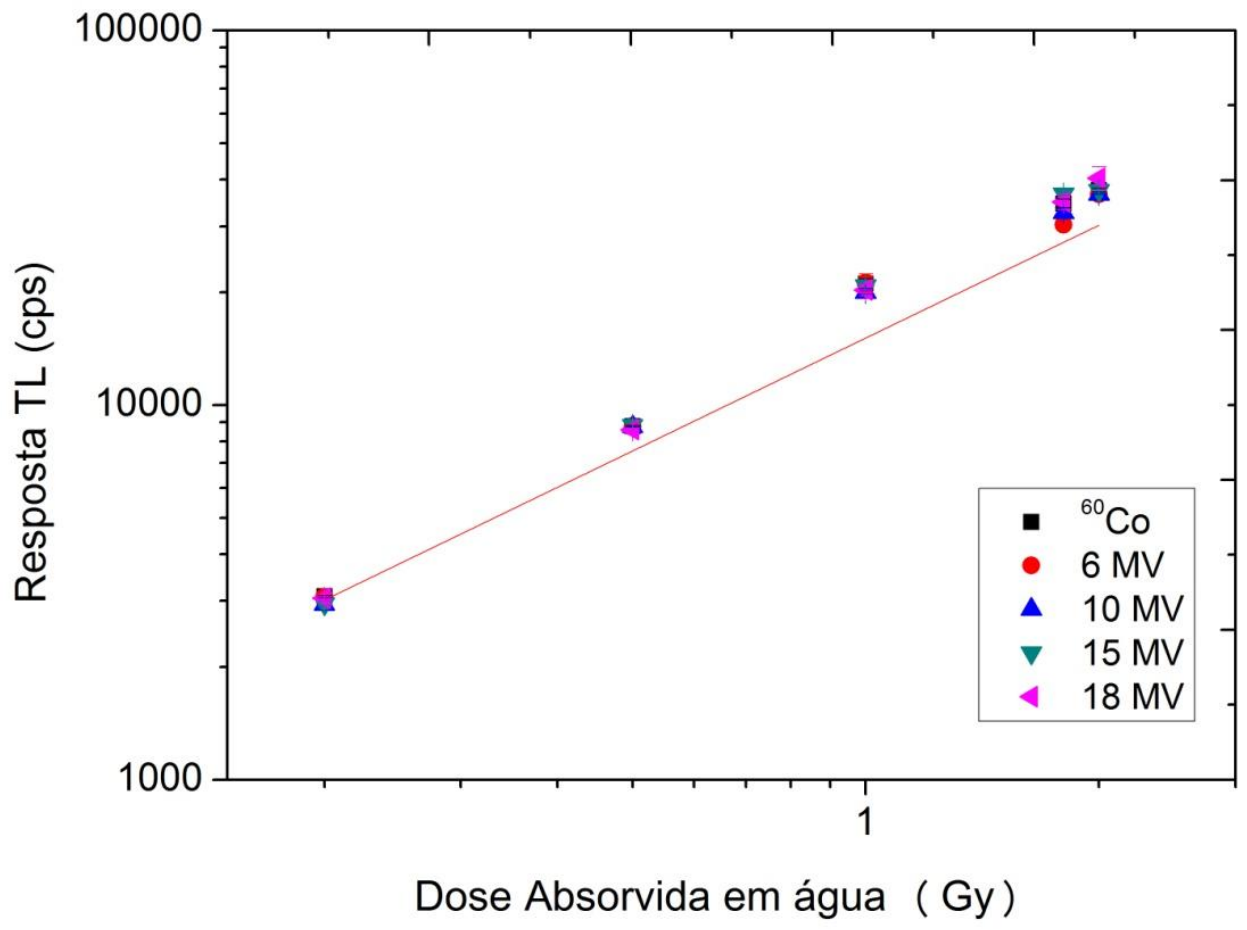

Figura 4-20: Resposta TL dos cristais de óxido de alumínio em função da dose absorvida em água. A reta representa o comportamento linear para comparação. 
Por não apresentar linearidade de resposta TL em função da dose, os fatores de dependência energética $\boldsymbol{F}_{\boldsymbol{C} \boldsymbol{o}}^{\boldsymbol{X}}$ do óxido de alumínio foram calculados pela equação 2-2 (considerando as razões médias para os pontos medidos ao invés do coeficiente angular de uma reta de calibração) e estão apresentados na Tabela 4-6.

\begin{tabular}{|c|c|c|}
\hline Feixe & $\mathrm{TPR}_{20,10}$ & $F_{C o}^{X}$ \\
\hline${ }^{60} \mathrm{Co}$ & 0,566 & $1,00 \pm 0,04$ \\
\hline $6 \mathrm{MV}$ & 0,673 & $0,97 \pm 0,04$ \\
\hline $10 \mathrm{MV}$ & 0,737 & $0,96 \pm 0,04$ \\
\hline $15 \mathrm{MV}$ & 0,763 & $1,00 \pm 0,04$ \\
\hline $18 \mathrm{MV}$ & 0,778 & $1,00 \pm 0,06$ \\
\hline
\end{tabular}




\subsection{Teste de sensibilidade a nêutrons}

\subsubsection{Curvas de emissão}

As figuras 4-21, 4-22, 4-23, 4-24 e 4-25 mostram as curvas de emissão dos dosímetros após serem irradiados pelo feixe de uma fonte de AmBe termalizado por $7 \mathrm{~cm}$ de parafina. Para efeitos de comparação, também estão mostradas curvas de emissão obtidas após irradiações com raios gama de uma fonte de ${ }^{60} \mathrm{Co}$. Todas as curvas foram normalizadas em relação ao seu ponto de máximo.

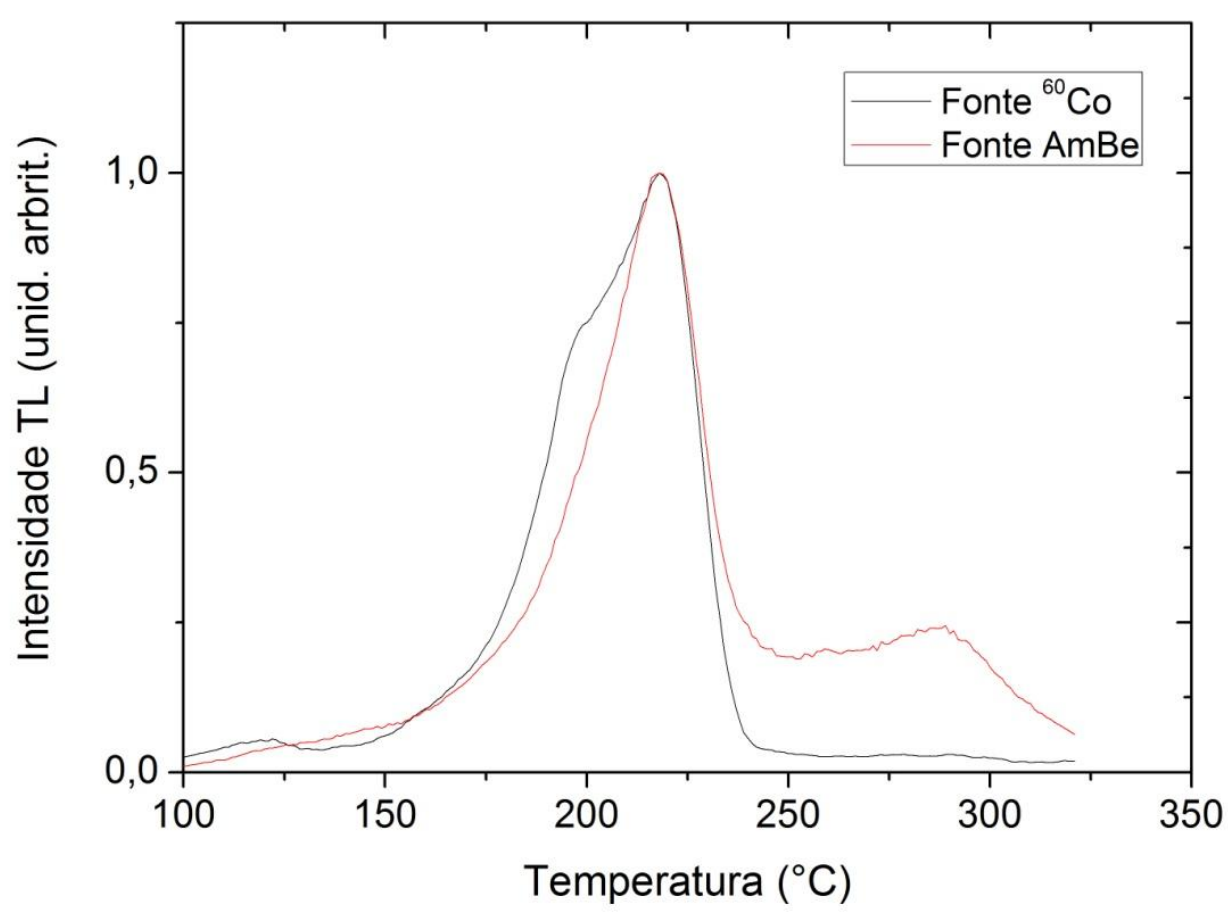

Figura 4-21: Curvas de emissão TL das pastilhas de LiF:Mg,Ti (TLD100) expostas a uma fonte de AmBe e a uma fonte de ${ }^{60} \mathrm{Co}$. 


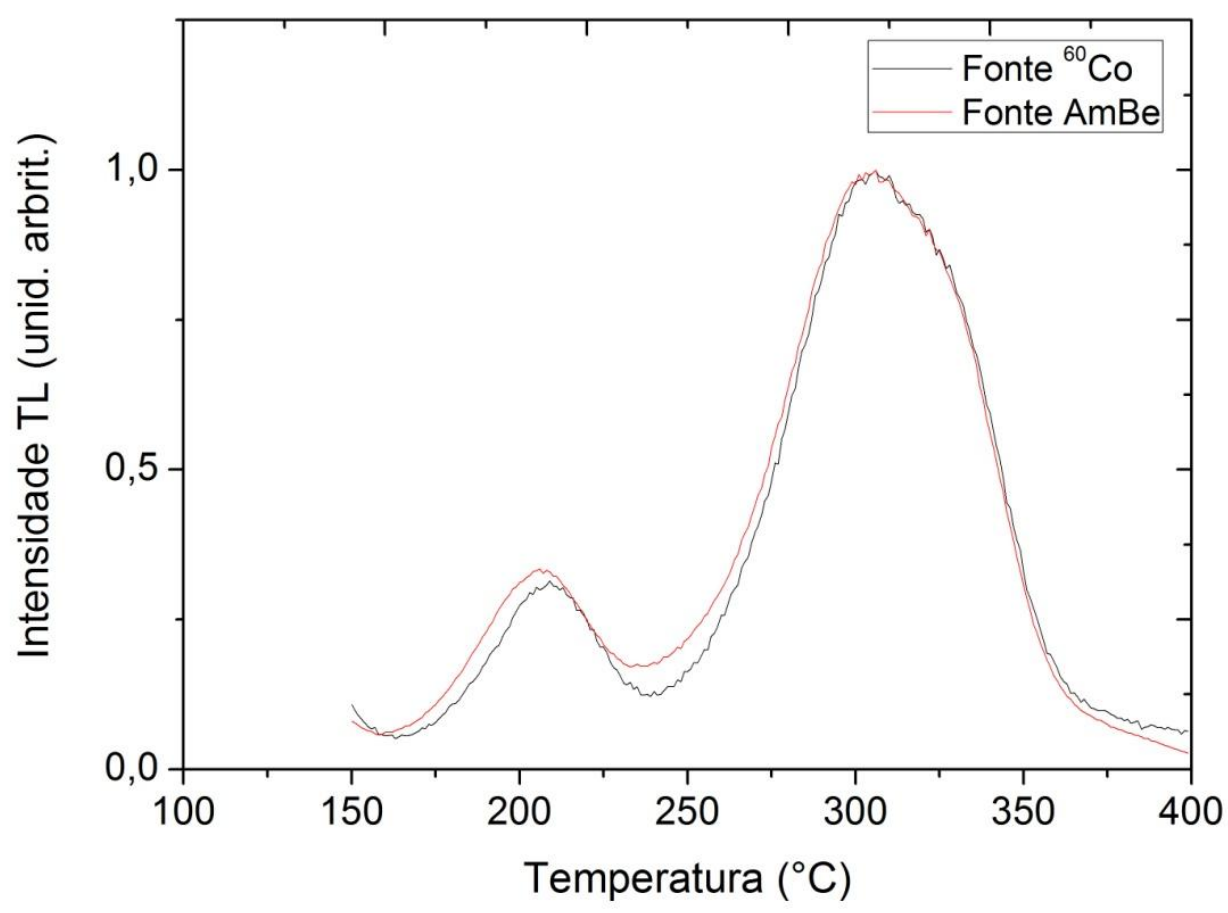

Figura 4-22: Curvas de emissão TL das pastilhas de fluorita expostas a uma fonte de AmBe e a uma fonte de ${ }^{60} \mathrm{Co}$.

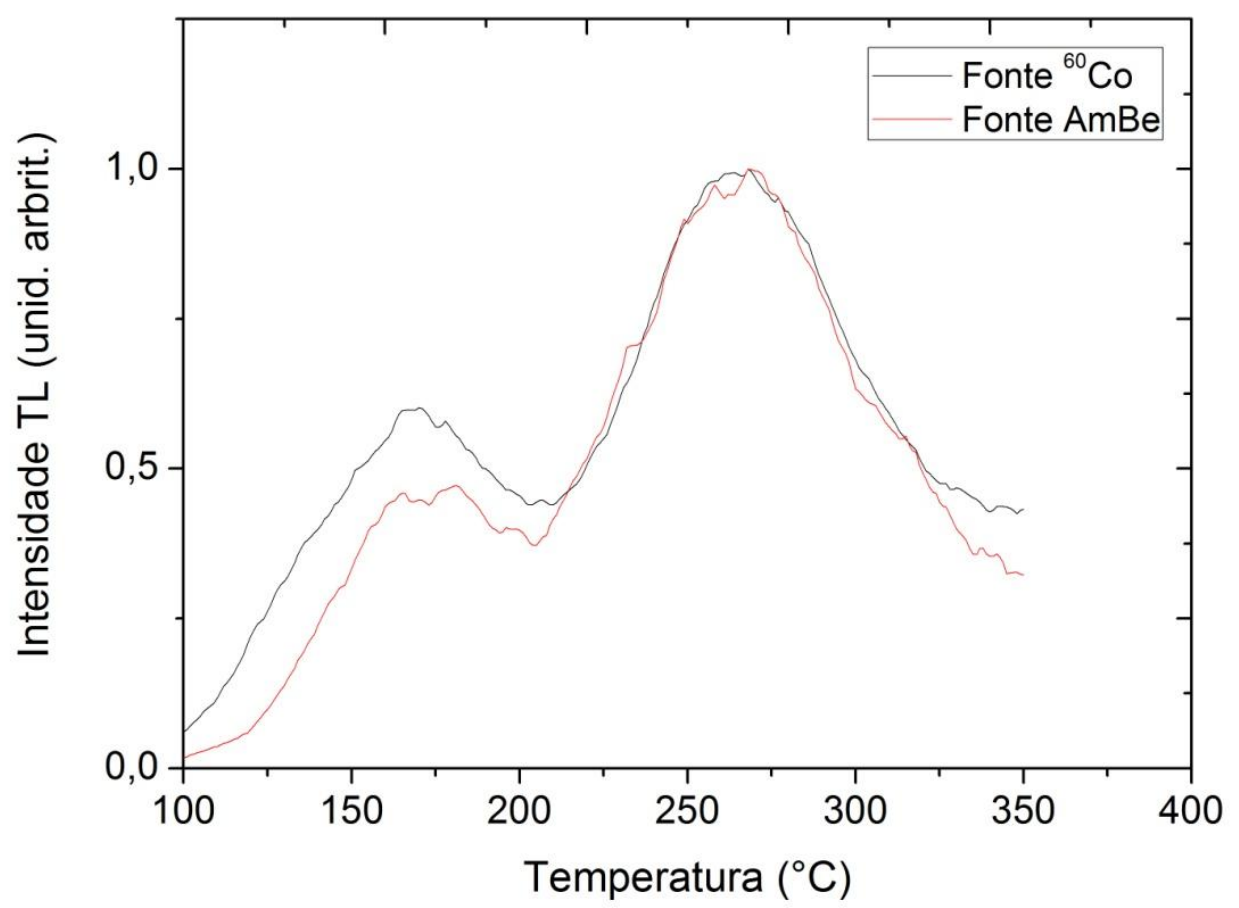

Figura 4-23: Curvas de emissão TL das pastilhas de sulfato de cálcio expostas a uma fonte de AmBe e a uma fonte de ${ }^{60} \mathrm{Co}$. 


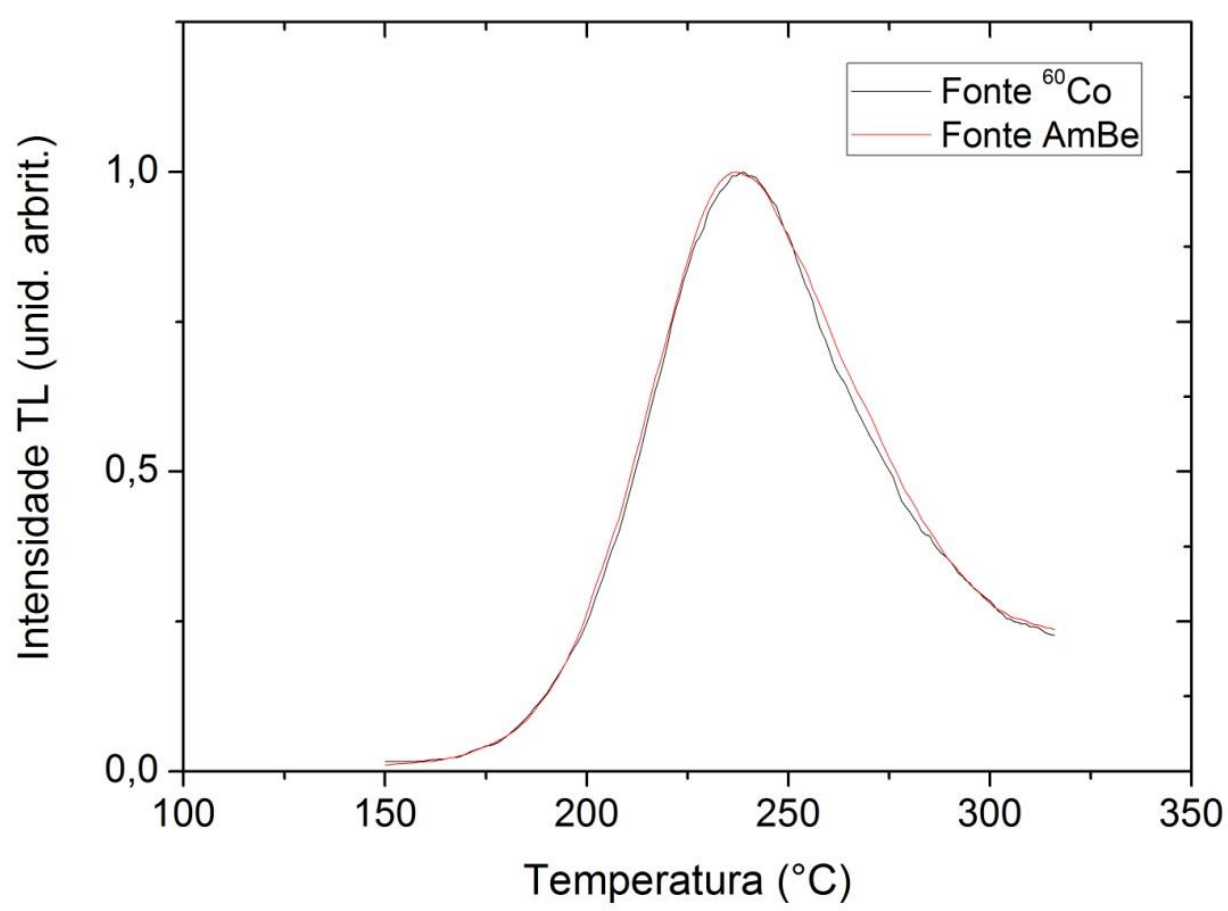

Figura 4-24: Curvas de emissão TL dos dosímetros de silicato de magnésio expostos a uma fonte de AmBe e a uma fonte de ${ }^{60} \mathrm{Co}$.

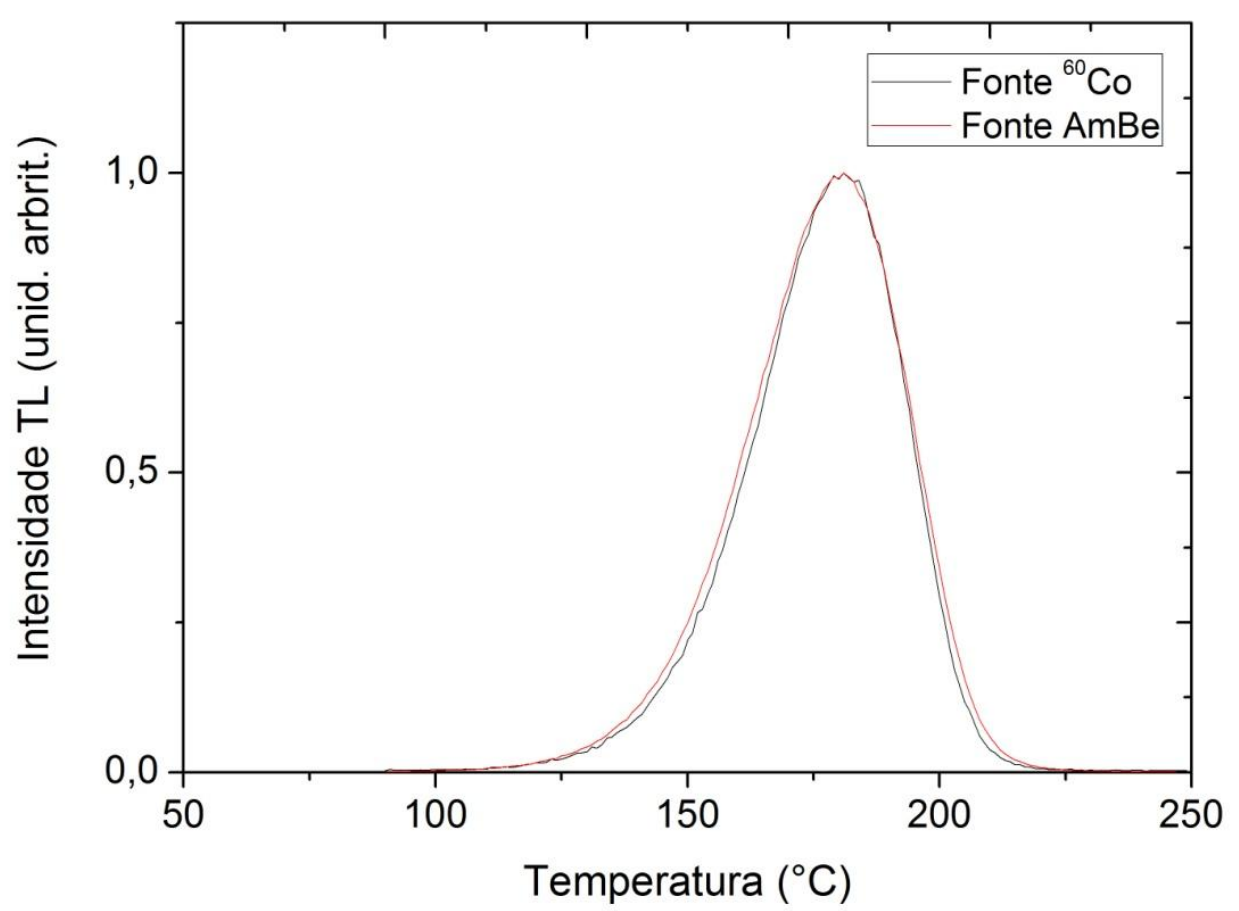

Figura 4-25: Curvas de emissão TL dos cristais de óxido de alumínio expostos a uma fonte de AmBe e a uma fonte de ${ }^{60} \mathrm{Co}$. 


\subsubsection{Resposta devido a radiação gama presente no feixe da fonte de $\mathrm{AmBe}$}

A resposta TL dos dosímetros irradiados com a fonte de AmBe pode ser vista na Tabela 4-7. A dose devido a contribuição de raios gama foi medida com o TLD-700 e, utilizando as curvas de calibração para o feixe de ${ }^{60} \mathrm{Co}$, foi possível estimar a resposta TL dos outros dosímetros para essa mesma dose absorvida devida a fótons. Esses resultados também estão na Tabela 4-7, juntamente com a razão entre a resposta esperada para raios gama e a resposta total medida.

Tabela 4-7: Resultados da irradiação com feixe misto proveniente da fonte de AmBe.

\begin{tabular}{ccccc}
\hline Dosímetro & Resposta TL (cps) & $\begin{array}{c}\text { Dose medida } \\
\text { com TLD-700 } \\
(\mathrm{mGy})\end{array}$ & $\begin{array}{c}\text { Resposta esperada } \\
\text { devido à } \\
\text { contribuição de } \\
\text { gama (cps) }\end{array}$ & $\begin{array}{c}\text { Razão entre } \\
\text { sinal gama e } \\
\text { sinal total }\end{array}$ \\
\hline $\mathrm{LiF}: \mathrm{Mg}, \mathrm{Ti}$ & $(6,8 \pm 0,2) \times 10^{4}$ & $(8,8 \pm 0,5)$ & $(2,40 \pm 0,05) \times 10^{3}$ & 0,04 \\
$\mathrm{CaF}_{2}$ & $(1,11 \pm 0,02) \times 10^{5}$ & $(8,8 \pm 0,5)$ & $(1,6 \pm 0,1) \times 10^{4}$ & 0,15 \\
$\mathrm{CaSO}_{4}: \mathrm{Dy}$ & $(3,9 \pm 0,2) \times 10^{2}$ & $(35 \pm 3)$ & $(4,6 \pm 0,3) \times 10^{2}$ & 0,22 \\
$\mathrm{Mg}_{2} \mathrm{SiO}_{4}: \mathrm{Tb}$ & $(2,08 \pm 0,04) \times 10^{4}$ & $(8,8 \pm 0,5)$ & $(5,3 \pm 0,2) \times 10^{3}$ & 0,25 \\
$\mathrm{Al}_{2} \mathrm{O}_{3}: \mathrm{C}$ & $(1,516 \pm 0,007) \times 10^{5}$ & $(8,8 \pm 0,5)$ & $(5,5 \pm 0,2) \times 10^{4}$ & 0,36 \\
\hline
\end{tabular}

\subsection{Simulações Monte Carlo}

Nas simulações realizadas com o programa PENELOPE um dos resultados calculados foi a energia depositada em cada material. Figura 4-26 mostra um arquivo de saída desse resultado gerado pelo programa. A energia depositada apresentada é a energia total depositada por história simulada e a incerteza equivale a dois desvios padrões. 


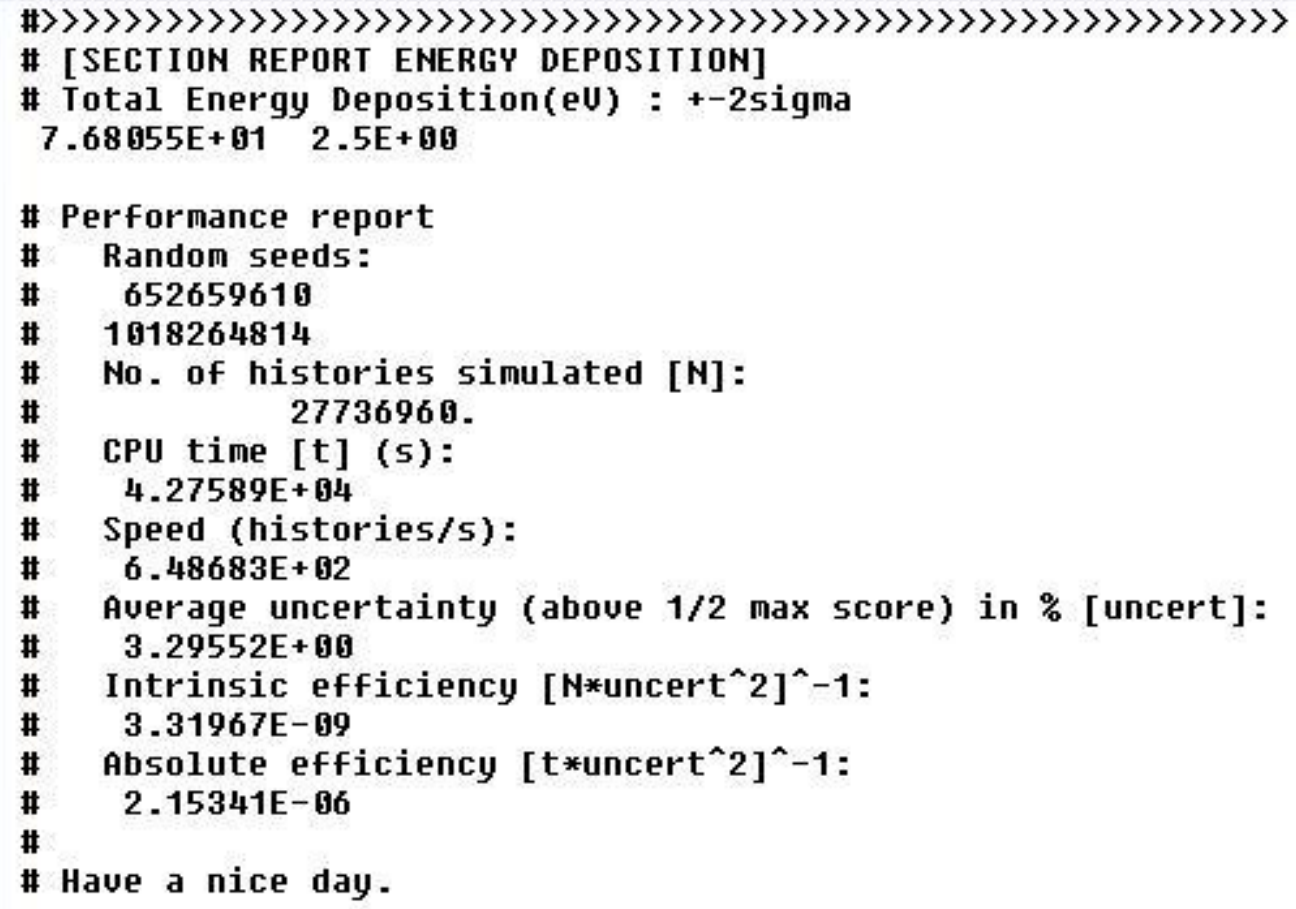

Figura 4-26: Relatório do programa PENELOPE para a rotina de cálculo de deposição de energia em um material. Nesse caso a simulação realizada foi a irradiação de pastilhas de fluorita em um feixe de potencial de aceleração nominal de $15 \mathrm{MV}$.

A Tabela 4-8 mostra como resultados as sensibilidades relativas e os fatores de dependência energéticas $f s_{C o}^{X}$ (equação 3-3) obtidos.

Tabela 4-8: Resultados das simulações Monte Carlo (continua).

\begin{tabular}{|c|c|c|c|c|c|}
\hline \multirow[b]{2}{*}{ Feixe } & \multirow[b]{2}{*}{$\mathrm{TPR}_{20,10}$} & \multicolumn{2}{|c|}{ LiF:Mg,Ti } & \multicolumn{2}{|c|}{ Fluorita natural } \\
\hline & & $\frac{D_{T L D}}{D_{\text {água }}}\left(10^{-1}\right)$ & $f s_{C o}^{X}$ & 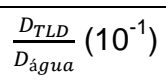 & $f s_{C o}^{X}$ \\
\hline${ }^{60} \mathrm{Co}$ & 0,566 & $7,95 \pm 0,04$ & $1,000 \pm 0,003$ & $8,88 \pm 0,06$ & $1,00 \pm 0,01$ \\
\hline $6 \mathrm{MV}$ & 0,673 & $8,00 \pm 0,05$ & $1,005 \pm 0,004$ & $8,68 \pm 0,08$ & $0,98 \pm 0,01$ \\
\hline $10 \mathrm{MV}$ & 0,737 & $8,24 \pm 0,07$ & $1,04 \pm 0,01$ & $8,8 \pm 0,1$ & $0,99 \pm 0,01$ \\
\hline $15 \mathrm{MV}$ & 0,763 & $8,33 \pm 0,08$ & $1,05 \pm 0,01$ & $8,9 \pm 0,1$ & $1,00 \pm 0,01$ \\
\hline $18 \mathrm{MV}$ & 0,778 & $8,10 \pm 0,08$ & $1,02 \pm 0,01$ & $8,6 \pm 0,1$ & $0,97 \pm 0,01$ \\
\hline
\end{tabular}


Tabela 4-8 (continuação): Resultados das simulações Monte Carlo.

\begin{tabular}{|c|c|c|c|c|c|c|c|}
\hline \multirow[b]{2}{*}{ Feixe } & \multirow[b]{2}{*}{$\mathrm{TPR}_{20,10}$} & \multicolumn{2}{|c|}{$\mathrm{CaSO}_{4}: \mathrm{Dy}$} & \multicolumn{2}{|c|}{$\mathrm{Mg}_{2} \mathrm{SiO}_{4}: \mathrm{Tb}$} & \multicolumn{2}{|c|}{$\mathrm{Al}_{2} \mathrm{O}_{3}: \mathrm{C}$} \\
\hline & & 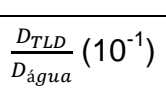 & $f s_{C o}^{X}$ & $\frac{D_{T L D}}{D_{\text {água }}}\left(10^{-1}\right)$ & $f s_{C o}^{X}$ & $\frac{D_{T L D}}{D_{\text {água }}}\left(10^{-1}\right)$ & $f s_{C o}^{X}$ \\
\hline${ }^{60} \mathrm{Co}$ & 0,566 & $9,0 \pm 0,1$ & $1,00 \pm 0,01$ & $9,1 \pm 0,2$ & $1,00 \pm 0,01$ & $8,81 \pm 0,09$ & $1,00 \pm 0,01$ \\
\hline $6 \mathrm{MV}$ & 0,673 & $9,2 \pm 0,2$ & $1,01 \pm 0,01$ & $8,9 \pm 0,2$ & $0,98 \pm 0,01$ & $8,8 \pm 0,1$ & $1,00 \pm 0,01$ \\
\hline $10 \mathrm{MV}$ & 0,737 & $9,1 \pm 0,2$ & $1,00 \pm 0,01$ & $9,0 \pm 0,3$ & $0,99 \pm 0,02$ & $9,2 \pm 0,2$ & $1,04 \pm 0,01$ \\
\hline $15 \mathrm{MV}$ & 0,763 & $9,1 \pm 0,2$ & $1,01 \pm 0,01$ & $9,3 \pm 0,3$ & $1,03 \pm 0,02$ & $8,9 \pm 0,2$ & $1,00 \pm 0,01$ \\
\hline $18 \mathrm{MV}$ & 0,778 & $8,9 \pm 0,1$ & $0,99 \pm 0,01$ & $8,9 \pm 0,2$ & $0,98 \pm 0,01$ & $9,0 \pm 0,2$ & $1,03 \pm 0,01$ \\
\hline
\end{tabular}

As figuras 4-27, 4-28, 4-29, 4-30 e 4-31 e a Tabela 4-9 mostram a comparação entre os fatores de dependência energética obtidos experimentalmente $\left(\mathrm{F}_{\mathrm{Co}}^{\mathrm{X}}\right)$ e por simulações Monte Carlo $\left(f s_{C o}^{X}\right)$ para os todos os dosímetros estudados.

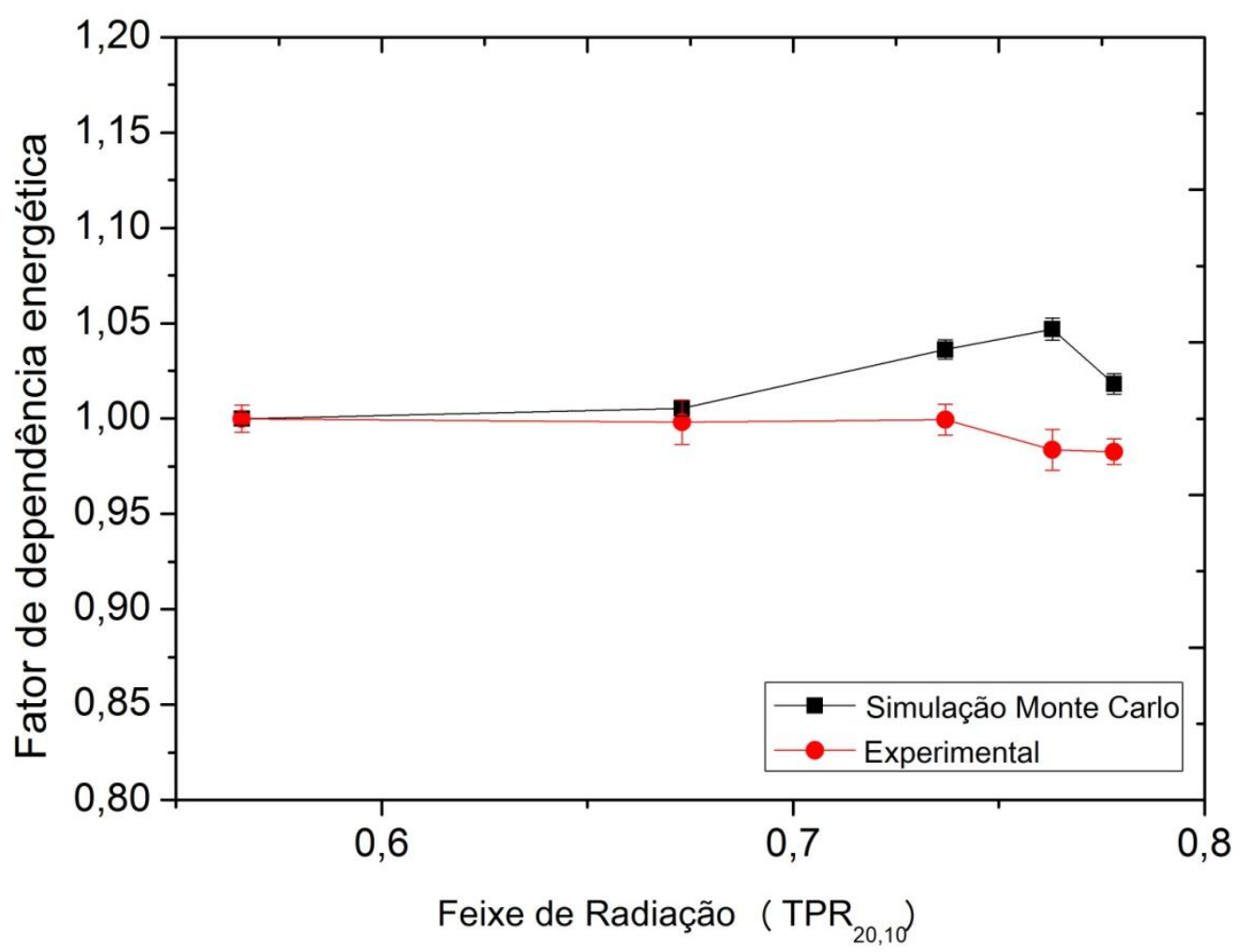

Figura 4-27: Fatores de dependência energética dos dosímetros de LiF:Mg,Ti para os diversos feixes estudados. Cada feixe está indicado pelo valor de seu TPR 20,10 . 


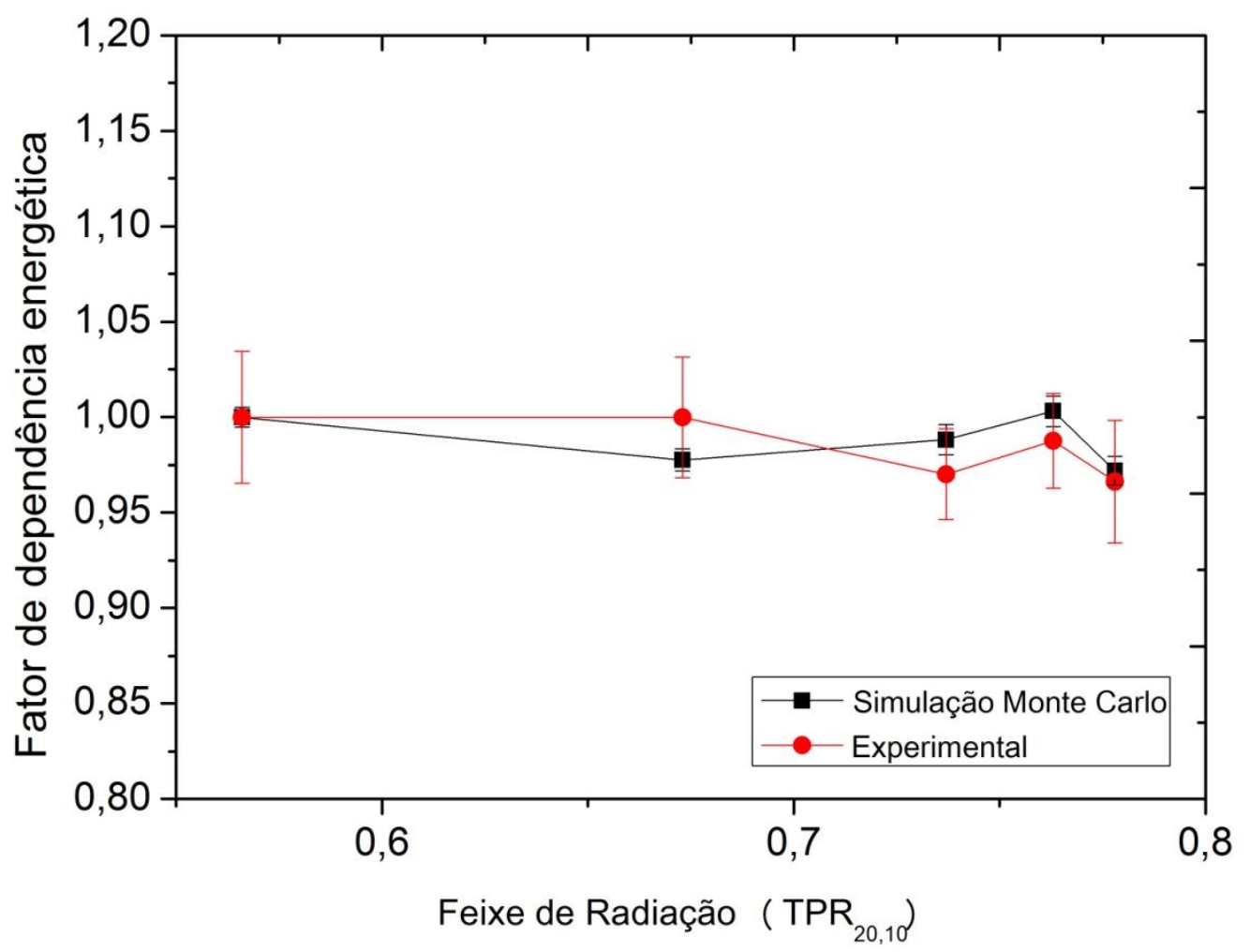

Figura 4-28: Fatores de dependência energética dos dosímetros de fluorita para os diversos feixes estudados.

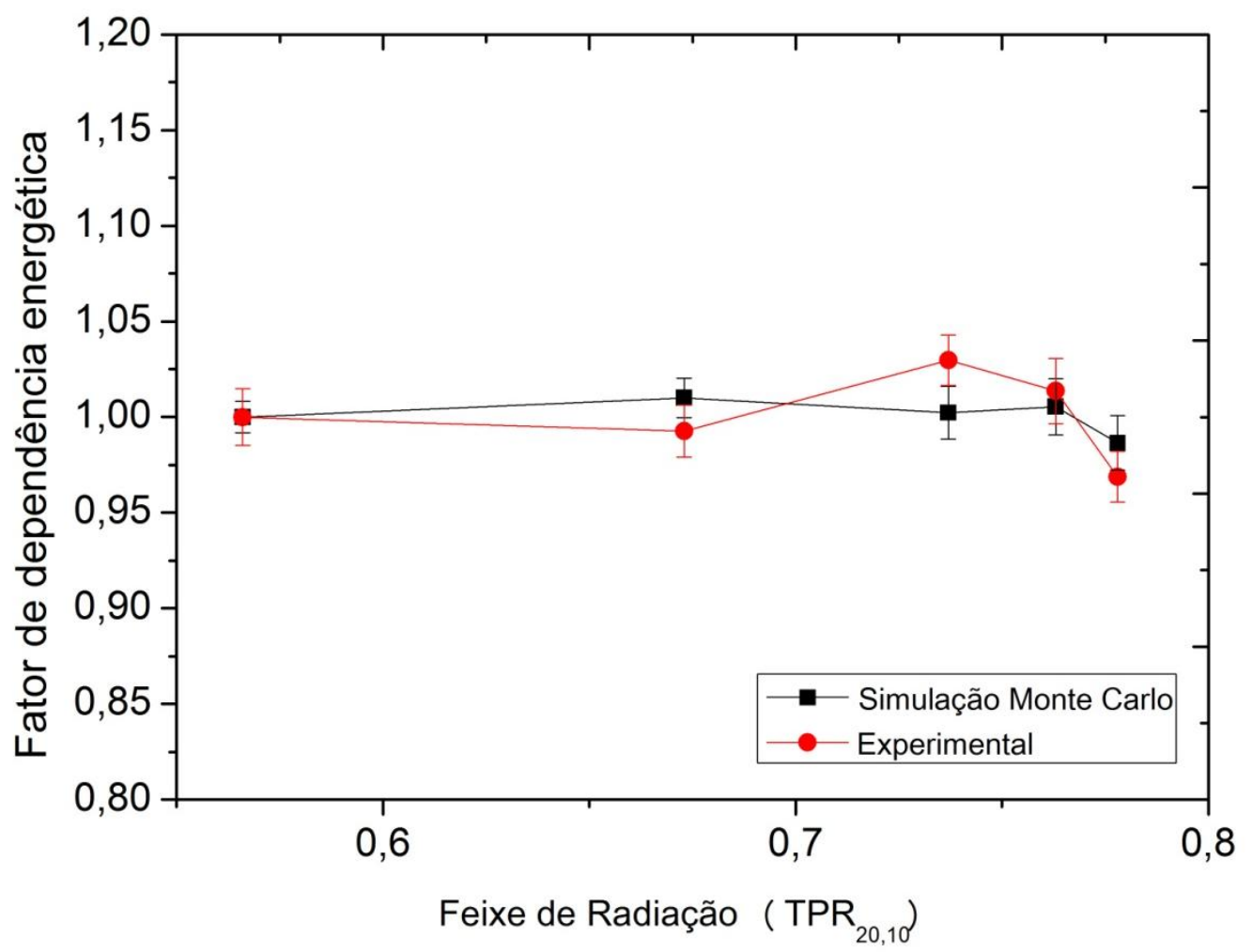

Figura 4-29: Fatores de dependência energética dos dosímetros de $\mathrm{CaSO}_{4}$ :Dy para os diversos feixes estudados. 


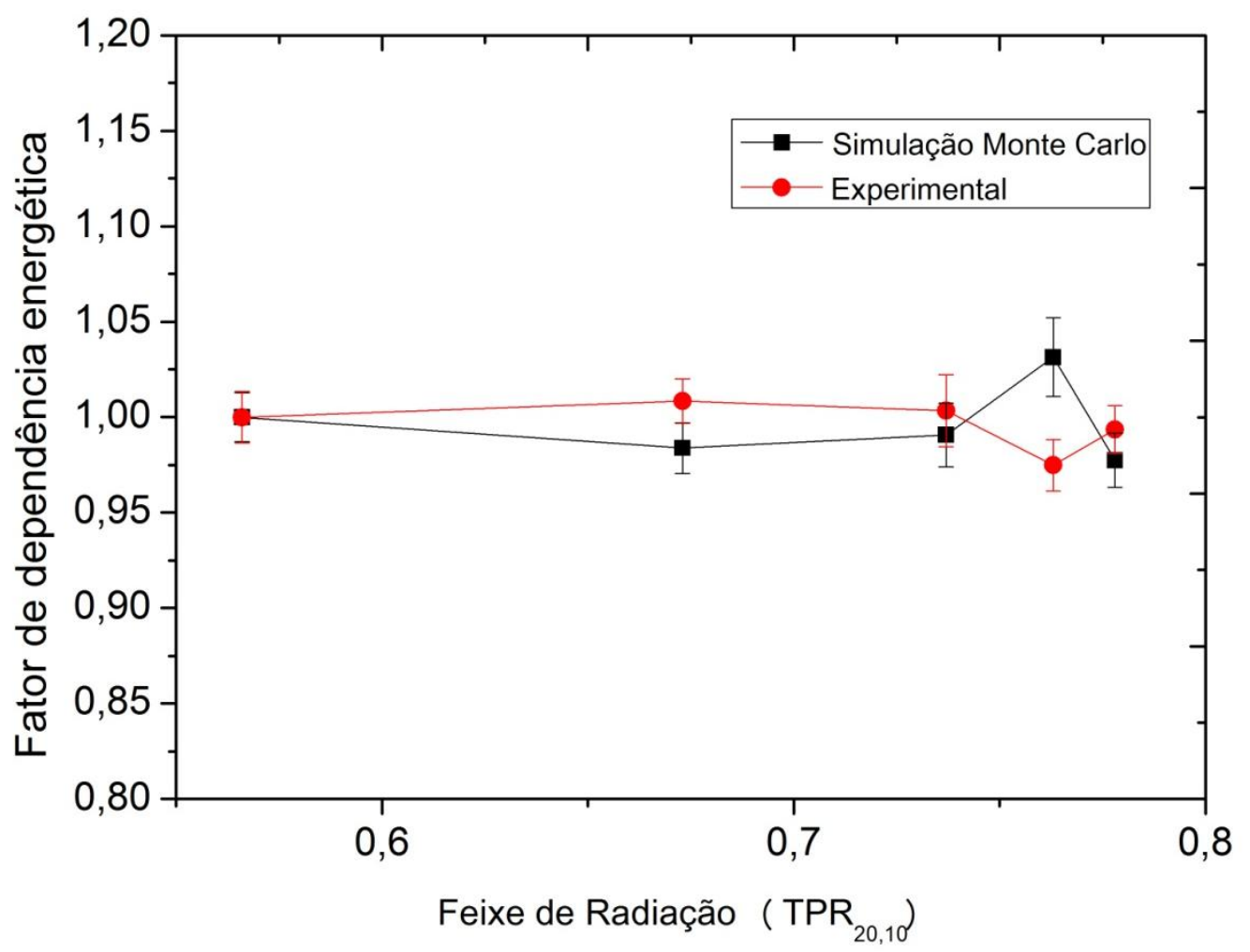

Figura 4-30: Fatores de dependência energética dos dosímetros de $\mathrm{Mg}_{2} \mathrm{SiO}_{4}: \mathrm{Tb}$ para os diversos feixes estudados.

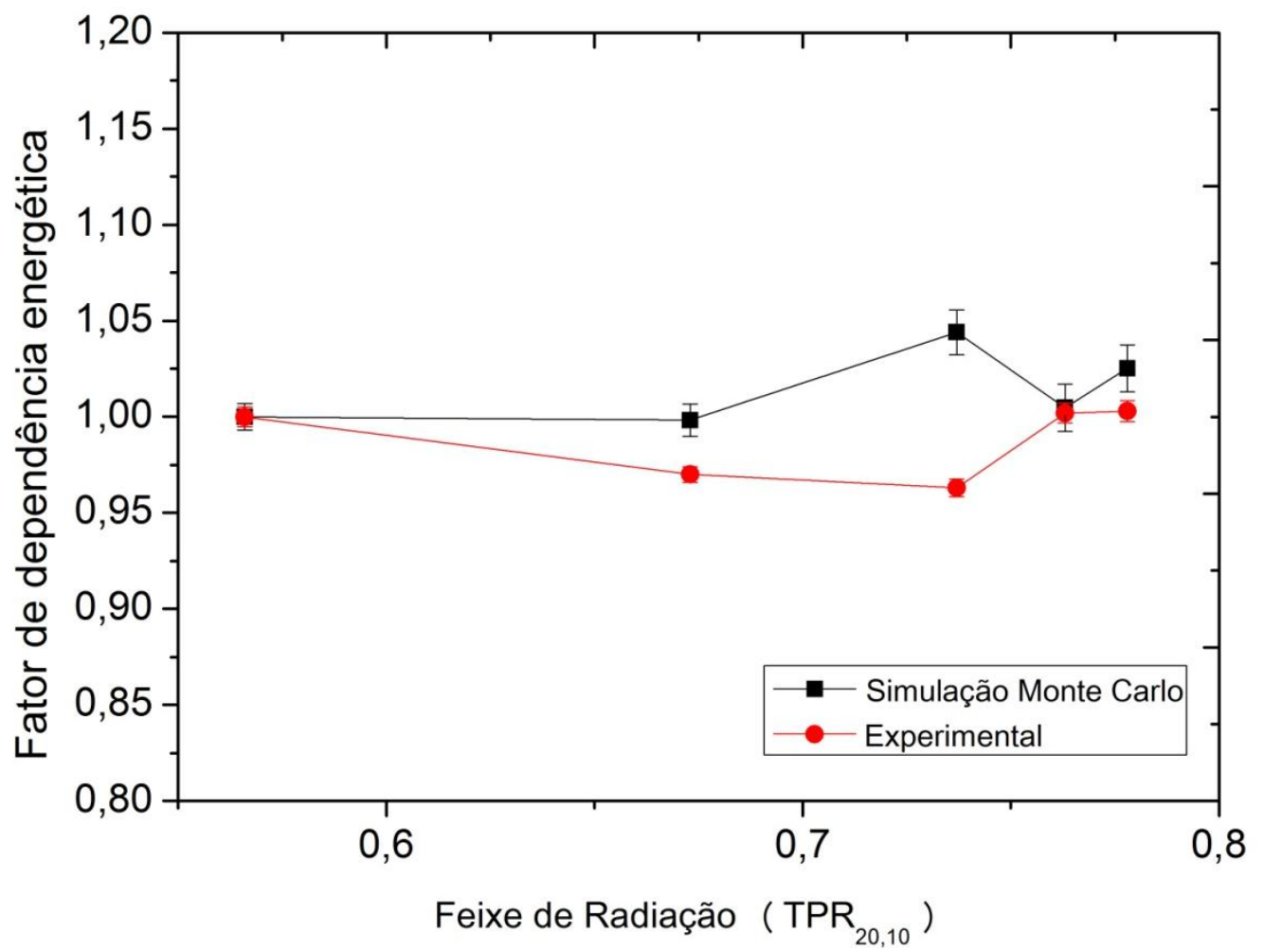

Figura 4-31: Fatores de dependência energética dos dosímetros de $\mathrm{Al}_{2} \mathrm{O}_{3}: \mathrm{C}$ para os diversos feixes estudados. 
Tabela 4-9: Fatores de dependência energética $\mathrm{F}_{\mathrm{Co}}^{\mathrm{X}}$ e $f s_{C o}^{X}$ (continua).

\begin{tabular}{|c|c|c|c|c|c|}
\hline \multirow[b]{2}{*}{ Feixe } & \multirow[b]{2}{*}{$\mathrm{TPR}_{20,10}$} & \multicolumn{2}{|c|}{ LiF:Mg,Ti } & \multicolumn{2}{|c|}{ Fluorita natural } \\
\hline & & $\mathrm{F}_{\mathrm{Co}}^{\mathrm{X}}$ & $f s_{C o}^{X}$ & $\mathbf{F}_{\mathrm{Co}}^{\mathrm{X}}$ & $f s_{C o}^{X}$ \\
\hline${ }^{60} \mathrm{Co}$ & 0,566 & $1,00 \pm 0,01$ & $1,000 \pm 0,003$ & $1,00 \pm 0,03$ & $1,00 \pm 0,01$ \\
\hline $6 \mathrm{MV}$ & 0,673 & $1,00 \pm 0,01$ & $1,005 \pm 0,004$ & $1,00 \pm 0,03$ & $0,98 \pm 0,01$ \\
\hline $10 \mathrm{MV}$ & 0,737 & $1,00 \pm 0,01$ & $1,04 \pm 0,01$ & $0,97 \pm 0,02$ & $0,99 \pm 0,01$ \\
\hline $15 \mathrm{MV}$ & 0,763 & $0,98 \pm 0,01$ & $1,05 \pm 0,01$ & $0,99 \pm 0,02$ & $1,00 \pm 0,01$ \\
\hline $18 \mathrm{MV}$ & 0,778 & $0,98 \pm 0,01$ & $1,02 \pm 0,01$ & $0,97 \pm 0,03$ & $0,97 \pm 0,01$ \\
\hline
\end{tabular}

Tabela 4-9 (continuação): Fatores de dependência energética $\mathrm{F}_{\mathrm{Co}}^{\mathrm{X}}$ e $f s_{C o}^{X}$.

\begin{tabular}{|c|c|c|c|c|c|c|c|}
\hline \multirow{2}{*}{ Feixe } & \multirow[b]{2}{*}{$\mathrm{TPR}_{20,10}$} & \multicolumn{2}{|c|}{$\mathrm{CaSO}_{4}: \mathrm{Dy}$} & \multicolumn{2}{|c|}{$\mathrm{Mg}_{2} \mathrm{SiO}_{4}: \mathrm{Tb}$} & \multicolumn{2}{|c|}{$\mathrm{Al}_{2} \mathrm{O}_{3}: \mathrm{C}$} \\
\hline & & $\mathbf{F}_{\mathrm{Co}}^{\mathrm{X}}$ & $f s_{C o}^{X}$ & $\mathbf{F}_{\mathrm{Co}}^{\mathrm{X}}$ & $f s_{C o}^{X}$ & $\mathbf{F}_{\mathrm{Co}}^{\mathrm{X}}$ & $f s_{C o}^{X}$ \\
\hline${ }^{60} \mathrm{Co}$ & 0,566 & $1,00 \pm 0,01$ & $1,00 \pm 0,01$ & $1,00 \pm 0,01$ & $1,00 \pm 0,01$ & $1,00 \pm 0,04$ & $1,00 \pm 0,01$ \\
\hline $6 \mathrm{MV}$ & 0,673 & $0,99 \pm 0,01$ & $1,01 \pm 0,01$ & $1,01 \pm 0,01$ & $0,98 \pm 0,01$ & $0,97 \pm 0,04$ & $1,00 \pm 0,01$ \\
\hline $10 \mathrm{MV}$ & 0,737 & $1,03 \pm 0,01$ & $1,00 \pm 0,01$ & $1,00 \pm 0,02$ & $0,99 \pm 0,02$ & $0,96 \pm 0,04$ & $1,04 \pm 0,01$ \\
\hline $15 \mathrm{MV}$ & 0,763 & $1,01 \pm 0,02$ & $1,01 \pm 0,01$ & $0,97 \pm 0,01$ & $1,03 \pm 0,02$ & $1,00 \pm 0,04$ & $1,00 \pm 0,01$ \\
\hline $18 \mathrm{MV}$ & 0,778 & $0,97 \pm 0,01$ & $0,99 \pm 0,01$ & $0,99 \pm 0,01$ & $0,98 \pm 0,01$ & $1,00 \pm 0,06$ & $1,03 \pm 0,01$ \\
\hline
\end{tabular}




\section{DISCUSSÃO}

\subsection{Resposta TL dos diferentes dosímetros em função da energia do feixe de fótons}

\subsubsection{Análise das curvas de emissão}

Comparando as curvas de emissão TL obtidas nas irradiações nos diferentes feixes de fótons (gráficos expostos no capítulo 4) não é possível observar diferenças apreciáveis no formato, na temperatura de máximo ou na relação entre os diferentes picos (quando houve mais de um) para nenhum dos materiais.

Para as curvas dos dosímetros de $\mathrm{CaSO}_{4}$ :Dy e fluorita é possível observar pequenas variações nos picos não utilizados para a dosimentria (pico 1 do $\mathrm{CaSO}_{4}$ :Dy e o pico 2 da fluorita). Como o sinal desses picos depende fortemente do tempo entre a irradiação e a leitura (e esse tempo não foi controlado rigidamente nesse trabalho), essas pequenas variações podem ser desprezadas na análise.

Apesar de ser uma análise qualitativa, a equivalência das curvas para os diferentes feixes indica que, ao variar o feixe de fótons, não ocorreram, em nenhum material, alterações no padrão de resposta. É sabido que diversos fenômenos que ocorrem com as curvas de emissão podem ser diretamente relacionados à densidade de ionizações no material dosimétrico [Horowitz e Olko, 2004]. O fato dessas curvas não terem sofrido alterações indica que os processos responsáveis pela emissão TL não foram afetados, ou melhor, indica que ao variar a energia do feixe, se tiver ocorrido alguma não homogeneidade na produção das ionizações no volume sensível do dosímetro ela não foi suficiente para afetar os processos de armadilhamento e recombinação de cargas no material.

\subsubsection{Linearidade de resposta TL em função da dose.}

Em relação à resposta $T L$ em função da dose absorvida, apenas os dosímetros de $\mathrm{Al}_{2} \mathrm{O}_{3}: \mathrm{C}$ apresentaram uma não linearidade na faixa de doses estudada: há uma acentuada supralinearidade (Figura 4-20), seguida de 
linearidade da resposta com o aumento da dose. Variações de sensibilidade com a dose já haviam sido descritas na literatura [Akselrod, 1993 e Yang et al, 2008] e são dependentes da concentração de carbono presente no cristal. Essa variação na sensibilidade relativa de resposta ficou evidenciada na Figura 4-19. Também nessa figura, é possível notar que, apesar da relação não ser linear, o comportamento da resposta se manteve o mesmo quando o feixe de radiação foi alterado, ou seja, a energia do feixe de fótons não muda a resposta dos dosímetros de $\mathrm{Al}_{2} \mathrm{O}_{3}: \mathrm{C}$ com a dose. Vale ressaltar que não era objetivo desse trabalho encontrar um bom ajuste para a variação da resposta com a dose. Porém, o fato dessa dependência não ser linear, apesar de comportada e unívoca, impõe algumas restrições quanto a fazer extrapolações dos resultados aqui obtidos.

Os dosímetros dos outros materiais, como pode ser visto nos gráficos da sensibilidade relativa em função da dose absorvida na água, apresentaram linearidade de resposta em função da dose absorvida na faixa de doses aqui estudada.

\subsubsection{Fatores de dependência energética}

A análise quantitativa da variação das respostas TL (altura de pico) em função da energia dos fótons, utilizando os fatores $\boldsymbol{F}_{\boldsymbol{C o}}^{\boldsymbol{X}}$ e $\boldsymbol{f} \boldsymbol{s}_{\boldsymbol{C o}}^{X}$, indica que não foi encontrada dependência energética significativa na faixa de energias estudadas para qualquer dos dosímetros.

O TLD-100 apresentou uma variação máxima de $2 \%$ para os valores de $\boldsymbol{F}_{\boldsymbol{C} \boldsymbol{}}^{\boldsymbol{X}}$. Esse resultado está em concordância com os resultados de outros autores [Bagne, 1977, Nyström et al, 1994, Rudén e Bengtsson, 1977 e Mobit, 1996] e mostra que, em geral, não é necessário nenhum fator de correção para energia nas medidas realizadas nesses feixes e o uso desse dosímetro nas diversas medidas em radioterapia é bastante indicado.

Os resultados dos dosímetros de fluorita também indicam uma dependência energética mínima, com os fatores $\boldsymbol{F}_{\boldsymbol{C} \boldsymbol{o}}^{\boldsymbol{X}}$ e $\boldsymbol{f} \boldsymbol{s}_{\boldsymbol{C o}}^{\boldsymbol{X}}$ variando no máximo $3 \%$. A pequena variação com a energia encontrada nesse trabalho garante que os dosímetros de fluorita brasileira podem ser utilizados para a 
realização de medidas como verificação de tratamentos em radioterapia com feixes de fótons de alta energia.

Os dosímetros de $\mathrm{CaSO}_{4}:$ Dy também apresentaram dependência energética pequena, sendo que os fatores $\boldsymbol{F}_{\boldsymbol{C o}}^{\boldsymbol{X}}$ e $\boldsymbol{f} \boldsymbol{s}_{\boldsymbol{C o}}^{\boldsymbol{X}}$ estão dentro de uma faixa de $3 \%$ em torno da unidade. Assim como o TLD-100 e os TLDs de fluorita, esses dosímetros podem ser aplicados em medidas de feixes de fótons de alta energia sem a necessidade de correções, embora a melhor prática seja calibrá-los no próprio feixe de interesse.

Apesar das dificuldades de leitura dos dosímetros do pó de $\mathrm{Mg}_{2} \mathrm{SiO}_{4}: \mathrm{Tb}$ encapsulado em invólucro de vidro, os resultados obtidos foram semelhantes aos dos demais materiais. A variação dos fatores $\boldsymbol{F}_{\boldsymbol{C o}}^{\boldsymbol{X}}$ e $\boldsymbol{f} \boldsymbol{s}_{\boldsymbol{C o}}^{\boldsymbol{X}}$ foi menor que $3 \%$. Um ponto importante a ser citado é a alta sensibilidade desses dosímetros. Como pode ser visto na Figura 4-14, mesmo utilizando um conjunto de filtros neutros que permitiam a transmissão de apenas $0,1 \%$ do sinal luminoso, a taxa de contagens medida foi alta. Essa alta sensibilidade, somada à linearidade de resposta com a dose e energia, faz desse dosímetro uma boa opção para medidas de dose periférica em radioterapia.

Para os dosímetros de $\mathrm{Al}_{2} \mathrm{O}_{3}: \mathrm{C}$ o fator $\boldsymbol{F}_{\boldsymbol{C} \text { o }}^{X}$ foi obtido pela equação 3-2 e, como dito na seção 3.7.1, ele não é suficiente para garantir uma conclusão sobre a dependência energética. Porém, se considerarmos junto com os valores desse fator (a maior variação foi de 4\%), a análise dos gráficos mostrados nas Figuras 4-17, 4-18 e 4-19, onde as curvas apresentadas são muito semelhantes para todos os feixes, podemos afirmar que esse material também não apresentou dependência energética considerável.

\subsubsection{Dispersão em função da dose medida}

As curvas de calibração dos dosímetros de fluorita e de $\mathrm{Mg}_{2} \mathrm{SiO}_{4}: \mathrm{Tb}$ (apresentadas no anexo) mostram pontos bastante afastadas da reta de ajuste e com incertezas relativamente grandes para as medidas de dose altas (acima de $1 \mathrm{~Gy}$ ). Para $\circ \mathrm{Al}_{2} \mathrm{O}_{3}: \mathrm{C}$, apesar de não haver uma reta de ajuste, os resultados para doses altas também estão mais dispersos. Embora não tenha sido possível identificar concretamente a causa, duas hipóteses podem explicar 
esse comportamento. Uma delas é sobre o processo de seleção de dosímetros e a outra se baseia no aumento da sensibilidade à luz desses dosímetros em medidas de doses altas.

Sobre o processo de seleção, pode ser que, como ele foi feito com medidas de dose de alguns mGy, não tenha sido suficiente para garantir que os dosímetros selecionados continuassem apresentando a mesma dispersão em medidas de doses bem mais altas. Isso pode ocorrer devido a algum processo de competição que esteja saturado em doses altas ou à ocorrência de uma distribuição não homogênea das impurezas e armadilhas de carga que não ficou evidenciada na faixa de doses usada na seleção.

A outra hipótese é que pode ter ocorrido algum vazamento de luz, na vedação dos dosímetros, em alguma parte do processo de medida. Como esses três materiais apresentam alta sensibilidade à luz e essa sensibilidade aumenta com o aumento da dose [Moscovitch et al, 1993, Lakshmanan et al, 1978] é de se esperar que, no caso de vazamento na vedação, os dosímetros mais afetados sejam aqueles que receberam maior dose.

Além de tomar precauções quanto à vedação de luz, para tentar minimizar as dispersões em medidas de dose altas, é recomendável realizar a seleção de dosímetros na própria faixa de doses a ser utilizada.

\subsection{Influência da contaminação por nêutrons na resposta TL}

$\mathrm{Na}$ análise das curvas de emissão apresentada na seção 4.7.1, a única alteração de curva de emissão encontrada (e que já era esperada e documentada na literatura [Busuoli et al, 1970 e Youssian, 1998]) foi na curva do dosímetro de LiF:Mg,Ti (TLD-100) quando esse foi irradiado com a fonte de AmBe. Nesse caso há um decrescimento nítido do sinal do pico 4 em relação ao sinal do pico 5, e o destaque de um grupo de picos em temperaturas além do pico dosimétrico. Os demais materiais não apresentaram alterações apreciáveis em suas curvas de emissão.

Na seção 4.7.2 foi possível observar que todos os dosímetros estudados apresentam sensibilidade a nêutrons térmicos e epitérmicos, mas esse fato não 
influenciou as medidas dos resultados TL para os feixes de potencial de aceleração nominal de 10,15 e $18 \mathrm{MV}$, para os quais se poderia esperar contaminação por nêutrons. Três resultados indicam que a dose devida aos nêutrons que contaminam esses feixes é praticamente desprezível.

O primeiro deles é o fato das curvas de emissão do TLD-100 para esses feixes não mostrarem diferenças no seu formato em relação às curvas obtidas nas medidas nos feixes de radiação do ${ }^{60} \mathrm{Co}$ e do acelerador linear com potencial de aceleração nominal de $6 \mathrm{MV}$. No caso de medidas de dose devida a nêutrons, uma nítida variação no formato da curva do TLD-100 é observada.

O segundo resultado que indica que a dose devida aos nêutrons contaminando esses feixes de fótons pode ser desprezada vem dos resultados das simulações de Monte Carlo. Como foi dito na seção 3.6, o programa PENELOPE não simula o transporte de nêutrons e nem propriedades TL específicas dos materiais. Um desacordo entre os resultados das simulações e dos experimentos para os feixes em questão poderia indicar uma variação das propriedades TL (hipótese descartada pela análise das curvas de emissão) ou a influência da deposição de dose por nêutrons na resposta dos experimentos. Como as Figuras 4-27, 4-28, 4-29, 4-30 e 4-31 mostram uma concordância entre os resultados experimentais e os resultados das simulações, pode-se concluir que a resposta TL devida à dose depositada por nêutrons de contaminação não foi significativa para os feixes em questão.

O terceiro argumento é o fato de não haver nos resultados, de nenhum dos materiais, uma tendência de aumento nas sensibilidades com o aumento da energia do feixe de fótons. Essa tendência seria esperada no caso de uma contribuição importante dos nêutrons na dose absorvida pelos dosímetros (uma vez que a contribuição dos nêutrons se somaria à dos fótons).

\subsection{Simulações com o método Monte Carlo}

Os resultados das simulações por método Monte Carlo apresentaram as razões $D_{T L D} / D_{\text {água }}$ próximas da unidade. O Monte Carlo só simula a deposição de energia nos dosímetros, as propriedades TL específicas e as distribuições de defeitos não são incluídas nessa metodologia [Chang, 2001] e, uma vez que 
os coeficientes de interação e absorção de energia dos materiais estudados são muito próximos dos coeficientes da água para essa faixa de energias [NIST, 2011], esse fato já era esperado.

A equivalência dos fatores $\boldsymbol{F}_{\boldsymbol{C o}}^{X}$ (obtido experimentalmente) e $\boldsymbol{f} \boldsymbol{s}_{\boldsymbol{C o}}^{X}$ (obtidos com os resultados das simulações), assim como a análise das curvas de emissão, indicam que nenhuma propriedade específica de TL foi modificada quando a energia do feixe de radiação foi alterada. Esse fato também leva ao resultado de que a dependência energética, nessa faixa de doses e energia, é desprezível para todos os dosímetros utilizados. 


\section{CONCLUSÕES}

Graças aos resultados obtidos nesse trabalho foi possível conhecer o comportamento de diversos dosímetros termoluminescentes (LiF:Mg, Ti (TLD100), fluorita natural brasileira, $\mathrm{CaSO}_{4}: \mathrm{Dy}, \mathrm{Mg}_{2} \mathrm{SiO}_{4}: \mathrm{Tb}$ e $\mathrm{Al}_{2} \mathrm{O}_{3}: \mathrm{C}$ ) quando irradiados em feixes de fótons de alta energia usados em tratamentos de radioterapia. As principais conclusões obtidas se referem aos efeitos causados nas respostas $T L$ desses dosímetros quando a energia do feixe de fótons era alterada.

A análise das curvas de emissão possibilitou concluir que ao variar 0 feixe de radiação, não ocorreu nenhum efeito que alterasse a distribuição de ionizações na estrutura dos fósforos a ponto de influenciar o padrão de resposta dos dosímetros.

$\mathrm{Na}$ faixa de doses utilizada, apenas os dosímetros de $\mathrm{Al}_{2} \mathrm{O}_{3}: \mathrm{C}$ não apresentaram comportamento linear de resposta em função da dose absorvida em água. Extrapolações para outras doses, diferentes das medidas nesse trabalho, devem ser feitas com cuidado uma vez que a variação da resposta em função da dose pode se modificar em outras faixas de dose. Entretanto, a não linearidade apresentada não influenciou a análise de dependência energética pois a variação da sensibilidade relativa foi a mesma para as irradiações em todos os feixes estudados.

Os resultados experimentais mostraram que nenhum dos materiais apresentou dependência de resposta considerável ao variar a energia do feixe de radiação. Na prática esse resultado significa que, para todos os feixes de fótons estudados, é possível realizar medidas de dose com os dosímetros, utilizando a calibração feita em apenas um dos feixes. Além disso, se os dosímetros forem selecionados e calibrados no feixe a ser utilizado e na faixa de doses a serem medidas, é esperada uma dispersão menor nos resultados.

Também foi possível verificar que os nêutrons que contaminam os feixes de fótons gerados em aceleradores lineares com potencial de aceleração nominal de 10, 15 e $18 \mathrm{MV}$ não depositaram dose suficiente para influenciar a resposta TL em nenhum dos materiais irradiados nesses feixes. 
As simulações com o método Monte Carlo serviram como argumento de comprovação dos resultados experimentais, sendo úteis na discussão da influência da dose depositada por nêutrons de contaminação e também na análise quantitativa da variação da resposta TL em função da energia do feixe.

Em geral, os resultados desse trabalho permitem concluir que a resposta $\mathrm{TL}$ dos dosímetros de $\mathrm{LiF}: \mathrm{Mg}, \mathrm{Ti}$, fluorita natural brasileira, $\mathrm{CaSO}_{4}: \mathrm{Dy}$, $\mathrm{Mg}_{2} \mathrm{SiO}_{4}: \mathrm{Tb}$ e $\mathrm{Al}_{2} \mathrm{O}_{3}: \mathrm{C}$ não varia com a energia do feixe de fótons, na faixa de energias mais utilizadas nos tratamentos de radioterapia com esse tipo de radiação atualmente (feixes de fótons com $\mathrm{TPR}_{20,10}$ variando de aproximadamente 0,5 até 0,8 ). Como a faixa de doses estudada também compreende doses comumente empregadas nos tratamentos fracionados, os resultados aqui obtidos podem ser diretamente aplicados na prática dos centros de radioterapia, seja para medidas de doses nos pacientes (dose na pele, dose na entrada de campos, doses periféricas, etc), verificação de tratamentos e calibrações (programas postais de auditoria) ou outros controles de qualidade. 


\section{ANEXO - CURVAS DE RESPOSTA TL EM FUNÇÃO DA DOSE ABSORVIDA EM ÁGUA PARA TODOS OS MATERIAIS ESTUDADOS.}

LiF:Mg, Ti (TLD-100)
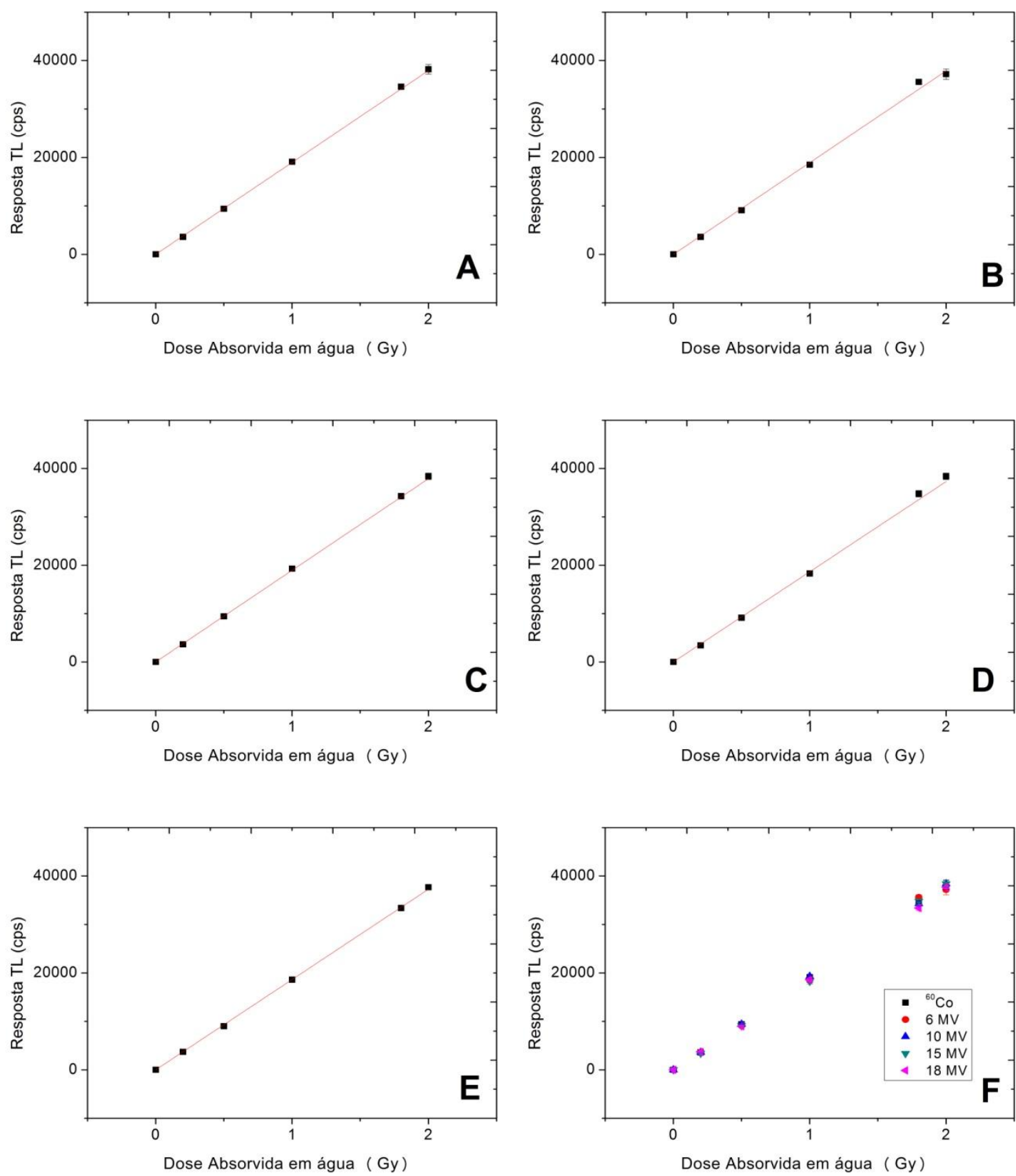

Figura A 1: Resposta TL do LiF:Mg,Ti em função da dose absorvida em água para os feixes de fótons de uma fonte de ${ }^{60} \mathrm{Co}(\mathrm{A})$ e de aceleradores lineares clínicos com potencial de aceleração nominal de $6 \mathrm{MV}$ (B), $10 \mathrm{MV}$ (C), $15 \mathrm{MV}$ (D) e $18 \mathrm{MV}$ (E). As retas representam os ajustes lineares realizados. Também estão representados, em um só gráfico (F), os resultados para as irradiações em todos os feixes estudados 


\section{Fluorita}
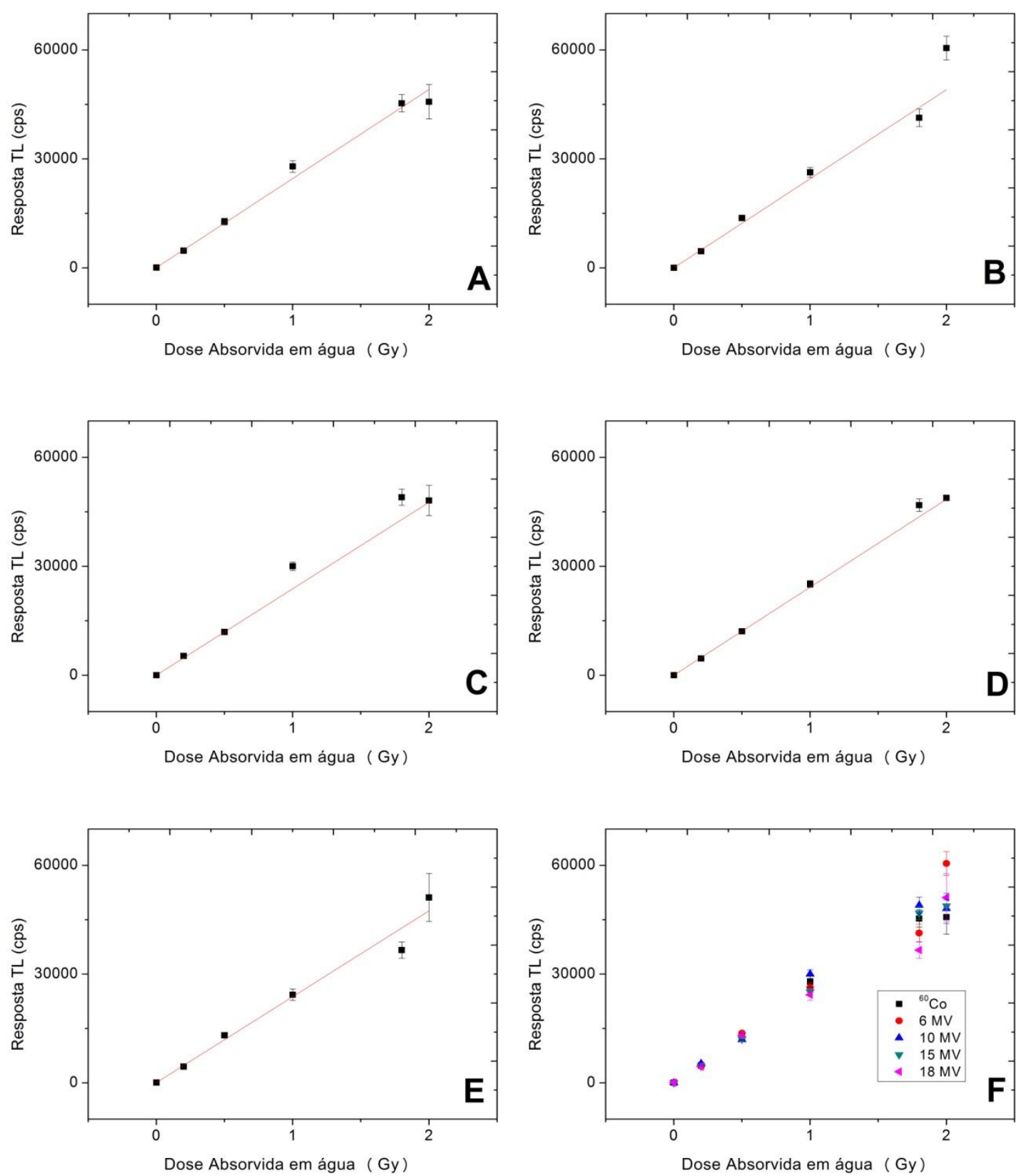

Figura A 2: Resposta TL da fluorita em função da dose absorvida em água para os feixes de fótons de uma fonte de ${ }^{60} \mathrm{Co}(\mathrm{A})$ e de aceleradores lineares clínicos com potencial de aceleração nominal de $6 \mathrm{MV}(\mathrm{B}), 10 \mathrm{MV}(\mathrm{C}), 15 \mathrm{MV}$ (D) e $18 \mathrm{MV}$ (E). As retas representam os ajustes lineares realizados. Também estão representados, em um só gráfico (F), os resultados para as irradiações em todos os feixes estudados 
$\mathrm{CaSO}_{4}: \mathrm{Dy}$
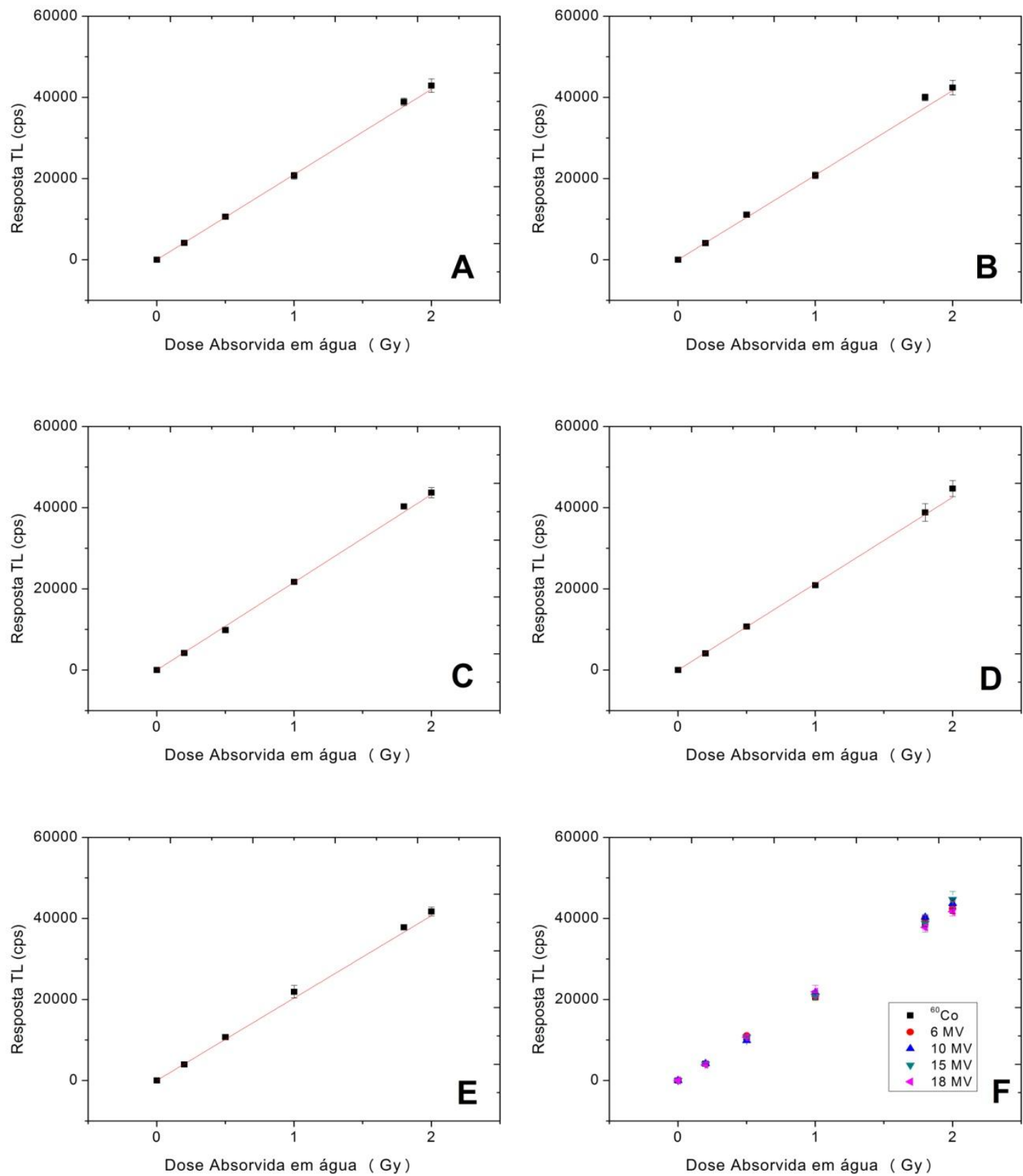

Figura A 3: Resposta $\mathrm{TL}$ do $\mathrm{CaSO}_{4}$ :Dy em função da dose absorvida em água para os feixes de fótons de uma fonte de ${ }^{60} \mathrm{Co}(\mathrm{A})$ e de aceleradores lineares clínicos com potencial de aceleração nominal de $6 \mathrm{MV}$ (B), $10 \mathrm{MV}$ (C), $15 \mathrm{MV}$ (D) e $18 \mathrm{MV}$ (E). As retas representam os ajustes lineares realizados. Também estão representados, em um só gráfico $(F)$, os resultados para as irradiações em todos os feixes estudados. 


\section{$\mathrm{Mg}_{2} \mathrm{SiO}_{4}: \mathrm{Tb}$}
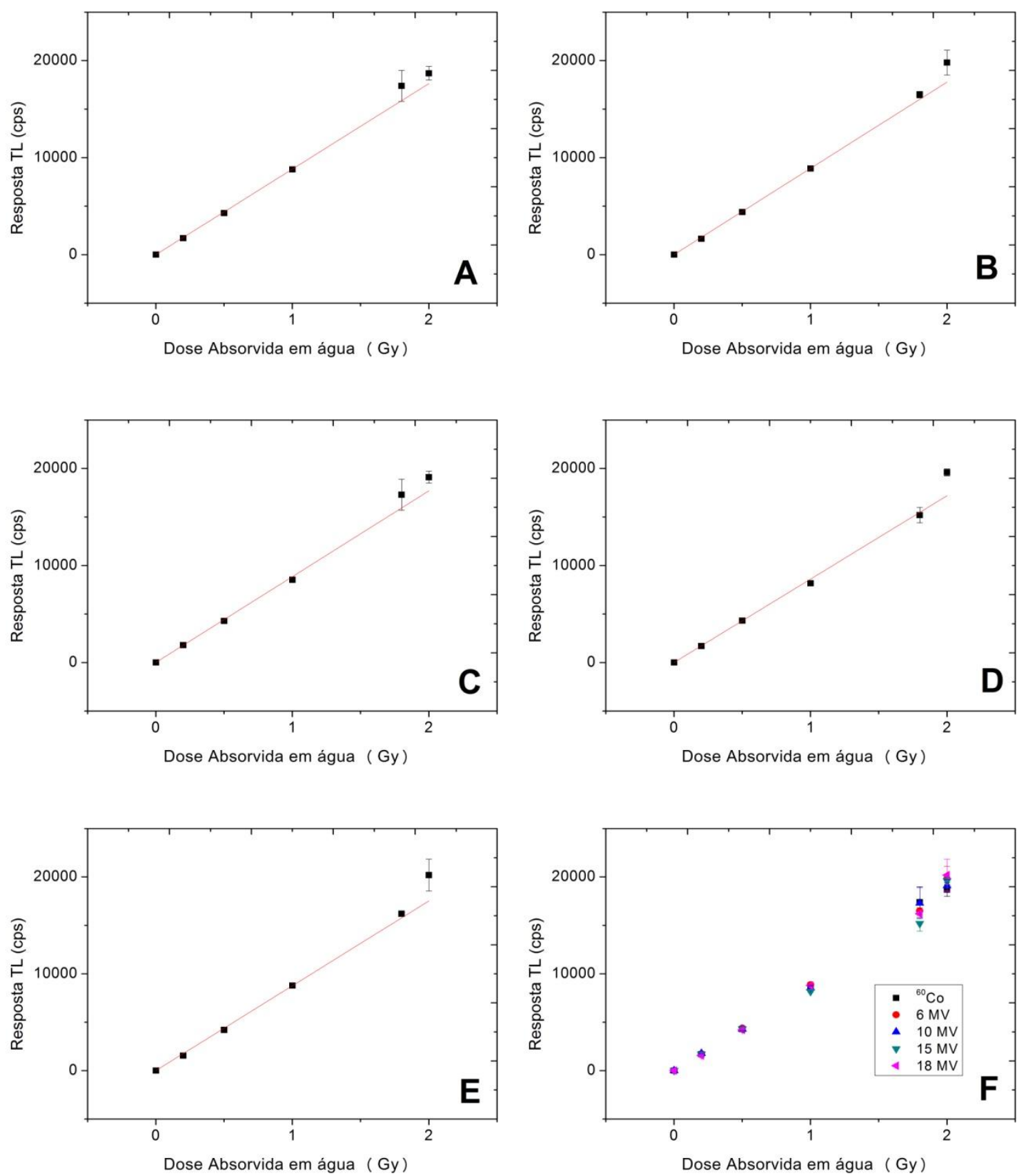

Figura A 4: : Resposta $\mathrm{TL}$ do $\mathrm{Mg}_{2} \mathrm{SiO}_{4}: \mathrm{Tb}$ em função da dose absorvida em água para os feixes de fótons de uma fonte de ${ }^{60} \mathrm{Co}(\mathrm{A})$ e de aceleradores lineares clínicos com potencial de aceleração nominal de $6 \mathrm{MV}$ (B), $10 \mathrm{MV}$ (C), $15 \mathrm{MV}$ (D) e $18 \mathrm{MV}$ (E). As retas representam os ajustes lineares realizados. Também estão representados, em um só gráfico $(F)$, os resultados para as irradiações em todos os feixes estudados. 


\section{$\mathrm{Al}_{2} \mathrm{O}_{3}: \mathrm{C}$}
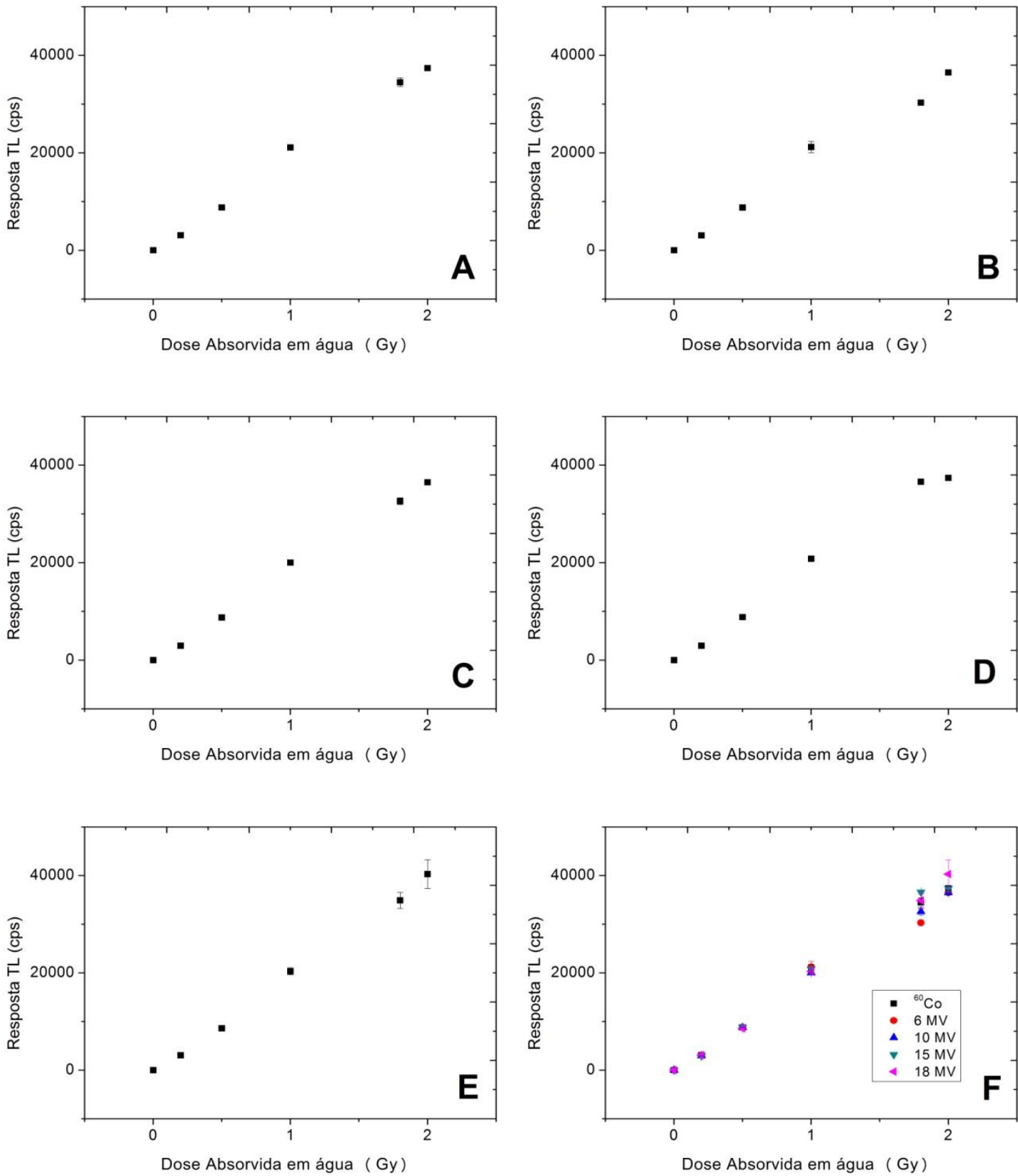

Figura A 5: : Resposta $\mathrm{TL}$ do $\mathrm{Al}_{2} \mathrm{O}_{3}: \mathrm{C}$ em função da dose absorvida em água para os feixes de fótons de uma fonte de ${ }^{60} \mathrm{Co}(\mathrm{A})$ e de aceleradores lineares clínicos com potencial de aceleração nominal de $6 \mathrm{MV}$ (B), $10 \mathrm{MV}$ (C), $15 \mathrm{MV}$ (D) e $18 \mathrm{MV}$ (E). Também estão representados, em um só gráfico $(F)$, os resultados para as irradiações em todos os feixes estudados 


\section{REFERÊNCIAS}

Agostinelli et al, 2003

Akselrod, 1993

Almond et al, 1999

Andersen et al, 2003

Andreo, 1986

Bagne, 1977

Battistoni et al, 2007

Becker, 1972

Becker, 1973
Agostinelli S, et. al. GEANT4 - a Simulation toolkit. Nuclear Instruments and Methods A. 506(3), 250-303. (2003).

Akselrod M S, Kortov V S, Gorelova E A. Preparation and Properties of $\alpha$-Al2O3:C. Radiation protection dosimetry. (1993); 47(1):159-164.

Almond P R, Biggs P J, Coursey B M, Hanson W F, Huq M S, Nath R, et al. AAPM's TG-51 protocol for clinical reference dosimetry of high-energy photon and electron beams. Medical physics. (1999); 26(9):1847-70.

Andersen C E, Aznar M C, Bøtter-Jensen L, Bäck S A J, Mattsson S, and Medin J. Development of optical fibre luminescence techniques for real time in vivo dosimetry in radiotherapy. Standards and Codes of Practice in Medical Radiation Dosimetry (Proc. Int. Symp. Vienna, 2002), Vol. 2, IAEA, (2003); 353-360.

Andreo P, Brahme A. Stopping power data for high energy photon beams. Phys. Med. Biol. 31 (1986); 839858.

Bagne F. A comprehensive study of LiF TL response to high energy photons and electrons. Radiat. Phys. 123 (1977); 753-60.

Battistoni G, Cerutti F, Fasso A, Ferrari A. The FLUKA code: Description and benchmarking. AIP Conference. (2007);130(4):403.

Becker K. Environmental monitoring with TLD. Nuclear Instruments and Methods. (1972); 104(2):405-407.

Becker K. Solid State Dosimetry. (1973) Cleveland, CRC Press. 
Berger, 1992

Bjarngard, 1967

Bos, 2007

Brown et al, 2003

Budd et al, 1979

Busuoli et al, 1970

Cadman et al, 2002

Cameron et al, 1968

Campos e Lima, 1986
Berger M J. ESTAR, PSTAR and ASTAR: computer programs for calculating stopping-power and range tables for electrons, protons and helium ions. Report NISTIR 4999 (National Institute of Standards and Technology, Gaithersburg, MD). (1992).

Bjarngard B. Proceedings of the first International conference on luminescence dosimetry. Stanford. (1967).

Bos A J J. Theory of thermoluminescence. Radiation Measurements. (2007); 4145-56.

Brown et al. MCNP - A General Monte Carlo N-Particle Transport Code, Version 5. Volume II: User's guide. Los Alamos, NM: Los Alamos National Laboratory, Distributed by the RSICC of the Oak Ridge National Laboratory. (2003); 4(7):403.

Budd T, Marshall M, Peaple L H J, Douglas J A. The low and high temperature response of LiF dosimeters to $\mathrm{X}$ rays. Phys. Med. Biol. 24, 71 (1979).

Busuoli G, Cavallini A, Fassò A, Rimondi O. Mixed radiation dosimetry with LiF (TLD-100). Physics in medicine and biology. (1970); 15(4):673-81.

Cadman P, Bassalow R, Sidhu N P S, lbbott G, and Nelson A. Dosimetric considerations for validation of a sequential IMRT process with a commercial treatment planning system. Phys. Med. Biol. 47 (2002); 3001-3010.

Cameron J R, Suntharalingam N, Kenney G N. Thermoluminescent Dosimetry. The University of Wisconsin Press. (1968).

Campos L, Lima M F. Dosimetric properties of CaSO4: Dy teflon pellets produced at IPEN. Radiation protection dosimetry. (1986); 14(4):333-335. 
Chang, 2001

Cruz, 1972

Curie e Garlick, 1963

Daniels et al, 1953

Dielhof et al, 1988

Esposito et al, 2008

Facure et al, 2005

Gomola et al, 2001
Chang J K, Nam Y M, Kim J L, Chang S Y, Kim B H. Calculated energy dependence of $\mathrm{CaSO}_{4}$ :Dy $\mathrm{TL}$ phosphor and phosphor embedded Te-on for $\mathrm{X}$ and gamma rays. Radiation Measurements 33 (2001); 675678.

Cruz M T. Propriedades termoluminescentes da fluorita brasileira de coloração violeta. São Paulo: Instituto de Física; Universidade de São Paulo. (1972). Tese de Doutorado.

Curie D, Garlick G F J. Luminescence in crystals. Methuen and Co Ltd. (1963).

Daniels F, Boyd C A, Saunders D F. Thermoluminescence as a research tooll. Science. (1953); 117-343.

Dielhof J, Bos A, Zoetelief J, Broerse J. Sensitivity of CaF2 Thermoluminescent Materials to Fast Neutrons. Radiation Protection Dosimetry. (1988); 23(1-4):

Esposito A, Bedogni R, Lembo L, Morelli M. Determination of the neutron spectra around an 18MV medical LINAC with a passive Bonner sphere spectrometer based on gold foils and TLD pairs. Radiation Measurements. (2008) Feb; 43(2-6):1038-43.

Facure $A$, Falcão $R C$, Silva $A X$, Crispim $V R$, Vitorelli J C. A study of neutron spectra from medical linear accelerators. Applied radiation and isotopes: including data, instrumentation and methods for use in agriculture, industry and medicine. (2005); 62(1):69-72.

Gomola I, Van Dam J, I-Verdum J, Verstraete J, Reymen R, Dutreix A, Davis B, Huyskens D. External audits of electron beams using mailed TLD dosimetry: preliminary results. Radiotherapy and Oncology 58 (2001); 163-168. 
Guimarães, 2005

Horowitz e Olko, 2004

Hufton, 1984

IAEA, 2001

Ibbott, 2008

ICRU, 1976

IEC, 1998
Guimarães C C. Monitoração individual externa: experimentos e simulações com o método Monte Carlo. São Paulo: Instituto de Física; Universidade de São Paulo. (2005). Tese de Doutorado.

Horowitz Y, Olko P. The effects of ionisation density on the thermoluminescence response (efficiency) of LiF:Mg, Ti and LiF: Mg, Cu, P. Radiation protection dosimetry. (2004); 109(4):331.

Hufton A P. Pratical aspects of thermoluminescence dosimetry. London: HPA. (1984).

IAEA International Atomic Energy Agency. Absorbed Dose Determination in External Beam Radiotherapy: An International Code of Practice for Dosimetry based on Standards of Absorbed Dose to Water. Technical Report Series nำ398, Vienna. (2001)

Ibbott $G$, Ma C M, Rogers D W O, Seltzer S M, Williamson J F. Anniversary Paper: Fifty years of AAPM involvement in radiation dosimetry. Medical Physics. (2008); 35(4):1418.

International Commission on Radiation Units and Measurements. Determination of absorbed dose in a patient irradiated by beams of X or Gamma rays in radiotherapy procedures. ICRU report 24. (1976).

International Electrotechnical Commission. Medical electrical equipment Part 2-1: particular requirements for the safety of electron accelerators in the range $1 \mathrm{MeV}$ to $50 \mathrm{MeV}$. IEC standard Report, 60601-2-1. Geneva. (1998). 
Izewska et al, 2000

Johns e Cunninghan, 1969

Kawrakou et al, 2010

Kortov, 1994

Kry et al, 2007

Lakshmanan e Vohra, 1978

Lakshmanan et al, 1978

Loncol, 1996

Maidana, 2011
Izewska J, Andreo P. The IAEA/WHO TLD postal programme for radiotherapy hospitals. Radiotherapy and oncology : journal of the European Society for Therapeutic Radiology and Oncology. (2000); 54(1):6572.

Johns $\mathrm{H} \mathrm{E}$, Cunningham $\mathrm{J}$ R. The physics of radiology. Thomas Springfield, Illinois. (1969).

Kawrakow I, Rogers D. The EGSnrc code system: Monte Carlo simulation of electron and photon transport. Workshop Proceedings Barcelona, Spain. (2010);4(7):403.

Kortov V S, Milman I I, Kirpa V I, Lesz J. Some Features of a-Al2O3 dosimetric thermoluminescent crystals. Radiation Protection Dosimetry. (1994); 55(4):279-283.

Kry S F, Price M, Followill D, Mourtada F, Salehpour M. The use of LiF (TLD-100) as an out-of-field dosimeter. (2007) Journal of Applied. 2007; 43(7):2015

Lakshmanan A, Vohra K. Gamma radiation induced sensitization and photo-transfer in Mg2SiO4: Tb TLD phosphor. Nuclear Instruments and Methods. (1979); 159(2-3):585-592.

Lakshmanan A R, B C, Bhatt R C. Gamma radiation induced sensitization in CaSO4:Dy TLD phosphor. Nuclear Instruments and Methods. (1978); 153 581-588.

Loncol $\mathrm{T} \quad \mathrm{H}$, Vynckier $\mathrm{S}$, Wambersie $\mathrm{A}$. Thermoluminescence in proton and fast neutron therapy beams. Radiat. Prot. Dosim. 66(1-4) (1996); 299-304.

Comunicação particular 
Marczewska, 2001

Mckeever et al, 1995

McKeever, 1985

Ministério da Saúde, 2001

Mittani et al, 2007

Mobit, 1996

Mora, 1999

Morato et al, 1982

Morlotti e Yoshimura, 2007
Marczewska B, Bilski P, Budzanowski M, Olko P, Chernov V. Dosimetry properties of Tm-doped single $\mathrm{CaF}_{2}$ crystals. Radiation Measurements 33 (2001); 571 576.

McKeever S W S, Moscovitch M, Townsend P D. Thermoluminescence Dosimetry Materials: Properties and Uses. Nuclear Technology Publishing. (1995).

McKeever S W S. Thermoluminescence of Solids. Cambridge: Cambridge University Press. (1985).

Ministério da Saúde. Protocolo de controle da qualidade no 1151. Aspectos físicos da garantia de qualidade. INCA. (2001).

Mittani J C, Prokic M, Yukihara E 2007. Optically stimulated luminescence and thermoluminescence of terbium-activated silicates and aluminates. Radiat. Meas. (2008); 43(2-6):323-326.

Mobit P N, Mayles P, Nahum A E. The quality dependence of LiF TLD in megavoltage photon beams: Monte Carlo simulation and experiments. Physics in medicine and biology. (1996); 41(3):387-98.

Mora G, Maio A, Rogers D. Monte Carlo simulation of a typical Co therapy source. Medical physics. (1999); 26(1):2494.

Morato S P; Gordon A, Santos E N; Gomes I, Campos I L; Prado I; Ferreira M; Bapat V N. Development of a solid state dosimetry based on the thermoluminescent properties of CaSO4: Dy crystals. Nucl. Instrum. Methods. 200:449. (1982).

Morlotti M S and Yoshimura E M. Internal dose measurements in photon beam radiotherapy using an anthropomorphic phantom (ARP) with TLD-100 dosimeters. (2007) 
Morlotti, 2007

Moscovitch et al, 1993

Nash e Johnson, 1977

Nisbet et al, 2004

NIST, 2011

Nunes, 2008

Nyström et al, 1994

Okuno e Watanabe, 1972
Morlotti M S. Verificação de tratamentos radioterápicos diversos com dosimetria termoluminescente. São Paulo: Instituto de Física; Universidade de São Paulo. (2007). Dissertação de Mestrado.

Moscovitch e Horowitz, 2007 Moscovitch M, Horowitz Y S. Thermoluminescent materials for medical applications: LiF:Mg, Ti and LiF:Mg, Cu, P. Radiation Measurements. (2007); 4171-77.

Moscovitch M, Tawil R A, Svinkin M. Light induced fading in a-Al2O3:C. Radiat. Prot. Dosim. (1993) 47, 251-253.

Nash A E, Johnson T L. Proceedings of the fifth International conference on luminescence Dosimetry. Sao Paulo. (1977); p. 393.

Nisbet A, Beange I, Vollmar H S, Irvine C, Morgan A, and Thwaites D I. Dosimetric verification of a commercial collapsed cone algorithm in simulated clinical situations. Radiotherapy and Oncology 73 (2004); 79-88.

National Institute of Standards and Technology. USA. http://physics.nist.gov

Nunes M G, Avaliação do desempenho dos detectores termoluminescentes de CaSO4:Dy e LiF:Mg, Ti na dosimetria de feixes clínicos de elétrons. São Paulo: IPEN; Universidade de São Paulo. (2008). Dissertação de Mestrado.

Nyström H, Bera P, Nette P. Beam quality dependence of TLDs irradiated in standardized geometry Proc. Int. Symp. on Measurement Assurance in Dosimetry (1994) IAEASM-330/72 (Vienna:IAEA) pp 527-39.

Okuno E, Watanabe S. UV Induced Thermoluminescence on Natural Calcium Fluoride. Health Physics. (1972); 23(3): 377-382. 
Okuno, 1970

Piters et al, 1993

Podgorsak, 2006

Pradhan e Bhatt, 1982

Prokié e Yukihara, 2008

Rivera, 2008

Rudén e Bengtsson, 1977

Salvat et al, 2006
Okuno E. Propriedades termoluminescentes da fluorita natural. São Paulo: Instituto de Física; Universidade de São Paulo. (1970). Tese de Doutorado.

Piters $T$ M. A study into the mechanism of thermoluminescence in a LiF:Mg,Ti Dosimetry material. Delft: Delft University of Technology. (1993). PhD Thesis.

Podgorsak E B, Kainz K. Radiation Oncology Physics: A Handbook for Teachers and Students. IAEA Viena (2006).

Pradhan A, Bhatt R C. Response of Sensitised CaSO4: Dy Phosphor and Phosphor Embedded Teflon TLD Discs to $X$ and Gamma Rays. Radiation Protection Dosimetry. (1982); 2(1):23-26.

Prokié M, Yukihara E G. Dosimetric characteristics of high sensitive Mg2SiO4:Tb solid TL detector. Radiation Measurements. (2008); 43(2-6):463-466.

Rivera J, Falcão R, Dealmeida C. The measurement of photoneutron dose in the vicinity of clinical linear accelerators. Radiation protection dosimetry. (2008); 130(4):403.

Rudén B-I, Bengtsson L G. Accuracy of megavoltage radiation dosimetry using thermoluminescent lithium fluoride Acta Radiat. Ther. Phys. Biol. 16 (1977); 157-75.

Salvat F, Fernández-Varea J M, Sempau J. PENELOPE2006: A code system for Monte Carlo simulation of electron and photon transport. In: Workshop Proceedings Barcelona, Spain. Citeseer. (2006); p. 403.

Sheikh-Bagheri e Rogers, Sheikh-Bagheri D, Rogers D. Monte Carlo calculation of 2002 code. Medical physics. (2002); 29(1):391. 
Swinnen et al, 2004

Toryu et al, 1973

Trzesniak, 1985

Tuyn e Lakshmanan, 1983

Weng e Chen, 1973

Yamashita el al, 1971

Yamashita et al, 1968

Yang et al, 2008
Swinnen A, Verstraete J, Huyskens D P. Feasibility study of entrance in vivo dose measurements with mailed thermoluminescence detectors. Radiotherapy and Oncology 73 (2004); 89-96.

Toryu $\mathrm{T}$, Sakamoto $\mathrm{H}$, Kotera $\mathrm{N}$, Yumada $\mathrm{H}$.. Compositions dependency of thermoluminescence of new phosphors for radiation dosimetry. In Proceedings of the International Conference on Luminescence. (1973). Leningrad, USSR, pp. 685-689.

Trzesniak P. Dosímetros termoluminescentes sólidos a base de fluorita brasileira. São Paulo: Instituto de Física; Universidade de São Paulo. (1985). Dissertação de Mestrado.

Tuyn J W N, Lakshmanan A. Light sensitivity of some common thermoluminescence dosimetry phosphors. Radiation protection dosimetry. (1983); 5(3):183.

Weng P, Chen K. Response of CaSO4(Dy) phosphor to neutrons. Nuclear Instruments and Methods. (1973) May 1;117(1):89-92 .

Yamashita T, Nada N, Onishi H, Kitamura S. Calcium sulfate activated by thulium or dysprosium for thermoluminescence dosimetry. Health Physics. (1971); 21(2):295.

Yamashita T, Nada N, Onishi H, Kitamura S. Proceedings of the second International conference on luminescence dosimetry. Gatlinburg. (1968).

Yang X-bo, Li H-jun, Bi Q-yu, Cheng Y, Tang Q, Xu J. Influence of carbon on the thermoluminescence and optically stimulated luminescence of a-Al2O3:C crystals. Journal of applied physics 104, 123112 (2008). 
Yasuda, 2000

Yasuda H, Fujitaka K. Responses of TLD Mg2SiO4:Tb and radiophotoluminescent glass to heavy charged particles and space radiation. Radiation protection dosimetry. (2000); 87(2):115-119.

Yoshimura e Yukihara, 2006 Yoshimura E M, Yukihara E G. Optically Stimulated Luminescence: searching for new dosimetric materials. Nuclear Instruments and Methods B, Nuclear. (2006).

Youssian et al, 1998

Youssian D, Horowitz Y S. Estimation of gamma dose in neutron dosimetry using peak 4 to peak 5 ratios in LiF:Mg, Ti (TLD-100/600). Radiation Protection Dosimetry. (1998); 77(3):151-158.

Yukihara, 2003

Yukihara E. The effects of deep trap population on the thermoluminescence of Al2O3:C. Radiation Measurements. (2003) Dec; 37(6): 627-638. 


\section{LISTA DE TABELAS}

Tabela 2-1: Principais vantagens e desvantagens dos dosímetros mais usados em radioterapia. 4

Tabela 3-1: Resumo das características dos dosímetros estudados. .............. 26

Tabela 3-2: Propriedades dos materiais simulados.................................... 36

Tabela 4-1: Resultados da seleção dos dosímetros. A dispersão apresentada é em relação à média das medidas. .................................................. 41

Tabela 4-2: Dependência energética do LiF:Mg, Ti.................................... 44

Tabela 4-3: Dependência energética da fluorita natural............................... 48

Tabela 4-4: Dependência energética de sulfato de cálcio .............................. 51

Tabela 4-5: Dependência energética do silicato de magnésio ......................... 54

Tabela 4-6: Dependência energética do óxido de alumínio. .......................... 58

Tabela 4-7: Resultados da irradiação com feixe misto proveniente da fonte de

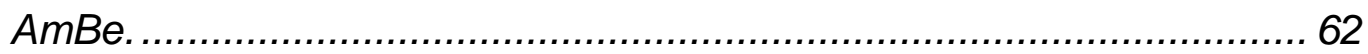

Tabela 4-8: Resultados das simulações Monte Carlo. ................................63 63

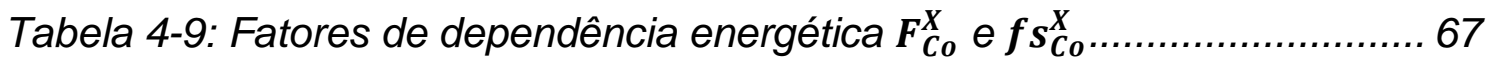




\section{LISTA DE FIGURAS}

Figura 2-1: Esquema de níveis de energia mostrando os processos de fluorescência (a) e fosforescência (b) [Curie e Garlick, 1963]

Figura 2-2: Modelo de bandas de energia mostrando as transições eletrônicas em um material TL: (a) geração de pares elétron-buraco; (b) aprisionamento dos portadores de carga; (c) elétron sendo liberado pelo aquecimento; (d) recombinação. 7

Figura 2-3: Curva de emissão TL calculada a partir do modelo de RandallWilkins. Os valores dos parâmetros envolvidos no cálculo foram $E=1,2$ eV; $s=10^{12} s^{-1}$ e $\beta=1{ }^{\circ} \mathrm{C}^{-1} \mathrm{~s}^{-1}$. O valor de $n_{0}$ foi escolhido de modo a normalizar a curva em relação à intensidade de máximo.

Figura 2-4: Curvas de emissão TL calculadas a partir do modelo de RandallWilkins. As diferentes curvas foram calculadas variando o valor de $n_{0} e$ mantendo os valores dos outros parâmetros fixos $\left(E=1,2 \mathrm{eV} ; \mathrm{s}=10^{12} \mathrm{~s}\right.$ ${ }^{1}$ e $\beta=1{ }^{\circ}{\left.\mathrm{C} . \mathrm{s}^{-1}\right)}$.

Figura 2-5: Espectro de fótons simulado no eixo central de um campo de $10 \times 10 \mathrm{~cm}^{2}$ e distância fonte detector de $100 \mathrm{~cm}$. O espectro corresponde ao de uma unidade de cobalto Eldorado 6 e leva em consideração o encapsulamento da fonte, o sistema de colimação e o espalhamento no ar.

Figura 2-6: Espectro de fótons simulado para diferentes aceleradores lineares: Três aceleradores da Varian de potencial de aceleração nominal de $6 \mathrm{MV}$ (a), $10 \mathrm{MV}$ (b) e $15 \mathrm{MV}$ (c) e um acelerador da Siemens com potencial de aceleração nominal de $18 \mathrm{MV}(d)$. 20

Figura 3-1: Curva de emissão do LiF:Mg, Ti obtida 24 horas após irradiação com ${ }^{60}$ Co e dose de $10 \mathrm{mGy}$. A leitura foi feita com aquecimento de $5^{\circ} \mathrm{C} / \mathrm{s}$ até $280^{\circ} \mathrm{C}$.

Figura 3-2: Curva de emissão do $\mathrm{CaF}_{2}$ obtida 24 horas após irradiação com ${ }^{60}$ Co e dose de $10 \mathrm{mGy}$. A leitura foi feita com aquecimento de $5{ }^{\circ} \mathrm{C} / \mathrm{s}$ até $380^{\circ} \mathrm{C}$

Figura 3-3: Curva de emissão do $\mathrm{CaSO}_{4}: D y$ obtida 24 horas após irradiação com ${ }^{60}$ Co e dose de $10 \mathrm{mGy}$. A leitura foi feita com aquecimento de $5^{\circ} \mathrm{C} / \mathrm{s}$ até $350^{\circ} \mathrm{C}$. 
Figura 3-4: Curva de emissão do $\mathrm{Mg}_{2} \mathrm{SiO}_{4}: \mathrm{Tb}$ obtida 24 horas após irradiação com ${ }^{60}$ Co e dose de $10 \mathrm{mGy}$. As leituras foram feitas com aquecimento

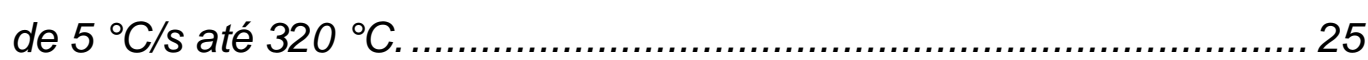

Figura 3-5: Curva de emissão do $\mathrm{Al}_{2} \mathrm{O}_{3}: \mathrm{C}$ obtida 24 horas após irradiação com ${ }^{60} \mathrm{Co}$ e dose de $10 \mathrm{mGy}$. A leitura foi feita com aquecimento de $1{ }^{\circ} \mathrm{C} / \mathrm{s}$ até

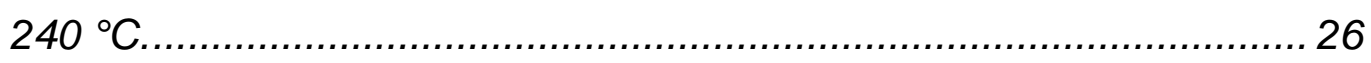

Figura 3-6: (a) suporte com formato da câmara de ionização tipo farmer. (b) suporte posicionado no objeto simulador...

Figura 3-7: Ponteira e bainha de vedação de luz para a pastilha de $\mathrm{Al}_{2} \mathrm{O}_{3}: \mathrm{C}$ e $\mathrm{O}$ projeto das demais ponteiras.

Figura 4-1: Curvas de emissão TL das pastilhas de LiF:Mg,Ti. Todas as curvas foram normalizadas em relação ao seu ponto de máximo e a legenda indica o material da fonte radioativa ou o potencial de aceleração nominal dos feixes de fótons com o qual os dosímetros foram irradiados.

Figura 4-2: Resposta TL dos dosímetros de LiF:Mg,Ti em função da dose absorvida em água para os diversos feixes de radiação utilizados. As leituras foram feitas utilizando os filtros Schott KG 1, Corning 4-70 e Oriel com transmissão de $10 \%$

Figura 4-3: Curva de calibração do LiF:Mg,Ti para o feixe de potencial de aceleração nominal de $10 \mathrm{MV}$. 44

Figura 4-4: Sensibilidade relativa dos dosímetros de fluoreto de lítio em função da dose absorvida na água. 45

Figura 4-5: Curvas de emissão TL das pastilhas de fluorita natural. Todas as curvas foram normalizadas em relação ao seu ponto de máximo.

Figura 4-6: Resposta TL dos dosímetros de fluorita natural em função da dose absorvida em água para os diversos feixes de radiação utilizados. As leituras foram feitas utilizando os filtros Schott KG 1, Corning 5-58 e Oriel com transmissão de $10 \%$.

Figura 4-7: Curva de calibração da fluorita natural para o feixe de potencial de aceleração nominal de 15 MV.

Figura 4-8: Sensibilidade relativa dos dosímetros de fluorita em função da dose absorvida na água. 48 
Figura 4-9: Curvas de emissão TL das pastilhas de sulfato de cálcio. Todas as curvas foram normalizadas em relação ao seu ponto de máximo. 49

Figura 4-10: Resposta TL dos dosímetros de sulfato de cálcio em função da dose absorvida em água para os diversos feixes de radiação utilizados. As leituras foram feitas utilizando os filtros Schott KG 1 e Oriel com transmissão de $1 \%$

Figura 4-11: Curva de calibração do sulfato de cálcio para o feixe de potencial de aceleração nominal de $18 \mathrm{MV}$.

Figura 4-12: Sensibilidade relativa dos dosímetros de sulfato de cálcio em função da dose absorvida na água.

Figura 4-13: Curvas de emissão TL dos dosímetros de silicato de magnésio. Todas as curvas foram normalizadas em relação ao seu ponto de máximo.

Figura 4-14: Resposta TL dos dosímetros de silicato de magnésio em função da dose absorvida em água para os diversos feixes de radiação utilizados. As leituras foram feitas utilizando o filtro Schott KG 1 e dois filtros Oriel com transmissão de $10 \%$ e $1 \%$.

Figura 4-15: Curva de calibração do silicato de magnésio para o feixe de potencial de aceleração nominal de $6 \mathrm{MV}$.

Figura 4-16: Sensibilidade relativa dos dosímetros de silicato de magnésio em função da dose absorvida na água. 54

Figura 4-17: Curvas de emissão TL dos dosímetros de óxido de alumínio. Todas as curvas foram normalizadas em relação ao seu ponto de máximo. 55

Figura 4-18: Resposta TL dos dosímetros de óxido de alumínio em função da dose absorvida em água para os diversos feixes de radiação utilizados. As leituras foram feitas utilizando os filtros Schott KG 1, Corning 4-70 e Oriel com transmissão de $1 \%$. 56

Figura 4-19: Sensibilidade relativa dos dosímetros de óxido de alumínio em função da dose absorvida na água.

Figura 4-20: Resposta TL dos cristais de óxido de alumínio em função da dose absorvida em água. A reta representa o comportamento linear para comparação. 
Figura 4-21: Curvas de emissão TL das pastilhas de LiF:Mg,Ti (TLD100) expostas a uma fonte de AmBe e a uma fonte de ${ }^{60} \mathrm{Co}$.

Figura 4-22: Curvas de emissão TL das pastilhas de fluorita expostas a uma fonte de AmBe e a uma fonte de ${ }^{60} \mathrm{Co}$.

Figura 4-23: Curvas de emissão TL das pastilhas de sulfato de cálcio expostas a uma fonte de $\mathrm{AmBe}$ e a uma fonte de ${ }^{60} \mathrm{Co}$. 60

Figura 4-24: Curvas de emissão TL dos dosímetros de silicato de magnésio expostos a uma fonte de AmBe e a uma fonte de ${ }^{60} \mathrm{Co}$.

Figura 4-25: Curvas de emissão TL dos cristais de óxido de alumínio expostos a uma fonte de $\mathrm{AmBe}$ e a uma fonte de ${ }^{60} \mathrm{Co}$.

Figura 4-26: Relatório do programa PENELOPE para a rotina de cálculo de deposição de energia em um material. Nesse caso a simulação realizada foi a irradiação de pastilhas de fluorita em um feixe de potencial de aceleração nominal de $15 \mathrm{MV}$. 63

Figura 4-27: Fatores de dependência energética dos dosímetros de LiF:Mg,Ti para os diversos feixes estudados. Cada feixe está indicado pelo valor de seu TPR 20,10

Figura 4-28: Fatores de dependência energética dos dosímetros de fluorita para os diversos feixes estudados.

Figura 4-29: Fatores de dependência energética dos dosímetros de $\mathrm{CaSO}_{4}: \mathrm{Dy}$ para os diversos feixes estudados. 65

Figura 4-30: Fatores de dependência energética dos dosímetros de $\mathrm{Mg}_{2} \mathrm{SiO}_{4}: \mathrm{Tb}$ para os diversos feixes estudados. 66

Figura 4-31: Fatores de dependência energética dos dosímetros de $\mathrm{Al}_{2} \mathrm{O}_{3}: \mathrm{C}$ para os diversos feixes estudados.

Figura A 1: Resposta TL do LiF:Mg,Ti em função da dose absorvida em água para os feixes de fótons de uma fonte de ${ }^{60} \mathrm{Co}(A)$ e de aceleradores lineares clínicos com potencial de aceleração nominal de $6 \mathrm{MV}(B)$, $10 \mathrm{MV}(C), 15 \mathrm{MV}(\mathrm{D})$ e $18 \mathrm{MV}(\mathrm{E})$. As retas representam os ajustes lineares realizados. Também estão representados, em um só gráfico (F), os resultados para as irradiações em todos os feixes estudados. 76

Figura A 2: Resposta TL da fluorita em função da dose absorvida em água para os feixes de fótons de uma fonte de ${ }^{60} \mathrm{Co}(A)$ e de aceleradores lineares clínicos com potencial de aceleração nominal de $6 \mathrm{MV}(B), 10 \mathrm{MV}(C)$, 
$15 M V(D)$ e $18 M V(E)$. As retas representam os ajustes lineares realizados. Também estão representados, em um só gráfico $(F)$, os resultados para as irradiações em todos os feixes estudados.

Figura A 3: Resposta $\mathrm{TL}_{\text {do }} \mathrm{CaSO}_{4}: \mathrm{Dy}$ em função da dose absorvida em água para os feixes de fótons de uma fonte de ${ }^{60} \mathrm{Co}(A)$ e de aceleradores lineares clínicos com potencial de aceleração nominal de $6 \mathrm{MV}(B)$, $10 \mathrm{MV}(C), 15 \mathrm{MV}(D)$ e $18 \mathrm{MV}(\mathrm{E})$. As retas representam os ajustes lineares realizados. Também estão representados, em um só gráfico $(F)$, os resultados para as irradiações em todos os feixes estudados. 78

Figura A 4: : Resposta $\mathrm{TL}$ do $\mathrm{Mg}_{2} \mathrm{SiO}_{4}: \mathrm{Tb}$ em função da dose absorvida em água para os feixes de fótons de uma fonte de ${ }^{60} \mathrm{Co}(A)$ e de aceleradores lineares clínicos com potencial de aceleração nominal de $6 \mathrm{MV}(B), 10 \mathrm{MV}(C), 15 \mathrm{MV}(D)$ e $18 \mathrm{MV}(\mathrm{E})$. As retas representam os ajustes lineares realizados. Também estão representados, em um só gráfico $(F)$, os resultados para as irradiações em todos os feixes estudados. 79

Figura A 5: : Resposta $\mathrm{TL}$ do $\mathrm{Al}_{2} \mathrm{O}_{3}: \mathrm{C}$ em função da dose absorvida em água para os feixes de fótons de uma fonte de ${ }^{60} \mathrm{Co}(A)$ e de aceleradores lineares clínicos com potencial de aceleração nominal de $6 \mathrm{MV}(B)$, $10 \mathrm{MV}(C), 15 \mathrm{MV}(D)$ e $18 \mathrm{MV}(\mathrm{E})$. Também estão representados, em um só gráfico $(F)$, os resultados para as irradiações em todos os feixes estudados 80 